Florida International University FIU Digital Commons

4-7-2004

\title{
Risk and resilience factors associated with delinquent behavior among African American adolescent males
}

Lynette Atteloney

Florida International University

DOI: $10.25148 /$ etd.FI14032369

Follow this and additional works at: https://digitalcommons.fiu.edu/etd

Part of the Social Work Commons

\section{Recommended Citation}

Atteloney, Lynette, "Risk and resilience factors associated with delinquent behavior among African American adolescent males" (2004). FIU Electronic Theses and Dissertations. 1335.

https://digitalcommons.fiu.edu/etd/1335

This work is brought to you for free and open access by the University Graduate School at FIU Digital Commons. It has been accepted for inclusion in FIU Electronic Theses and Dissertations by an authorized administrator of FIU Digital Commons. For more information, please contact dcc@fiu.edu. 
FLORIDA INTERNATIONAL UNIVERSITY

Miami, Florida

\title{
RISK AND RESILIENCE FACTORS ASSOCIATED WITH DELINQUENT BEHAVIOR AMONG AFRICAN AMERICAN ADOLESCENT MALES
}

\author{
A dissertation submitted in partial fulfillment of the \\ requirements for the degree of \\ DOCTOR OF PHILOSOPHY \\ in \\ SOCIAL WELFARE \\ by \\ Lynette Atteloney
}

2004 
To: Dean Ronald M. Berkman

College of Health and Urban Affairs

This dissertation, written by Lynette Atteloney, and entitled Risk and Resilience Factors Associated with Delinquent Behavior Among African American Adolescent Males, having been approved in respect to style and intellectual content, is referred to you for judgment.

We have read this dissertation and recommend that it be approved,

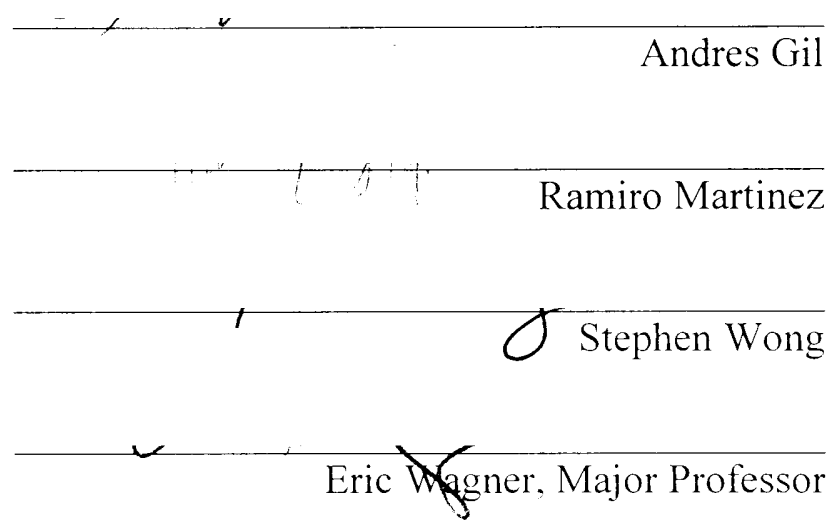

Date of Defense: April 7, 2004

The dissertation of Lynette Atteloney is approved.

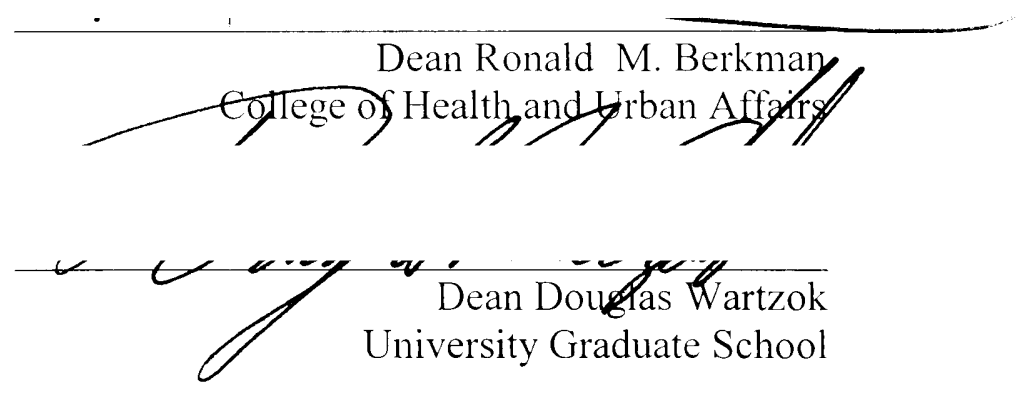

Florida International University, 2004 
(C) Copyright 2004 by Lynette Atteloney

All rights reserved. 


\section{DEDICATION}

I dedicate this dissertation to my husband; Alden V. Barnett Sr. Without his patience, understanding, support and love, the completion of this work would not have been possible. 


\section{ACKNOWLEDGMENTS}

I wish to thank my committee for their collective intellectual expertise, support, and patience during this process. Dr. Stephen Wong provided stringent and timely critiques at various stages of this study. Dr Ramiro Martinez provided expertise and knowledge of the subject area. Dr Andres Gil provided support and guidance in obtaining and managing the data for this study. Finally, I would like to thank my major professor, Dr. Eric Wagner who supported, encouraged, critiqued, challenged and believed in my ability to complete this dissertation with excellence.

I also wish to thank Dr. Stan Bowie and Kathleen Cordon for assisting me in resolving various administrative issues. 


\section{ABSTRACT OF THE DISSERTATION \\ RISK AND RESILIENCE FACTORS ASSOCIATED WITH DELINQUENT BEHAVIOR AMONG AFRICAN AMERICAN ADOLESCENT MALES}

by

Lynette Atteloney

Florida International University, 2004

Miami, Florida

Professor Eric Wagner, Major Professor

Juvenile crime is a social problem of increasing concern to many citizens in the United States. In 2000, there were an estimated 2.4 million juvenile arrests for a variety of crimes ranging from misdemeanors to violent felony offenses. African American males are disproportionately represented among juvenile offenders in the United States. In 2000, black youth were approximately $16 \%$ of the U.S. population between the ages of $10-17$; however, they accounted for $42 \%$ of juvenile arrests for violent crime.

This study explored putative factors associated with juvenile offending among a sample of African American adolescent males. The independent variables in this study were academic achievement, religiosity, parenting styles and discrimination. The dependent variables were delinquent behavior and arrest. The data used in this study were from a larger NIDA funded longitudinal study that included approximately 425 African American youths. The data collection method involved structured interviews and questionnaires. The participants for the original study were selected via random sampling from all students attending middle school in Miami-Dade County. The study examined 
the hypotheses that African American males retrospectively reporting (a) high academic achievement, (b) high religiosity, (c) authoritarian parenting and (d) low perceptions of discrimination are less likely to be involved in delinquent behavior and are also less likely to be arrested.

Results indicated that among African American adolescent males, delinquent behavior had a significant relationship $(\mathrm{p}<.05)$ with academic achievement, perceived discrimination and the interaction between perceived discrimination and experienced discrimination. Arrest was significantly related to academic achievement $(\mathrm{p}<.001)$, religious perception $(\mathrm{p}<.05)$, and church attendance $(\mathrm{p}<.05)$. Neither dependent variable was significantly related to parenting styles.

The findings indicated that experimental studies are needed to clarify cause and effect relationship among the variables associated with juvenile offending among African American males, which may differ from those associated with juvenile offending among other groups. 
I INTRODUCTION

II LITERATURE REVIEW ....................................................... 17

Current Research Findings ....................................................... 17

Co-occurring Behaviors ............................................................ 18

Interacting Risk Factors ........................................................... 19

Protective Factors ...................................................................... 19

Theoretical Framework ……................................................... 20

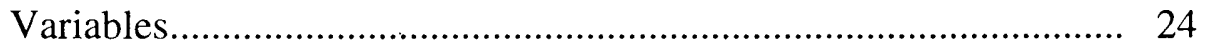

Implications of the Literature Review.............................................. 44

Research Hypotheses.................................................................. 46

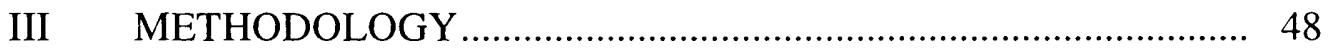

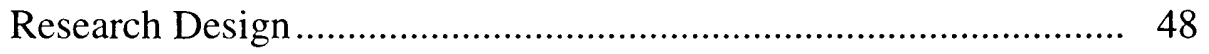

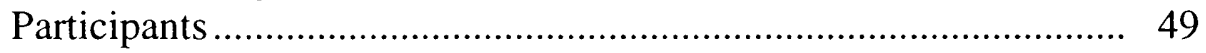

Descriptive Statistics for Total Study Sample................................. 50

Data Collection........................................................................ 52

Reliability Analysis of Instruments ................................................ 53

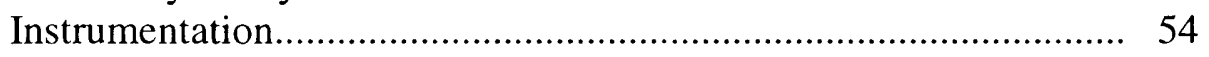

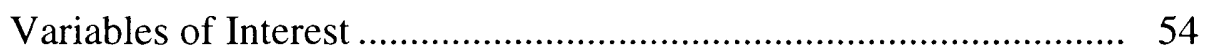

Data Analysis ........................................................................ 59

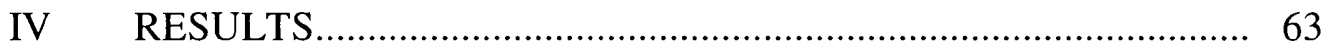

Variable Properties ................................................................... 63

Comparison to National, State and County Sample ......................... 70

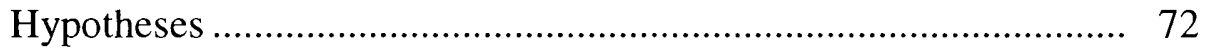

V DISCUSSION _........................................................... 79

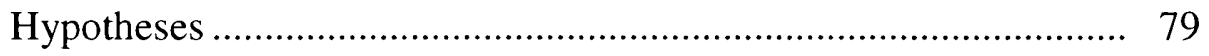

Limitations ......................................................................... 84

Implication for Future Research................................................. 91

Implications for Social Welfare Policy and Social Work Practice ... 94

Summary and Conclusion ............................................................... 98

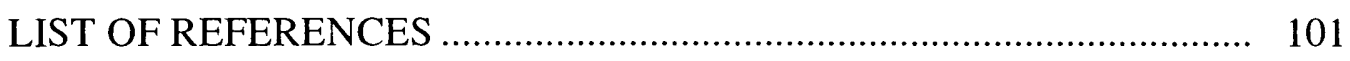

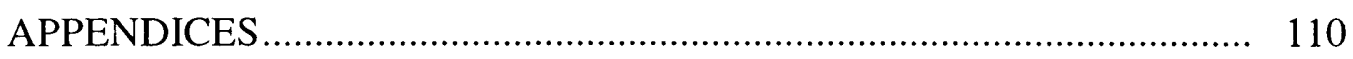

VITA 


\section{LIST OF TABLES}

TABLE

PAGE

1. Risk Factors 6

2. Descriptive Statistics of Demographics for Total Study Sample ...... 51

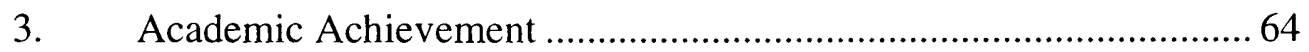

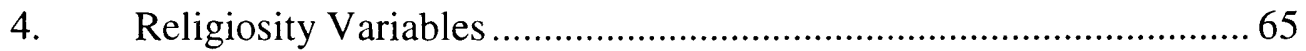

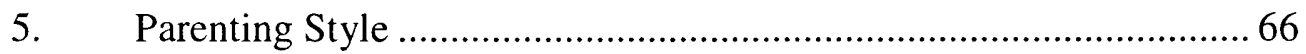

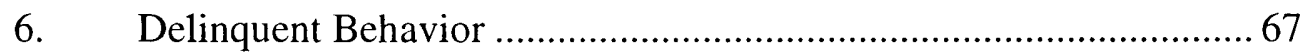

7. Descriptive Statistics for Delinquent Behavior ..................................6 68

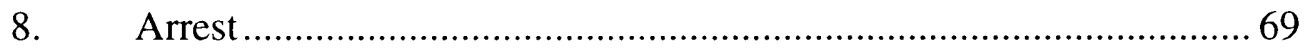

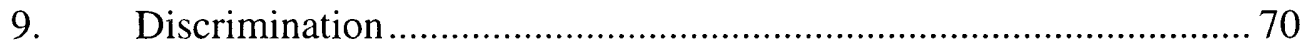

10. Delinquent behavior regressed on academic achievement................73

11. Arrest regressed on academic achievement ..................................... 73

12. Delinquent behavior regressed on religiosity factors ....................... 74

13. Arrest regressed on religiosity factors.......................................... 75

14. Delinquent behavior regressed on parenting style ......................... 76

15. Delinquent behavior regressed on discrimination factors ................ 77

16. Arrest regressed on discrimination factors..................................... 78 


\section{CHAPTER I}

\section{Organization of this Dissertation}

This dissertation is organized in the following manner: Chapter one introduces the target population, the scope of the problem, the theoretical foundations, the variables used in the study, and the significance of the study to the field of social work. Chapter two includes a presentation of the major findings of previous research studies on juvenile delinquency, and a discussion of the Juvenile Justice System's current responses to juvenile offenders. Chapter two also includes a review of the literature on the theoretical bases and the variables used in the study. Chapter two concludes with the implications of the literature review. Chapter three presents the research design, methodology and data analysis techniques used in the study. Chapter four provides the results of the study. Chapter five discusses the findings of the study and their relevance to the field of social work. Chapter five also presents the limitations of this study and the implications for further research.

\section{Introduction}

Juvenile crime is a problem of increasing concern to many citizens in the United States (Moore \& Tonry, 1998). Citizens are concerned with not only the number of offenses committed by juveniles but also with the level of increasing violence associated with juvenile crime (Moore \& Tonry, 1998). For purposes of this dissertation, the term juveniles will refer to persons over the age of 10 but under the age of 18 . It is estimated that in 1998, more than 70 million persons in the United States population were juveniles and of those, approximately 30.6 million are between the ages of $10-17$ (Snyder \& Sickmund, 1999). According to the U.S. Census Bureau, the total juvenile 
population is expected to increase by approximately $21 \%$ between 1995 and 2030 with minority populations experiencing the largest growth (Snyder \& Sickmund, 1999). Struckhoff (2000) also estimated that the total juvenile population will be 74 million by the year 2010 .

\section{Scope of the Problem}

Statistics show that in 2000 , law enforcement officials made approximately 2.4 million arrests of persons classified as juveniles (Snyder, 2001). Included in this arrest statistic are the 98,900 juveniles arrested for violent crimes such as murder, manslaughter and rape. These juveniles are classified as serious, violent offenders (Howell, Krisberg \& Jones, 1995). The types of crimes they commit differentiate serious offenders from the general delinquent population (Loeber and Farrington, 1998) and are as follows:

1. Violent offenses, for example, homicide, aggravated assault which includes weapon offenses and attempted murder, robbery, kidnapping, voluntary manslaughter, rape or attempted rape and arson of an occupied building.

2. Felony larceny/theft, auto theft, fraud, dealing in stolen property, burglary, breaking and entering, carjacking, extortion, forgery and counterfeiting, embezzlement, drug trafficking, arson of an unoccupied structure and weapons violation and firearms regulations/statutes.

While serious and violent offenders (category $\# 1$ above) constitute $5 \%$ of the arrested juvenile offender population, they are responsible for approximately $62 \%$ of all the offenses committed by juveniles (Wolfgang et al., 1972; Tracy et al., 1990). This statistic can be attributed to the fact that serious and violent offenders commit not only major offenses but also many other minor offenses such as trespassing, petty theft, 
resisting arrest without violence and loitering. The second Philadelphia birth cohort study (Tracy et al., 1990) revealed $7 \%$ of the total cohort and $23 \%$ of the offenders were responsible for $61 \%$ of all offenses, $65 \%$ of aggravated assaults, $60 \%$ of homicides, $75 \%$ of forcible rapes and $73 \%$ of robberies. The results of this and other cohort studies show that even though the serious, violent and chronic offender population is relatively small in comparison to the total delinquent population, they are responsible for a disproportionate share of the crimes that are committed. Howell et al. (1995) stated that this characteristic provides evidence to all stakeholders that serious and violent offenders should receive specialized attention.

\section{Minority Over-representation}

A disproportionate number of minority juveniles are arrested for violent and nonviolent crimes (Snyder 2002). Statistics show that black youth were $16 \%$ of the population in 2000 , however they accounted for $42 \%$ of the 98,900 juvenile arrests for violent crimes in that year (Snyder 2002). These statistics seem to indicate that black youth are either (a) committing the majority of these types of crimes or (b) disproportionately arrested for these crimes. The impact of these arrests have far reaching consequences, including that increasing numbers of black youth are being transferred to the adult court where they are sentenced and incarcerated with adult offenders. These juveniles face additional negative consequences within the adult system and receive little or no rehabilitative treatment (Howell, 1997).

The National Center for Juvenile Justice reported that in 1999 there was a 9\% decrease in juvenile arrests (2.5 million) as compared to arrests statistics for 1995 (Snyder, 2000). While the most recent statistics for 2000 , indicate juvenile crime has 
reportedly declined in every category, stakeholders in the field of juvenile justice are cautioned against complacency and encouraged to increase efforts to combat juvenile violence and the control of delinquency (Snyder, 2000). Additionally, there has been no evidence that this decline in juvenile crime is likely to continue or that it may be indicative of a cyclical trend. Regardless of this decrease, the issue of black youths' overrepresentation in serious crimes remains one of a public health concern due to the negative impact on the present and future lives of the offenders and also the negative impact on their families, neighborhoods and society in general. The portrayal of black youth in the media impacts on the perceptions of the public by presenting these individuals as dangerous criminals. Consequently, this negative perception is believed to have led to discriminatory practices that have impacted on the economic survival of blacks (Wilson, 1996). While there is a lack of empirical evidence of the impact of these practices, the belief persists. Wilson (1996) argued that white Americans perceive blacks (especially males) as dangerous criminals, which affects the blacks' ability to secure jobs in the majority white owned businesses and industries, leading to further erosion of the neighborhoods in which black people reside. The increasing rate of joblessness leads to the breakdown in the social control mechanisms in these neighborhoods and facilitates the infiltration of illegal drugs and its accompanying violence. Joblessness is directly related to increasing violence and crimes (Wilson, 1996). Black youth are also at increased risk of homicide based on their involvement in serious crime, especially crimes involving drugs and firearms (Fagan \& Wilkinson, 1998; Lattimore, 1997; Paschall, 1998; Snyder and Sickmund, 1999). 
General Risk Factors

Williams et al. (1997) performed an extensive review of the research literature on risk and protective factors regarding delinquency and conduct disorders. Based on this review, they identified a common definition for risk and protective factors and developed a typology for delinquency using these factors. "Risk factors predict the increased probability of a subsequent undesirable outcome (Williams et al., 1997, p.145)." Protective factors are viewed in several ways: they may be seen as the opposite of risk factors or as freestanding variables that interact or buffer the effect of risk factors (Williams et al., 1997). The risk factors for delinquency and conduct disorders were divided into two major categories: contextual or community risk factors and interpersonal or individual risk factors (Williams, et al., 1997). The following table lists the two major categories of risk factors and the respective variables under each category as developed by Willams et al. (1997). The risk factors listed in Table 1 are general factors that may be associated with all ethnic or racial groups. This typology is very similar to the risk typology for adolescent alcohol and other drug use. Both typologies share commonalities such as neighborhood disorganization, low commitment to school, and family management factors (Jenson, 1997). 
$\underline{\text { Table } 1}$

$\underline{\text { Risk Factors }}$

\begin{tabular}{|c|c|}
\hline Contextual or Community Risk Factors & $\begin{array}{l}\text { Interpersonal or Individual Risk } \\
\text { Factors }\end{array}$ \\
\hline $\begin{array}{l}\text { - Structure and values within the individual's } \\
\text { social environment that supports } \\
\text { delinquency } \\
\text { - The accessibility of drugs and weapons } \\
\text { - Poverty and neighborhood disorganization }\end{array}$ & $\begin{array}{l}\text { - Family management } \\
\text { - } \text { Froblems } \\
\text { - } \text { Eamily conflict } \\
\text { behavior } \\
\text { - Academic failure } \\
\text { - Employment } \\
\text { - Low commitment to school } \\
\text { - Association with delinquent } \\
\text { - } \text { peers } \\
\text { - } \text { Alienation } \\
\text { - } \text { Febelliousness } \\
\text { - delinquent behavior } \\
\text { - Thysiological abnormalities } \\
\text { - Cognitive and } \\
\text { - } \text { neuropsychological deficits } \\
\text { Hyperactivity }\end{array}$ \\
\hline
\end{tabular}

$\underline{\text { Risk factors specific to black youth }}$

In their study, Williams, Stiffman and O’Neal (1998) explored an ecological approach to violence in African American youths. They sought to provide additional empirical evidence regarding the effects of environmental and behavioral risk factors on the involvement of African American youths in violent behavior. Williams and his associates examined several predictor variables including exposure to violence, deteriorated neighborhood, deteriorated schools, family instability, negative peer environment and traumatic experience. Individual level predictor variables included alcohol dependence and abuse, substance dependence and abuse and posttraumatic stress 
symptoms. The dependent variable was involvement in violent behavior. The sample consisted of 796 adolescents, whose ages ranged from 14 to 17 (mean ages of 15.3 years). Eighty-six percent of the sample was African Americans, $13 \%$ were white and $1 \%$ was from other ethnic groups. Forty-three percent were males and 57\% were females.

The findings of the study indicated that for African American males, exposure to violent behavior, deteriorated schools, negative peer environment and traumatic experiences were significant predictors of violent behavior. While this study did not report on relationship between risk factors and other racial or ethnic groups, other studies have examined this relationship. Magin and Loeber (as cited in Williams et al. 1997) reported that there was a stronger relationship between academic performance and delinquent behavior among white students than among African American students. Masueda and Heimer (as cited in Williams et al., 1997) found that the effect of delinquent peers was greater for white youths than for African American youths. Despite the fact that there have been some studies that seem to indicate racial differences, Williams et al. (1997) stated that current research has been unable to conduct comparative studies of delinquency risk factors across racial groups due to the lack of adequate multiethnic samples.

The sample studied by Williams et al. (1998) included only African-American youths residing in neighborhoods characterized as having high levels of crime and violence. The researchers were therefore limited in their assumptions of a causal relationship between exposure to violence and involvement in violence. While they were able to establish that self-reported behavior was significantly correlated with exposure to violence, their study did not show a direct causal relationship between the adolescents' 
violent behavior and their exposure to violence. Even though the study had several limitations, it demonstrated that there were strong associations between various environmental and behavioral risk factors and violent behavior. The data suggested that being a victim of violence may increase the risk of involvement in violent behavior.

\section{Rationale for the Current Study}

The theoretical foundation for this study is the theory of social ecology (Bronfenbrenner, 1979). This study is also based on the research findings regarding (a) academic achievement (b) religiosity (c) parental styles and (d) discrimination The Theory of Social Ecology

Bronfenbrenner (1979) conceptualized an ecological environment as a set of nested structures, each inside the next, similar to the construction of a set of Russian dolls. The innermost setting contains the developing individual. Bronfenbrenner views the individual as a dynamic and growing entity, who is not only impacted by the environment and also engaged in restructuring the surrounding environment. The theory posits that the interaction between the individual and the environment is reciprocal in nature. The theory presents a view of the individual in the context of multiple interacting systems and subsystems (Bronfenbrenner, 1979). This theory is applicable to the juvenile and his environment as it offers a context for studying the youth and his environment in relation to the development of delinquent behavior.

Bronfenbrenner (1979) specified four levels of social systems: microsystem, mesosystem, exosystem, and macrosystem. The microsystem involves not only the immediate face-to-face environment in which the individual is functioning (i.e., school, work, family and peer groups) but also the perceptions of the individual regarding that 
environment. The mesosystem is composed of the linkages between two or more face-toface settings in which the individual participates such as school and family. The exosystem is defined by Bronfenbrenner (1979) as being composed one or more setting in which the individual is not an active participant, however the individual would be affected by the activities of that setting (s) (i.e., the activities of the local school board). The macrosystem involves the larger societal and cultural circumstances experienced by the individual, depending on factors such as the person's race, gender, socioeconomic status, ethnic background, place of birth, religion, sexual orientation, and rural or urban place of residence (Bronfenbrenner, 1979).

The theory of social ecology provides a basis for examining a wide range of interconnected systems such as the individual, family, school, religion and neighborhood, which are important systems in the lives of juveniles (Williams et al., 1997). Williams et al. (1998) advocated for the use of an ecological approach to the study of violence among African American males, based on the current knowledge of the relationship between individuals and their respective social and physical environments.

The data gathered from the sample of African American youths in this study will be analyzed to determine the relationship between delinquent behavior and the following variables: academic achievement, religiosity, style of parenting in the household and perceptions of discrimination. These variables have been identified as important components in the social and physical environments of African American youths in several previous research studies of this population (Durant et al., 1994; Joseph, 1996; Williams et al., 1998; Williams et al., 1999). 
Poor academic achievement has been identified through numerous longitudinal studies and epidemiological investigations as a risk factor for delinquency and violence, (Brewer et al., 1995; Maguin \& Loeber, 1996). Youth who display a lack of commitment to school and consequently academic failure are at increased risk for the development of delinquent behavior (Brewer et al., 1995; Maguin \& Loeber, 1996).

While academic achievement or failure is widely recognized as a risk factor in the development of delinquency, there are only a few studies that have examined the relationship between school variables and the development of delinquent behavior in African American males (Cernovich \& Giordano, 1992; Joseph 1996). Joseph (1996) found that among African American males, lack of academic achievement was a significant predictor of delinquency among junior high school male students, while involvement in school and attitudes toward school were significant predictors of delinquency among high school male students. Cernovich and Giordano (1992) examined the effect of school bonding on delinquency as they relate to black youth. While their findings revealed that there were no significant differences in the effect of school bonding on delinquency across race-sex subgroups, they cautioned against a general acceptance of these findings due to limitations in the study. They explained that one of the limitations in the study was the lack of qualitative information from black youth regarding their perceptions of their role in American society. Qualitative information of this type may clarify the role of race in the development of delinquent behavior. 
Religiosity

The landmark study by Hirschi and Stark (1969) regarding the effects of religious participation on the development of delinquent behavior has raised numerous debates on both sides of the issue. Hirschi and Stark found that religiosity, conceptualized as church attendance had no significant effect on delinquency. The current literature on the effect of religion on delinquency provides inclusive and inconsistent evidence of a relationship. Some researchers have documented a relationship between religious involvement and the development of delinquency (Benda, 1995; Johnson et al., 2001; Stark et al., 1982), while others assert that the relationship is nonexistent (Hirschi \& Stark, 1969). Rodney Stark has been involved in two of the above cited studies with conflicting results, Hirschi and Stark (1969) where it was emphatically stated that there was no relationship and Stark et al. (1982) whose findings indicated that a relationship exists. Stark revisited the issue because he suspected that the relationship between religiosity and delinquency might be attenuated by the religious commitment of the community studied. Stark et al (1982) also attempted to collect data on black youth, however their efforts were unsuccessful, as they did not have a sufficient number of black participants. The study conducted by Stark et al (1982) will be discussed more fully in the upcoming chapter.

\section{Parental Styles}

Poor family management practices are also among the identified risk factors for the development of delinquent behaviors. Family management problems refers to practices such as poor monitoring and supervision, lack of clear expectations for youth's behavior, and severe and inconsistent disciplinary techniques (Gray-Ray \& Ray, 1990; Hawkins et al., 2000). Research has shown that these behaviors are strongly predictive of 
future delinquency and substance abuse (Capaldi \& Patterson, 1996; Hawkins, Arthur \& Catalano, 1995, Wells \& Rankin, 1988). Parental styles are important in the study of adolescent juvenile offending as research has shown that appropriate disciplinary methods, appropriate communication between parents and youths, and consistent monitoring by parents influence involvement in delinquent behavior (Bank et al., 1991; Chamberlain \& Bell, 1998; Patterson \& Stouthamer-Loeber, 1984; Henggeler et al., 1998). Interventions that focus on building competencies in families of youths with serious and violent delinquent involvement such as Multisystemic Therapy (Henggeler et al., 1998) have shown positive short-term results (Borduin et al., 1995). Despite of what is currently known about the role of parental involvement in delinquent behavior, there is a paucity of research using exclusively African American youths and families (Gray-Ray \& Ray, 1990; Jang \& Krohn, 1995). Lack of ethnic minority samples has resulted in a gap in the knowledge base regarding parental involvement.

The research conducted by Diana Baumrind $(1966,1972,1978,1991)$ provides a framework for conceptualizing parental involvement, using the three parental styles: permissive, authoritarian, and authoritative. Mason et al. (1996) incorporated Baumrind's conceptualization of parental styles in their examination of the interaction between parental control and problem peers with adolescent problem behavior. They found that parental control was positively correlated with the level of problem behavior associated with the child's peer group.

\section{Discrimination}

The most recent statistics indicate that black juveniles were approximately $15 \%$ of the juvenile population in the United States and accounted for $26 \%$ of juvenile arrests. 
Approximately $45 \%$ of juvenile detainees were black. Statistics of this type have been the basis for arguments concerning the over-representation of African Americans in the criminal justice system of the United States. Conley (1994) reported that the issue of minority over-representation has been studied and debated for over three decades by sociologists, criminologists and other social scientists; however, the problem remains unresolved. In a literature review of 46 studies published between 1970 and 1980, Pope and Feyerherm (1990) focused on minority status and juvenile processing. They found that processing decisions in the juvenile justice system of several States were not racially neutral. The direct and indirect effects of race were present at various stages of processing and the effects may accumulate as processing progresses (Pope \& Feyerherm, 1990a, 1990b,1995). Pope and Feyerherm (1995) provided further evidence that more than half of the juveniles incarcerated nationwide are minority youth. Evidence suggested that the high rates of incarceration of minority youth's might be attributable to disparities in case processing and not necessarily to higher crime rates among this population (Pope \& Feyerherm, 1995). In a 1990 review of Florida's juvenile justice system, Bishop and Frazier (as cited in Pope \& Feyerherm, 1995) found that the probability of receiving harsher sentencing was greater for non-white than for white juveniles even after controlling for age, gender, seriousness of offense and prior record.

Pope and Feyerherm (1995) found that despite the increasing concern by researchers and the public, policies such as the Juvenile Justice Prevention Act of 1974 has been ineffective in addressing disproportionate racial/ethnic representation in juvenile justice processing. Miller (1996) reiterated one of the major questions that continues to confound scholars in the criminal justice field, is, whether the arrest rates and 
imprisonment of African Americans reflect racial bias or higher crime rates. The work of Shaw and Mckay (1969) and Elliot (1994) will be presented in Chapter two of this work as well as other researchers in an effort to address this question.

\section{Current Study}

The current study attempts to address the roles of academic achievement, religiosity, parenting styles and discrimination with the development of delinquency and the occurrence of arrests among the African American males in a community sample. The study will incorporate a multisystemic causal model based on the theory of social ecology which posits that an individual's behavior is impacted by multiple and interacting systems (Bronfenbrenner, 1970, 1979). The participants in the sample presented in the current study responded to measures based on their individual perceptions, recall and self-reports.

\section{Implications for Social Welfare}

The information gleaned from this study will make several contributions to knowledge relevant to social welfare. One contribution will be promoting an ecological approach to the study of delinquent behavior among African American males. This study will provide information about African American males and some of the factors in their social environment that promote or detract from the development of this type of delinquent behavior such as academic achievement and parental styles. This study will also increase the current knowledge concerning the role of religion in the development of delinquent behavior. Findings concerning the role of religion in adolescent delinquent behavior have been equivocal; therefore more studies of this type are necessary in order to further clarify this relationship. 
Identification of the factors associated with risk and resilience among African American males is critical to the development of future prevention and treatment efforts aimed at this population. Previous research studies have included samples of mainly white males and have provided information specifically related to that population (Moffitt, 1993; Williams et al., 1997).

The possibility exists that there are racial/ethnic differences among the factors associated with risk and resilience for juvenile delinquency. If these differences exist, then treatment/interventions that are sensitive to these differences must be developed . Current treatment modalities were developed using mainly white male samples (e.g. Multisystemic Therapy). While African American males are the major racial and ethnic group identified as juvenile offenders, very little is known about the mechanisms responsible for this phenomenon (McCubbin et al., 1998). Significance of the Study

Current efforts aimed to juvenile delinquency among African American males generally consider these youth within the context of the risk and resilience factors identified using samples of mainly white male offenders (Borduin et al., 1995, Chamberlain \& Bell, 1998). The proposed study will examine the factors that promote risk and resiliency among a sample of exclusively African American males regarding juvenile delinquency. The study is significant for the following reasons: First, since African American males are over-represented among juvenile offenders, it is crucial that the factors that promote risk and resilience among this group are identified. Secondarily, the study is significant because of its implications for the development of effective 
interventions related to the treatment of African American males who are juvenile offenders. 


\section{CHAPTER II}

\section{Literature Review}

\section{Current Research Findings}

The most frequently cited findings concerning juvenile offenders come from the Office of Juvenile Justice and Delinquency Prevention (OJJDP). This office is a component of the Office of Justice Programs of the United States Department of Justice (Wilson and Howell, 1993). The President and Congress through the Juvenile Justice and Delinquency Prevention Act of 1974, Public Law 93-415 established it. The Major goal of OJJDP is to assist the juvenile justice community in the prevention and control of delinquency through the provision of leadership, direction and resources.

The major findings regarding juvenile offending were derived from three longitudinal studies commissioned by the Office of Juvenile Justice and Delinquency Prevention (OJJDP). The studies were named for the cities in which they took place; they are the Denver Youth Study, the Pittsburgh Youth Study and the Rochester Youth Development Study (Thornberry, Huizinga, \& Loeber, 1995). A major goal of these studies was to provide information that would enhance the understanding of the development of serious delinquency, violence and drug use. These studies are recognized as the largest most comprehensive effort undertaken in the study of serious delinquency as they involved a total sample of 4,500 inner city youth ranging in ages from $7-15$ years old who were studied over several years.

The studies' major findings regarding juvenile offending were as follows (Loeber \& Farrington, 1998): 
1. Youth classified as violent offenders constituted approximately $14 \%$ of the sample but were responsible for approximately $82 \%$ of all the violent offenses reported among the sample.

2. Serious violent offenders begin offending at earlier ages then other offenders and as a result they have longer criminal careers.

3. The pathways to delinquent behaviors are multiple, with substantial variation in individual, peer and family characteristics among minor and serious delinquents. 4. The majority of the offenders classified as serious and violent offenders were African American youth.

5. The individual risk factors involved in serious and violent offending include, low IQ, poor impulse control, academic failure, and association with delinquent peers and family conflict.

6. The macro factors identified as being related to serious and violent offending include low socioeconomic status, and family receipt of welfare.

\section{Co-occurring Behaviors.}

Included in the studies' findings were co-occurring behaviors. Co-occurring behaviors include dropping out of school, gun ownership, gun use, teenage sexual activity, teenage parenthood, early independence from families, drug and alcohol use, gang membership, and involvement in drug sales (Thornberry et al., 1995, Windle, 1991). These co-occurring behaviors place additional stress on the lives of the juveniles and also pose additional difficulties in the design of appropriate and effective interventions. Identification and treatment of only the exhibited delinquent behavior will not be 
effective; interventions with this population must address these co-occurring behaviors in the treatment protocol.

Interacting Risk Factors.

The research suggests that multiple risk factors interact with each other to produce a higher level of risk among this population (Thornberry et al., 1995).Influences of peers and parents on delinquency are two of the major risk factors for the development of delinquent behaviors.

The data from the Denver Youth Study suggests that peer behavior may be more influential on the development of juvenile delinquency than parental behavior. However, the combined influence of friends and parents has a stronger impact on the development of delinquent behavior than the impact of the individual factors themselves (Thornberry et al., 1995).

Protective Factors.

Even in the presence of numerous risk factors, there are some youth that manage to avoid involvement in delinquency or violence. The presence of buffering or protective factors in their particular environment, serve to counteract the negative influences of the risk factors (Thornberry et al., 1995). These protective factors include a high level of commitment to school, high levels of parental supervision and attachment, and association with conventional peers who the parents approve of. Identification of protective factors is important for policy and practice because they suggest areas for improvement in interventions. Examining protective factors changes the focus of the research to prevention rather than intervention. The research then centers on the rationale 
for the avoidance of delinquent behavior rather than the reasons for engaging in problem behavior.

\section{Theoretical Framework}

\section{Multisystemic Causal Model}

As described in chapter 1, the theory of social ecology presents a view of the individual in the context of multiple, interacting systems and subsystems (Bronfenbrenner, 1970,1979). The interconnectedness of these systems and subsystems requires broad-based interventions that would be amenable to these levels of complexity (Kazdin, 1997; Henggeler, Smith \& Schoenwald, 1994).

Kazdin (1997) presented several rationales for employing broad-based treatments instead of using a single treatment approach. He argued that many dysfunctions experienced by children affect and are affected by multiple domains (i.e. child's social cognition, parenting deficits and familial communication deficits). He gives the example of parent unemployment leading to increased parent stress or increased alcohol consumption which consequently affected the functioning of the child (Kazdin, 1997, p. 123). Kazdin states that associated features of many dysfunctions may require a broader range of interventions that any one treatment approach can reasonably provide (Kazdin, 1997, p. 123)." The theory of social ecology is consistent with Kazdin's argument, as the theory examines the complexity of the interactions between the individual and the multiple domains of his/her environment (Bronfenbrenner, 1970, 1979).

The theory of social ecology has been used by Scott Henggeler and his associates in the development and testing of multisystemic therapy with serious and violent juvenile delinquents of both sexes (Borduin,1994,1999;Borduin et al., 1995;Henggeler et al., 
1991, 1992,1993). The treatment design centers on two general principles: the multidimensional systems in which adolescents are embedded, and the bidirectional and reciprocal nature of the interacting systems (Henggeler et al., 1986). The interventions are structured towards the microsystems such as family relations, school performance, peer relations, and other social systems that are identified in the analysis of the problem, and mesosystems such as family-peer and family school interactions (Henggeler et al., 1994). Multisystemic therapy is viewed as promising in the field of interventions for serious and violent offenders due to the "quality of evidence and consistency of outcomes" (Kazdin \& Weisz,1998, p. 28).

There are a number of other theories that have been used in the study of delinquent behavior such as social control theory (Hirschi, 1969), differential association theory (Sutherland, 1947), labeling theory (Tannenbaum, 1938), and social disorganization theory (Shaw \& Mckay, 1969). While there are many other theories regarding delinquency such as opportunity theory (Cloward \& Ohlin, 1960), and cultural deviance theory (Miller, 1958), the former four theories recur most often in the literature base. These theories address some of the youth's interacting systems related to the development and sustainment of delinquency however they do not address the multiple systems in which youth are embedded to the extent of the theory of social ecology.

According to the tenets of social control theory, delinquent behavior is linked to the quality of the bond that the individual maintained with society (Hirschi, 1969). If the bond is weak or broken then delinquent behavior is likely to develop (Hirschi, 1969). Travis Hirschi (1969) theorized that individuals who are tightly bonded to social groups such as the family, school, and peers are less likely to develop delinquent behaviors. 
While this theory acknowledges some of the systems in which the youth is embedded it is mainly concerned with the individual's bond or responsiveness to these systems. The theory does not address the complexity involved in the interactions among and between these systems that either lend support to or detract from delinquent behavior.

Differential association theory is most closely associated with Edwin $\mathrm{H}$. Sutherland. Sutherland (1947) proposed that delinquents learn this behavior from other delinquents. The behavior is viewed as a product of social interaction. While the theory stresses the youth's relationship to negative peer groups, it does not address the other factors such as family, school and other systems in which the youth interacts.

Labeling theory is associated with Frank Tannenbaum. Tannenbaum (1938) proposed that society creates deviants by labeling them as different from others; consequently the individual internalizes the label and begins acting in a deviant manner. This theory focuses on the relationship between the juvenile and society; however, the other relationships are not addressed. The interaction between society and the youth is important in the development of juvenile delinquency and even more important in the outcome of delinquent behavior based on the imposed sanctions. This theory has value in viewing society's role once delinquent behavior has occurred, however it did not provide a basis for examining other factors or systems that promote the development and continuance of delinquent behavior.

Clifford R. Shaw and Henry D. McKay (1969) felt the social disorganization of the community leads to juvenile delinquency due to the resultant loss of social control of groups such as the family and the neighborhood. Consequently, the youths then choose delinquent behaviors as their preferred mode of socialization because other more 
conventional modes of socialization have broken down (Shaw \& McKay, 1969).

Processes such as rapid industrialization, urbanization and immigration contribute to the disorganization of the community (Shaw \& McKay, 1969). While this theory addresses more of the interacting systems related to delinquent behaviors, it did not address as many as the theory of social ecology. The theory of social disorganization primarily focuses on the contextual or community risk factors (Shaw \& McKay, 1969), it fails to fully address the individual risk factors associated with the adolescent's personal environment such as peers and academic problems. The theory views factors as being the results of disintegration in neighborhoods or communities (Shaw \& McKay, 1969).

Research on juveniles and delinquent behavior informs that juvenile offending is impacted by many interacting systems such as their peer group, families, schools, and communities, as well as external systems in which juveniles are not directly connected such as parental work environments, society and culture. Therefore, in order to effectively study and develop treatments for delinquency, a theory that encompasses these complex systems and which also provides a basis for direct intervention in the appropriate systems is needed (Henggeler, Smith \& Schoenwald, 1994). The theory of social ecology provides a way of viewing the development of delinquent behavior that the aforementioned theories do not, as the theory allows for the incorporation of all the youth's interrelated systems (Bronfenbrenner, 1970, 1979). The theory provides a model through which we can view the youth and all the systems in which he or she is embedded (Bronfenbrenner, 1979) and also attempt to intervene in the development or progression of delinquency. Multisystemic Therapy is an intervention based on the theory of social 
ecology that has shown promising results in the treatment of serious and violent delinquency (Borduin et al., 1995).

The work of Scott Henggeler and associates in the development and testing of Multisystemic Therapy provides support for the utility of the theory of social ecology. MST interventions are focused on the microsystems related to the youth's delinquent behavior such as the individual, family relations, peer relations, and school performance (Henggeler et al.,1994). The intervention are also targeted towards the transactions between the mesosystems (i.e. family-peer and family-school) identified as being involved in the presenting problem (Henggeler et al., 1994). MST interventions are conducted in the youth and family's home environment, allowing for easier access to services and enhancement of treatment generalization (Henggeler et al., 1998).

\section{Variables}

\section{Academic Achievement}

Academic failure is a risk factor for delinquency and violence which has been identified through numerous longitudinal studies and epidemiological investigations (Brewer et al., 1995; Maguin \& Loeber, 1996). Youth who display a lack of commitment to school and consequently academic failure are at an increased risk for the development of delinquent behavior (Brewer et al., 1995; Maguin \& Loeber, 1996).

Maguin and Loeber completed a metanalytic review of 106 naturalistic studies (studies in which no intervention was given) and twelve intervention studies. The studies were selected based on the following criteria: one or more measures of delinquency and academic performance, an upper cutoff age of eighteen years, and sufficient data with 
which to calculate a viable effect size. The goal of the study was to build on the results of three prior reviews of the relationship between academic performance and delinquency conducted by Silberberg and Silberberg (1971), Gottfredson (1981) and Hawkins and Lishner (1987). Some of the major goals of this study were to: (1) quantitatively summarize the magnitude of cross-sectional and longitudinal association between academic performance and delinquency, (2) determine whether the association was attenuated by age, gender, and or ethnicity, (3) identify variables which have a common relationship with both delinquency and academic performance (4) identify variables that are related to either delinquency and academic performance but do not share a common relationship to both.

Maguin and Loeber (1996) found that youth with poor academic performance (grades of $\mathrm{D}$ or $\mathrm{F}$ ) had higher incidences of delinquency than youth with high academic performance ( grades of $\mathrm{C}$ or above). Specifically, $35 \%$ youth with low academic performance became delinquent versus $20 \%$ of the youth with high academic performance. Delinquent males and females exhibiting higher involvement in serious and violent offenses also had low academic performance. Delinquent youth with low academic performance were more likely to escalate in the seriousness and persistence of their offending than delinquent youth with better academic performance. Better academic performance was associated with desistance in delinquent behavior. The relationship between poor academic performance and delinquency was stronger for males than for females. The association between academic performance and delinquency was inconsistent when ethnicity was factored in. The relationship varied based on the type of 
study examined. Cross-sectional studies indicated that the association was not significant among African American and White youths, however longitudinal studies indicated that the mean association was stronger for White youths than for African American youths. The authors attributed this difference to the larger sample and effect sizes of the longitudinal studies. Older age was also determined to strengthen the association between academic performance and delinquency.

Intelligence and attention problems were determined to be possible common causes of delinquency and academic performance. Socioeconomic status (SES) and prior conduct problems were determined to have little if any, effect on the association between delinquency and academic performance. Based on these results it appears that interventions that focus on improving attention and intelligence may be more effective in increasing academic performance and reducing delinquency. These findings indicate the extent of the knowledge on the relationship between delinquency and academic performance. The inconsistencies regarding the association between academic performance, delinquency, and race or ethnicity call attention to a gap regarding the association between these three variables. While academic achievement or failure is widely recognized as a risk factor in the development of delinquency, there are only a few studies that have examined the relationship between school and the development of delinquent behavior in African American youth (Cernovich \& Giordano, 1992; Joseph 1996). Consequently, most of what is known about the relationship between academic performance and delinquency is based on White youth and not youth of other ethnic 
backgrounds and therefore caution should be stressed in applying these findings equally across the board without the benefit of further research.

Cernkovich and Giordano (1992) examined the effect of school bonding on delinquency among racial groups (Black and White youth). They hypothesized that there would be differential effects on delinquency due to varying effects of race and perceived racial environments in schools. The researchers hoped to enhance the literature base by providing information that would reduce the "racial gap" resulting from lack of or failure to provide information on the combined impact of race and school factors in the development of delinquent behavior. While there is a vast amount of information available on the role of school in the lives of White youth, there is a paucity of information on the role of school in the lives of Black youth (Cernovich \& Giordano, 1992).

The research sample in Cernovich and Giordano's study consisted of 942 participants of whom $45 \%$ were White youth, the remaining $55 \%$ were predominantly Black youth, and 51\% were females. The participants ranged in ages from 12 through 19 years old: $53 \%$ were 15 or less; $32 \%$ were 16 or 17 ; and $15 \% 18$ or 19 years old. A cross sectional sample of youth between 12 and 19 years of age in the Toledo, Ohio area was obtained through the use of a multistage, modified probability sample design. One of the variables studied were school commitment defined as "the degree to which a student has a stake in conformity that insulates him or her from involvement in delinquency" (p.270). The youth were asked about the their grades, and how far they would like to go in school versus how far they think they will actually get in school. The researchers controlled for 
age, sex, race and socioeconomic status (SES) and school context (the racial composition of the school being predominantly White or Black).

The findings of the research indicated that for Black males school commitment was significantly predictive of delinquency, higher levels of commitment to school were associated with lower levels of delinquency. This relationship was not affected by the racial composition of the school among Black males; among Black females, attendance in predominantly Black schools was more predictive of delinquent behavior. This could be associated with intervening factors that may be present in an all Black school environment which were not included in this study. Due to the limitations in the study there were many such unanswered questions.

Joseph (1996) further explored the relationship between school and delinquency in African American youth while controlling for type of school and gender. Joseph (1996) hypothesized that negative school experiences create alienated youth that form delinquency subcultures in school. Joseph (1996) argued that the passive instructional techniques used in schools negatively impact learning of verbal concepts of Black youths, as research shows that a instructional method is better suited to their ability to learn verbal concepts. Joseph hypothesized that the cognitive style of Black youths emphasizes people rather than objects and the current teaching styles is object oriented which serves to further limit the abilities of African American student. Tracking is also viewed as another factor that has an adverse effect on the present and future success of Black students (Joseph, 1996). Tracking refers to the practice in the educational system of assigning youths to low-ability or special education classes based on aptitude or 
intelligence tests, which some have argued are racially or culturally biased (Joseph, 1996). From this perspective, school failure in Black or African American youth is mainly due to factors found in the conventional methods of the current educational system rather than individual factors (Joseph, 1996).

Joseph (1996) collected data by interviewing a nonrandom sample of 272 African American youths from junior and senior public schools in New Jersey. The demographic composition of the sample was $57 \%$ males, $17 \%$ between 12 an 13 years old, $41 \%$ between 14 and 15 years old, and $42 \%$ between 16 and 17 years old. All participants were involved in the juvenile justice system. Joseph examined variables such as academic achievement (average grade in last year in school), experiences in school (number of teachers who seem to care if you do well in school, and youth's perception of discrimination by teachers) and future educational plans. Findings indicated that future education $(\mathrm{p}<.001)$ and academic achievement $(\mathrm{p}<.001)$ were significantly related to delinquency for the total sample. Future educational plans were not significantly correlated with delinquency. The results of the mean school variables by gender and type of schools indicated that experiences in school $(\mathrm{p}<.001)$ and academic achievement $(\mathrm{p}$. $<.05)$ were significantly higher among males than females. Future education $(\mathrm{p}<.05)$, academic achievement $(\mathrm{p}<.001)$ and experiences in school $(\mathrm{p}<.05)$ were higher among high school students than among junior high school students. Academic achievement $(\mathrm{p}<$. 05) was a significant predictor of delinquency among males in junior high school. Among junior and senior high school females however, the variable involvement in school was a significant predictor of delinquency ( $\mathrm{p}<.05$ and $\mathrm{p}<.01$ respectively). Involvement in 
school was measured by number of times youth participated in school social activities, other school activities and attendance in school activities. Involvement in school was also a highly significant predictor of delinquency in high school males $(\mathrm{p}<.001)$.

These findings seem to indicate that school experiences are related to delinquency. Lack of academic achievement and other negative experiences in the school environment were more likely to result in delinquency among African American males especially during the senior high school years. Joseph (1996) recommended the implementation of new teaching styles that are sensitive to the needs of African American youth and elimination of the practice of placing youths into lower tracks based on tests that are culturally biased. She also recommended training for teachers to increase their sensitivity to the needs of African American students. Joseph advocated these changes as an additional method of controlling and preventing delinquency among African American youth. Religiosity

The current literature on the effect of religion on delinquency is inconclusive and inconsistent. Some researchers have produced studies that provide evidence that there is a relationship between religious involvement and the development of delinquency (Benda, 1995, 1997; Johnson et al., 2001; Stark et al., 1982), while others assert that the relationship is nonexistent (Hirschi \& Stark, 1969) or spurious (Cochran et al., 1994). Hirschi and Stark's landmark study has raised debates on both sides of the issue among criminologists. Earlier researchers such as Hirschi and Stark (1969) defined religiosity in terms of frequency of church attendance. More contemporary researchers such as Benda 
(1995) and Johnson (2001) have expanded the definition to include several dimensions of religiosity (e.g. time in prayer, importance of religion in one's life, time spent on community-based religious activities.) This expansion has allowed researchers to explore a larger domain of the concept that was lacking in earlier research which focused on only one dimension.

Hirschi and Stark's (1969) study included a sample of 4,077 junior and senior high public school students in Western Contra Costa County, California. Data were collected from three sources: a lengthy self-report questionnaire, school records and police records. Their findings indicated that church attendance did not affect the rate of delinquency. Students who were frequent church attendees were just as likely to commit delinquent acts as students who did not attend church. Race and sex did not attenuate this effect.

Stark, Kent and Doyle (1982) revisited the issue focusing on the religious ecology of the community. They conducted a longitudinal study that included five waves of data collected from 1966 to 1974 . They obtained their final sample composed of twenty-five boys from eighty-seven high schools in the nation, by using multiple stage sampling. The sample included mainly White males as very few Black students voluntarily participated. Therefore, the final analyses included no data on Black participants. The participants were divided into religious classifications of moral or secular communities as determined by their self-reported scores on a measure of religious values. Scores on three dimensions of religiosity: religious values; personal importance of religion and church attendance were correlated with self-reported delinquent behavior. 
Their findings indicated that there was a relationship between religion and delinquency. In the moral communities, twenty-four percent of participants reported a "high frequency of delinquent acts" versus thirty-one percent in the secular communities. The correlations between religiousness and frequency of delinquency in the moral communities versus the secular communities were -.31 and -.15 respectively. This correlation suggested that the youths in the secular communities participated in more acts of delinquent behavior than youth in the moral communities. This relationship was based on the religious climate of the youth's social environment. Stark et al (1982) concluded that the strength and existence of religiosity in social environment reinforced the youth's religious convictions and thereby reduced the incidences of delinquent behavior.

Benda (1995) began with the premise that there is a relationship between religion and delinquency and subsequently studied variations in the effects based on type of crime and type of communities. The sample comprised 1,093 public high school students, randomly selected from a total of five schools located in Baltimore, Maryland; Little Rock, Dequeen and Horatio Arkansas; and Arkhoma, Oklahoma. The sample composition was $46 \%$ male, $59 \%$ White, and 36\% Black. The participants ranged in age from 13 to 20 years old and the mean age was 16 years. The participants varied in terms of their religious affiliations.

Benda (1995) hypothesized that anti-ascetic behaviors which are crimes such as "status offenses, alcohol and other drug use would be more influenced by religiosity than crimes such as property crimes and crimes against persons (p.448)." Benda also hypothesized that religiosity would have a stronger effect on the delinquent behavior of 
youth in "homogeneous rural communities than youth in culturally diverse urban areas (p.449)." The study did not control for race or sex.

The findings did not support the hypothesis that anti-ascetic behaviors were more affected by religiosity than other criminal behaviors. The findings of this study did not offer support for Stark and his associates (1982) results that the community's religious ecology was related to delinquency. Benda found that in this sample there was no indication of a relationship between the community context and delinquency. However, Benda reaffirms that religion is significantly predictive of delinquency based on previous studies of the relationship.

Johnson (2001) conducted a study of the relevance of religiosity in the etiology of delinquency using data from the National Youth Survey (NYS). The National Youth Survey is a longitudinal study of a national probability sample of 1,725 youths ranging in ages from 11 to 17 years. The study began in 1977 and the principal investigator is Delbert Elliot. Johnson (2001) used a definition of religiosity that included several dimensions of the concept such as, frequency of attending religious services; importance of religion in the individual's life; time spent in community-based religious activities; and importance of involvement in community-based religious activities.

Johnson (2001) found that there was an inverse relationship between religiosity and delinquency in the sample. As the adolescents' religiosity increased their participation in delinquency decreased. The adolescents' disapproval for delinquent behavior and their association with conventional peers were related to the level of 
religiosity. The study was limited as there was insufficient data to examine causality, and there were also no analyses of possible race or sex differences.

\section{Parental Styles}

Family management practices such as discipline and monitoring are positively correlated with self-reported delinquency and police contacts (Smith \& Stern, 1997; Patterson \& Stouthamer-Loeber, 1984.). Parental lack of or failure to provide monitoring provides the opportunity for an adolescent to engage in delinquent behavior (Gray-Ray \& Ray, 1990; Patterson \& Dishion 1985). Laub and Sampson (1988) found that parental styles of discipline (ranging from strictness to laxity) were one of the strongest predictors of delinquency. Conversely, Gray-Ray and Ray (1990) found that among Black youth, perceived parental rejection was significantly related to delinquent behavior while parental supervision and control was not. This finding is inconsistent with previous research studies and consequently adds to the controversy surrounding the role of parenting in determining delinquency. Inconsistencies in findings of this type further support the need for research on the relationship between parenting and delinquent behavior especially among African American adolescent males.

Parental styles vary in terms of disciplinary practices, monitoring of youth's whereabouts and communication patterns between the youth and parent. Consequently, Diana Baumrind $(1966,1972,1978,1991)$ identified three styles of parental control, permissive, authoritarian and authoritative. Baumrind stated that the permissive parent is characterized by his or her lack of control over the household and the child's behavior. The permissive parent provides explanations to the child regarding household rules and 
policies to the degree where it appears that the child is the final authority in the household. The permissive parent sets few boundaries in terms of regulating acceptable or unacceptable conduct. The child in the permissive household has few or no limitations on their conduct or whereabouts. This happens because the permissive parent rarely if ever attempts to implement any restrictions or structure in the household. The permissive parent acts in a passive, non-punitive and affirmative manner towards the child regardless of the child's negative behavior. The permissive parent uses manipulation and reason in the attempt to maintain order and control in the household.

Baumrind described the authoritarian parental style as an attempt to dominate the child's sense of autonomy through the use of strict rules and standards of conduct. The authoritarian parent may use a theological basis as support for controlling and shaping the child's behavior in this manner. This parental style stresses order, work and traditional structure as valued attributes in child rearing. The authoritarian parent does not engage in or encourage discussions of the rules, as the parent's power and decisions are final and absolute.

According to Baumrind, the authoritative parent is neither overly strict nor overly permissive. The authoritative parent functions in a more rational and directive manner in interactions with the child. This type of parent encourages discussion of the rules and policies with the child, however the parent makes the final decision. The authoritative parent encourages autonomy but also sets boundaries as to acceptable and unacceptable behavior. The child's rights and individuality are respected however the authoritative 
parent also provides adult supervision and guidance. The authoritative parent governs the household through the use of reason, power and reinforcement.

Baumrind (1972) conducted a study of the effects of parental authority on preschool children. Due to low participation, data from the Black families could not be standardized and were therefore used for comparison to their White counterparts as. This resulted in Black families being characterized as authoritarian by White standards. This characterization seemed inappropriate when Black families were viewed individually as the parent-child interactions were not consistent with the rigidity of the classification (Baumrind, 1972). Mason et al (1996) argued that the categories do not accurately describe African American families. Despite this criticism and possibly due to a lack of alternative models, Mason et al., (1996) used the three categories as a basis for studying the relationship between maternal control and problem behavior among African American youth . The sample in their study was mostly composed of African American females (64\%). The measures focused on psychological control or restrictiveness, and behavioral control. The results of Mason and associates' study showed the existence of a curvilinear relationship between psychological control and behavioral control with problem behavior. These relationships were moderated by the youth's involvement with problem peer groups. Mason et al (1996) suggested that "appropriate" parental psychological or behavioral control is determined by the degree of involvement with problem peer groups. African American parents tend to increase the level of restrictiveness based on the problems resulting from involvement with delinquent peers (Mason et al., 1996). Mason et al., (1996) stressed caution in the use of Baumrind's 
categories as African American parents may be mistakenly classified as very restrictive or authoritarian, if the youth's involvement with problem peers is not considered as a moderating variable.

Parenting styles that are more authoritarian have been credited with increased academic achievement among adolescents (Steinberg, Elmen \& Mounts, 1989; Steinberg \& Lamborn et al., 1992). Authoritative parenting and high parental involvement in school, have been shown to be associated with increased academic success and positive attitudes toward school, among adolescents (Steinberg, Elmen and Mounts, 1989; Steinberg \& Lamborn et al., 1992). This effect was not consistent across racial groups, as African American youth with authoritative parents who were also involved in school were not achieving the academic success that was hypothesized. In examining the ethnic differences in adolescent academic achievement, Steinberg and associates (1992) argued that academic achievement among African American youth appeared to be affected by two factors. The first factor is the belief among most African American youth in the study, that lack of academic success will not necessarily lead to negative future outcomes, which then, limits the youths' desire to achieve (Steinberg et al., 1992). The second factor affecting the academic achievement of African American youth with authoritative parents is the lack of peer group support within their specific ethnic group (Steinberg et al., 1992). African American youth with high academic achievement have difficulty assimilating in a peer group of their ethnic background, consequently despite authoritative parenting these youth tend to fail in order to fit in with their peers (Steinberg et al., 1992). 
Parenting, specifically parental supervision is negatively correlated with delinquency (Jang \& Smith, 1997). Consequently, the treatment protocol of interventions such as Multisystemic Therapy (Henggeler et al., 1998) and Multidimensional Treatment Foster Care have been incorporated parent training skills (Chamberlain, 1998;

Chamberlain \& Bell, 1995, 1998). These interventions focus on increasing parental monitoring, structuring of appropriate disciplinary techniques, and improved communication among youths and parents. Despite the knowledge gained from research on these interventions, there are still serious gaps in the knowledge regarding African American families. Currently, the majority of the participants in the samples used in researching these interventions are White male therefore, the findings are limited, as they are mainly associated with this population. This limitation causes a lack of clarity regarding the style of parenting that would prevent or reduce delinquent behavior among African American youth, and further limits the development of appropriate interventions.

\section{Discrimination}

While recent statistics show that the majority of youth arrested for serious and violent offending are African American males, currently there is insufficient evidence to support a hypothesis that African American males are more predisposed to committing these types of offenses than other racial or ethnic groups. The following studies serve to illustrate the gaps in knowledge specifically regarding the involvement of African American males. According to Loeber et al. (1998), studies of racial differences in offending have focused primarily on comparing the social conduct among individuals of different races who share similar socioeconomic status. There have been few studies that 
examined the extent to which socioeconomic status may account for the differences in rates of violence between Blacks and Whites (Loeber et al., 1998). Regardless of the fact that there is little empirical evidence, Loeber et al. (1998) stated that researchers continue to attribute the high rate of criminal offenses among African-Americans to their disadvantaged economic status. Loeber et al (1998) concluded that the violence rates across racial groups (Black and White specifically) appear to be affected by the same sociostructural factors. The causes of violent offending (juvenile or adult) appear to be similar across race and are rooted in structural differences across communities and cities (Loeber et al., 1998). These researchers support multiethnic studies across Black, White and other racial/ethnic groups as a way of differentiating individual and neighborhood effects in the study of serious and violent offending.

Shaw and McKay (1969) were instrumental in promoting an understanding of the relationship between race and crime. Shaw and McKay's work highlights the connection between race, crime and disorganized communities. Their findings indicated that high delinquency rates existed in certain urban communities regardless of the ethnic group in residence. This finding provided evidence linking delinquent rates with the level of social disorganization and social control in a neighborhood (Shaw \& McKay, 1969). The work of Hawkins, Laub and Lauritsen (1998) was also supportive of these findings. Their research findings indicated that the rates of violence for Black and White juveniles were affected by the same sociostructural factors. They found that the causes of violence were similar across races and were related to structural differences in communities and cities (Hawkins et al., 1998). 
Durant et al. (1994) conducted a study of the factors associated with violence among Black adolescents living in urban environments characterized by high crime. The study focused on the relationship between the use of violence and exposure to or victimization by violence. Durant et al's (1994) findings support an ecological approach to the study of violent behavior among Black or African American youths. They found that the use of violence by Black youths (males and females) was significantly correlated with the exposure to violence and victimization, degree of family conflict and severe corporal punishment or discipline.

Elliot (1994) called for more attention to racial differences in the prevalence of serious violent behavior. He stated that based on the findings of his earlier research study (Elliot, Huizinga and Menard, 1989), during the adolescent years there were little differences in the rates of offending among Black and White serious, violent offenders from the same socioeconomic background. He also found little racial difference in the propensity towards violence among Black and White youths of the same ages. However, the variables examined were unable to account for the differences in the rate of arrest for violent offenses among adolescent Black and White males (5:1 respectively).

Elliot conducted an analysis of the age distribution of serious and violent offending using the data gathered in the National Youth Survey (NYS). His analysis revealed that serious violent offending was primarily an adolescent-early adulthood phenomenon. He discovered that the peak ages for serious and violent offending was 17 years old among Black and White non- Hispanic males. He found that as the juveniles aged, White males continued to decline in incidences of serious and violent offending, 
whereas Black males did not. The incidence of serious and violent offending among Black males reversed direction in the mid-twenties and began to increase. The rate of this increase was documented for males up to 27 years old. In his analysis of the length of violent careers, Elliot found that Black males were twice as likely as White males to continue their pattern of offending into their twenties (Elliot, 1994). These observations led Elliot to hypothesize that Black males may continue offending due to fewer opportunities for engaging in conventional adult roles. This lack of opportunity may result in greater dependence on the economic rewards of their delinquent/criminal behavior thereby trapping the Black male in behaviors that would be more characteristic of the adolescent years (Elliot, 1994). Elliot (1994) advocated for the continued development of interventions, which may assist these youth in making the transition to conventional adult roles. This finding offers support to continuing research efforts focusing on African American adolescent males and specifically addressing the needs of those in the juvenile delinquent population. Additionally, research is needed to examine the variables that may offer insight into the disproportionate arrest rates for African American male juvenile offenders.

Wilson (1994) argues that there is a direct relationship between violent crime and joblessness . He cited the findings of Delbert Elliot's longitudinal research using data from the National Youth Survey as evidence of this relationship (Wilson, 1994). Elliot's analyses revealed that there was no significant difference in the rate of termination or suspension of violent behavior among employed Black and White adults in their twenties. However, Elliot's findings indicated that the rate of violence among jobless adult Black 
males was significantly higher than among jobless adult White males. These findings suggest that among Black males, violent behavior is positively correlated with joblessness.

Wilson (1994) referred to the "new urban poverty" which he defined as occurring in poor segregated communities in which the majority of the adults are unemployed or have dropped out of the labor force. High rates of joblessness in neighborhoods result in the decline of the neighborhood's ability to exert social control over its residents. These types of neighborhoods experience higher crime rates that other urban neighborhoods. The overwhelming majority of residents in these neighborhoods tend to be African Americans. Wilson stated that African Americans have experienced segregation and isolation at a higher rate than any other group in the United States. Segregation of African Americans is supported by systemic discriminatory practices such as redlining by banks and the construction of major highways through predominantly Black neighborhoods. The overarching effect of these practices is to contain African Americans in particular locations, specifically urban communities.

Joblessness impacts on families as it destroys the organization of daily family life (Wilson, 1994). Wilson reported that in the fifties and sixties, the majority of Black males were employed. The jobs may have been low paying and involved physical labor but they provided a basis by which family life was organized. Wilson contends that, in the current society, Black males and females find themselves competing for low-wage service sector jobs against the expanding immigrant population (Wilson, 1994). Black males find themselves in a vicious cycle of joblessness caused employers' fears of their 
violent behavior that was initially precipitated by joblessness (Wilson, 1994). The stress of being unable to provide for their families and fulfilling the male role as head of a household may have resulted in many Black males abandoning their families or never assuming that role to begin with. Joblessness can then be seen as a major factor in the destruction of Black families.

High rates of joblessness also result in the loss of social institutions (i.e. banks, stores, and churches) in neighborhoods. The loss of social institutions leads to deterioration in the formal and informal social control of neighborhoods. Churches and other neighborhood organizations serve to unify community residents. The decline in membership resulting from the loss of employed residents as they move out of the community, disrupts the ability of these institutions to provide social control. Wilson reiterated that as social control declines the levels as crime and violence in the community increases. This results in a negative cycle as lack of social control leads to higher crime and higher crime further deteriorates social control.

Wilson (1994) stated that government (specifically the Reagan and Bush Republican administrations) has also played a role in the increase of joblessness and the decline of social control in urban neighborhoods by reducing federal aid to cities. These cuts in funding resulted in reductions in spending on job training programs, social services, and urban development programs. Joblessness and socially unstable neighborhoods also result in what Wilson called "natural breeding grounds" for violent crime, drug addiction, AIDS and homelessness. These unhealthy social conditions have almost become synonymous with the view of urban Black neighborhoods. 
Miller (1996) responded that the answer to the question of whether the high arrest rate of African American males is reflective of racial bias or indicative of higher rates of crime is a "qualified yes" (p.56). He explained that cities always have higher crime rates than other areas of the country regardless of the ethnic group in residence (Shaw \& Mckay, 1969). Discrimination has a part in determining who gets arrested and also the severity of the sentence imposed on the offender (Miller, 1996).

The foregoing research studies provide evidence that supports an ecological approach to the study of violent offending among African American males. There is no conclusive evidence that African American males are predisposed to violent behavior as a consequence of race (Elliot, 1994). There is however, evidence of linkages among environmental factors (i.e. deteriorated neighborhoods), societal factors (i.e. racism) and violent behavior in some African American males (Shaw \& Mckay, 1969; Wilson, 1994).

\section{Implications of the Literature Review}

The purpose of the current study is to examine risk and resilience factors associated with delinquent behavior among African American adolescent males. The specific factors examined in this study are academic achievement, religiosity, parental styles, arrest and discrimination. While there is a plethora of information available in the current literature regarding delinquent behavior, the literature base is lacking in information regarding African American youths. The majority of the current studies on juvenile offending have reported findings that are mainly based on White males. This is problematic as statistics show that the majority of juveniles classified as serious, violent juvenile offenders are African American males (Snyder \& Sickmund, 1999). 
While there is a large amount of information on the relationship among academic achievement, religiosity and juvenile offending, there are few studies that focus on samples of African American youths exclusively. The findings of this study regarding the relationship among academic achievement, religiosity, arrest, discrimination and delinquent behavior among the sample of African American youth, will increase the current knowledge base.

There is also a paucity of information available regarding the impact of varying parental styles on delinquent behavior among African American youth. Research on delinquent behavior and parental styles among African Americans has been limited due to controversy regarding the appropriateness of the categories of parental styles when used with African American families (Mason et al., 1996). The literature base is also limited because interventions that incorporate aspects of parental styles such as parental supervision, have been studied using samples of mainly White males.

This study also seeks to explore the relationship between delinquent behavior and participants perceptions of discrimination. Many delinquency studies have been conducted using mainly samples of White youth, however the overwhelming majority of youths in the justice system are African American. While the other variables in this study may account for some of the factors involved in the over-representation of African American youth in the justice system, they may not present a complete picture. The impact of racial discrimination on the arrests of African American males has not been fully explored in the current literature base (Elliot, 1994). Consequently there are no 
conclusive explanations regarding the high numbers of African Americans who have been incarcerated for juvenile crimes or remain at high risk for arrest and incarceration.

\section{Research Hypotheses}

This study will focus on delinquent behavior, and arrest and their association with the following variables: (a) Academic achievement (b) Religiosity (c) Parental styles (d) Discrimination. The following are the hypotheses to be tested in this study: Hypothesis One

a) Among African American adolescent males, participants with low levels of academic achievement are more likely to self-report involvement in delinquent behavior than participants with high levels of academic achievement.

(b) Among African American adolescent males, participants with low levels of academic achievement are more likely to be arrested than participants with high levels of academic achievement.

Hypothesis Two

(a) Among African American adolescent males, those who are very religious are less likely to be involved in delinquent behavior than those who are not religious.

(b) Among African American adolescent males, those who are very religious are less likely to be arrested than those who are not religious.

\section{Hypothesis Three}

(a) Among African American males, participants with authoritative parents are less likely to be involved in delinquent behavior than participants with authoritarian parents. 
a) Among African American males, participants with authoritarian parents are less likely to be involved in delinquent behavior than participants with permissive parents.

b) Among African American males, participants with authoritative parents are less likely to be involved in delinquent behavior than participants with permissive parents.

\section{Hypothesis Four}

(a) Among African American males, those who report high perceptions of discrimination are more likely to be involved in delinquent behavior than those who report low perceptions of discrimination.

(b) Among African American males, those who report high perceptions of discrimination are more likely to be arrested than those who report low perceptions of discrimination. 


\section{CHAPTER III}

\section{Methodology}

This study was conducted using data gathered from a recently completed NIDA funded longitudinal study that included approximately 425 African American youth. The parent study was a major epidemiological study focused on substance use among a multiethnic cohort of young adolescents residing in Dade County, Florida (Vega \& Gil, 1998). The research design, data collection, instrumentation and sample demographic information in the present chapter were gleaned from the original study, Vega and Gil (1998) and also from the recently completed study follow-up study. Only data gathered from the African American youth will be used in this study. This chapter includes a discussion of the research design, participants, data collection, and instrumentation and data analysis. Descriptive statistics for the demographic variables are presented and reliability analyses of three of the instruments (Delinquency Scale, Parental Authority Scale, and Discrimination Scale) used in the study are also provided.

\section{Research Design}

The parent study was a longitudinal, cohort study that began in 1989(Vega \& Gil, 1998). Data used in this study were collected from self-reports of boys and girls entering the sixth and seventh grades of the Dade Counties Public Schools (DCPS) in the fall of 1990. The first wave of data collection began in the fall of 1990 . Cohort studies focus on examining the changes in behavior of a specific sub-population over time (Rubin \& Babbie, 1993). Cohort studies are appropriate for the study of adolescent behavior problems because they provide a picture of the progression of criminal careers (Bartollas, 1993). 
In the subsequent follow-up study by Turner and colleagues, the fourth wave of data collection occurred in 1999-2000 when the respondents were at ages 19-21 years old. The follow-up study has successfully contacted and interviewed 1803 subjects from the original study.

\section{Participants}

The subjects for the parent study (Vega \& Gil, 1998) were obtained from the 48 Dade County public middle schools. Informed consent forms were sent to the parents and guardians of all prospective participants. Approximately $85 \%$ of the forms were returned giving consent for the youth to participate in the study. At time one (fall 1990), the numbers of males were 6,934, which included 946 classified as African Americans. The second data collection occurred in the fall of 1991, the third data collection occurred in the spring of 1993 and the fourth data collection occurred during 1999-2000. The sample size fluctuated between data collection intervals, however, analyses determined that there was no difference in the representativeness of the sample.

The current study included data from the follow-up study (wave 4). The total sample was composed of 242 African Americans. At the first data collection during fall 1990 , the mean age of participants was 11.6 years old and they were entering the sixth or seventh grade (Vega \& Gil, 1998). Among the African American participants 42.1\% lived in two-parent households, and $29.9 \%$ lived in single-mother households. The socioeconomic status of the students was low, as approximately $50 \%$ of the participants were in the free or reduced-cost lunch program. Student achievement as determined by the scores on the Stanford Achievement Tests ( $7^{\text {th }}$ edition), was low in comparison to the 
national average (Vega \& Gil, 1998). The data analyzed in the current study were from the fourth wave of data collection which occurred during 1999-2000.

\section{Descriptive statistics for the total study sample.}

Respondents were African American males, 50\% of whom were from low socioeconomic backgrounds as determined by their eligibility for the free and reduced price lunch program at the first wave of data collection. During the fourth wave of data collection (1998-2000), subjects ranged in age from 18 to 23 years, with a mean age of 20.05 years $(\mathrm{SD}=1.06)$. In terms of educational achievement, $15.3 \%(\mathrm{n}=37)$ had completed high school and attended college, $66.9 \%(n=162)$ graduated high school, $12.4 \%(\mathrm{n}=30)$ completed the $11^{\text {th }}$ grade, $3.7 \%(\mathrm{n}=9)$ completed the $10^{\text {th }}$ grade, $1.2 \%(\mathrm{n}=3)$ completed the $9^{\text {th }}$ grade and $0.4 \%(n=1)$ completed the $8^{\text {th }}$ grade. At the time of the fourth wave interview, $54.1 \%(n=131)$ of respondents were currently in school, while the remaining $42.6 \%(n=103)$ were not enrolled in school. With respect to plans for continuing education, $96.3 \%(n=233)$ of respondents planned to continue their education, while $3.3 \%(n=8)$ did not plan to continue their education, and $0.4 \%(n=1)$ reported "other". With respect to the 233 respondents with future educational plans, $5.4 \%(n=13)$ planned to obtain a General Equivalency Diploma (GED), 3.3\%(n=8) planned to complete high school, $12.8 \%(\mathrm{n}=31)$ planned to obtain a 2-year (Associates) degree, $38.4 \%(n=93)$ planned to obtain a four-year degree, $14.9 \%(n=36)$ planned to attend business, trade or vocational school, $21.1 \%(n=51)$ planned to obtain a professional or graduate degree, and $0.4 \%(n=1)$ reported other plans. The descriptive statistics for the demographic characteristics for the total study sample are summarized in Table 2. 
Table 2

Descriptive Statistics of Demographics for the Total Study Sample $\mathrm{N}$

Race

African American

$100 \%$

Age (years) at Wave 4 contact

18

19

20

21

22

23
7

75

87

50

18

5
$2.9 \%$

$31.0 \%$

$36.0 \%$

$20.7 \%$

$7.4 \%$

$2.1 \%$

Education

Highest grade completed

$$
\begin{aligned}
& 8^{\text {th }} \text { grade } \\
& 9^{\text {th }} \text { grade } \\
& 10^{\text {th }} \text { grade } \\
& 11^{\text {th }} \text { grade } \\
& 12^{\text {th }} \text { grade }
\end{aligned}
$$

Other
1

3

9

30

162

37

131

103

8

$54.1 \%$

$44.0 \%$

$3.3 \%$

Plan to continue Education

Yes

233

$96.3 \%$

No

Missing

8

$3.3 \%$

1

$0.4 \%$

Educational Plans

GED

High School Diploma

2-year Degree

4-year Degree

Business/trade/vocational school

Professional/graduate Degree

Other $10.4 \%$
13

8

31

93

36

51
$5.4 \%$

$3.3 \%$

$12.8 \%$

$38.4 \%$

$14.9 \%$

$21.1 \%$ 


\section{Data Collection}

\section{Ethical Issues/Protection of Confidentiality}

The parent study by Vega and Gil (1998) was funded by NIDA. The Institutional Review Board of University of Miami approved the use of human subjects. The National Institutes of Health granted a Certificate of Confidentiality to protect the confidentiality of data. Ensuring anonymity was problematic due to the longitudinal design of the study, as participants were tracked over time and periodic contact occurred for data collection purposes. The investigators protected all project identifiers assigned to the participants and no visible identifiers were included on protocols. Students were recontacted between waves using information that they themselves provided or information provided by Dade County Public Schools. The tracking system was modified at T-3 through the use of invisible ink to record the student numbers on the protocols. A special scanning instrument was used to determine the student number. All student questionnaires were destroyed after being checked, coded and entered in a data file.

The student questionnaire in was developed using four focus groups and two pilot studies over a period of 18 months. The English version of the questionnaire was administered to the African American students in the study. Only trained members of the project staff administered the questionnaires. The administration of the student questionnaire was accomplished using several different methods due to reading difficulties among the participants. One method involved gathering data during a class period from the students who had no difficulty with reading or responding to the questionnaire. Another method was to administer the questionnaire over two class periods allowing students with reading difficulties extra time in which to complete the 
questionnaire. Questionnaires were also administered orally to students with severe difficulties in reading.

Reliability Analyses of Instruments

The internal consistency of three of the instruments (Delinquency Scale, Parental Authority Scale, and Discrimination Scale) used in the present study was assessed by Cronbach's alpha coefficient. Cronbach's alpha determines internal consistency by assessing the homogeneity of the measure by taking an average of all the possible correlations when the instrument is randomly divided in half (Rubin \& Babbie, 1989).

The study sample's Delinquency scores ranged from a minimum of zero to a maximum of five, the mean score was $0.0(S D=0.69)$. The reliability analysis found an alpha coefficient for Delinquency of $.50(n=240)$. After conducting a factor analysis, the study sample's Discrimination scores were divided into two factors Discrimination Perception (DISC_PER) and Discriminatory Behavior (DISC_ACT). The Discrimination Perception scores ranged from a minimum of one to a maximum of five, with a mean of $2.42(S D=0.76)$. The reliability analysis found an alpha coefficient of $.85(n=242)$. The Discriminatory Behavior scores ranged from a minimum of one to a maximum of five, with a mean score of $1.68(S D=0.78)$. The reliability analysis found an alpha coefficient of .74 ( $\mathrm{n}=241)$. The study sample's Parental Authority scores were divided by male or female parent. The male parent scores ranged from a minimum of 18 to a maximum of 44 , with a mean of 32.50 (SD 5.20). The reliability analysis found an alpha coefficient of $.51(n=149)$. The female parent scores ranged from a minimum of 19 to a maximum of 44 , with a mean score of 33.97 (SD 4.40). The reliability analysis found an alpha coefficient of $.35(n=232)$. Despite the low alpha score, this instrument will be used in this current 
study as it is the only instrument used in the parent study to collect data on parenting styles. A discussion of the limitations of this instrument due to its low alpha will be presented in Chapter V (see pp. 87-89)

\section{Instrumentation}

The parent study involved several student questionnaires; however, this study will include only demographic information and questionnaires pertinent to the variables of interest. Demographic information included gender, age, and place of birth and ethnic identity. All variables used in the current study were collected at Wave 4, when participants were on average 20 years of age.

\section{Variables of Interest}

\section{Academic achievement.}

Academic achievement was measured by asking the respondent to indicate the highest grade completed. The scale was nominal and included eight items beginning with the sixth grade and continuing through the twelfth grade. The scale ended with "other" in which the participant would indicate a level higher than the twelfth grade.

\section{Religiosity.}

Religiosity was measured by a asking participants to indicate how often they attend church. The scale involved ratio measurement from $1=$ never, $2=$ once or twice a year, $3=$ once a month, $4=$ once a week, $5=$ more than once a week. This measure was used in the original study as part of the demographic information questionnaire. 


\section{Parental styles.}

Parental styles were measured using a 24-item questionnaire in which the participant was asked to rate the parental style of each parent (i.e. mother/female guardian and father/male guardian) (Baumrind, 1991). This measure was used in the follow-up study. The first twelve questions referred to the mother /female guardian and the rest referred to the father/male guardian. The questions were identical except for the gender of the parent to which it referred. For example, participants were asked to respond to "As I was growing up my mother did not allow me to question any decision she had to make." The corresponding question in the father/male guardian section asked, "As I was growing up my father did not allow me to question any decision he had to make." The item is rated on a 5 point scale indicating $1=$ strongly disagree, $2=$ disagree, $3=$ neither agree nor disagree, 4 agree, $5=$ strongly agree.

\section{Delinquent behavior.}

Delinquent behavior was measured in the original study, using an 8-item scale. The scale measured delinquent behavior in the last month and included items such as "carried a hand gun when you went out," and "broken into or entered a home, store or building." Participants were asked to respond by indicating "yes" or "no" to each item on the questionnaire. This questionnaire was adapted from Kaplan et al. (1986). The alpha coefficients for African Americans were .74 (T-1), .75 (T-2), and .71 (T-3). 


\section{Arrest.}

Individual arrest rates were determined by asking participants if they had been arrested or incarcerated in jail or juvenile hall. Participants were also asked about the frequency of arrest and their age at first arrest.

\section{Discrimination.}

Discrimination was measured using a 9-item scale with responses ranging from "“almost always" to "never." Participants were asked questions such as "people act as if they are afraid of you" and "You are treated with less respect than you deserve." Participants were also asked to identify the main reasons for their experience based on a list of thirteen reasons, which included items such as race, age and ethnicity. Participants were also asked to identify the most important reason for this treatment.

\section{Reliability and Validity}

Self-reports are the most commonly used data gathering method in juvenile studies (Junger-Tas \& Marshall, 1999). The method gained popularity as researchers realized the limitations inherent in the use of official statistics (Junger-Tas \& Marshall, 1999). Official statistics such as police reports tend to be limited as not every criminal activity leads to an arrest. Some types of juvenile crime such as truancy, and are not criminal offenses but are considered status offenses only when committed by a juvenile. These types of offenses rarely lead to arrest or detainment, similarly not every crime committed resulted in an arrest. These undetected crimes lead to variations between official records and self-reported offenses. Official records such as police statistics are influenced or biased by other factors such as offense seriousness, willingness of victims to report crime and organizational requirements, resulting in the increasing use of self- 
report measures (Junger-Tas \& Marshall, 1999). Official records are also limited in addressing problems such causality, change or stability of delinquent behaviors and these questions are more readily answered using self report measures (Junger-Tas \& Marshall, 1999).

The prevalence in the use of self-report measures does not negate the problems inherent in the method. There are several crucial issues concerning the reliability and validity of the self-report method in this study. One of the issues is the use of a cohort sample in the study of serious and violent offending. Junger-Tas and associates stated that cohort studies do not have some of the problems inherent in community samples such as attrition and under-representation of serious offenders. Cohort samples are more likely to maintain most of the original participants due to the use of school or birth registration records for locating participants in longitudinal studies. The cohort sample is also less likely to under-represent serious offenders than other general population samples (JungerTas \& Marshall, 1999). The use of a known population of offenders would greatly increase the incidence of the dependent variable (serious and violent offending) however, this would also limit the generalizability of the study's findings. One of the goals of this study is to present the factors affecting juvenile offending in the context of a general population of African American youth with more generalizability.

The construction and conceptualization of the instruments are also critical areas in the reliability and validity of data generated by the participants. The scales used in the current study were developed and tested over an 18 month period using four focus groups and two pilot studies. The original study also included parent and teacher ratings in an 
effort to triangulate data sources. The participants in the parent study were aware of their parents and teachers participation so this may have also improved the reliability of the self-reports. The measures used in the follow-up study incorporated multiple indicators of delinquent behaviors resulting in an attempt for more precise measurement of the different dimensions of the construct (Pedhazur \& Pedhazur-Schmelkin, 1991). The measures included information on varying levels of delinquent behavior such as petty theft to serious personal assaults. The measures have face validity, as they appear to measure the identified construct by asking for information directly associated with the construct.

Differential participation and response rates are also factors that affect the reliability and validity of the self-report methodology (Junger-Tas et al., 1999). Differential participation and low response rates occur when participants are absent while measures are being administered or as a result of poor reading skills and language difficulties. Response rates were increased in the current study by allowing extra time for the completion of the questionnaire and also by administering the questionnaire orally to students with difficulties in reading (Natalino, 1981).

There are also factors affecting the self-report methodology that are specific to working with adolescent ethnic minority populations. Junger-Tas et al. (1999) argued that the validity of self-reported criminal activity is higher in juvenile samples as compared to adult samples. Adult participants are more likely to present a prosocial image than juvenile participants and therefore may not be truthful in disclosing information regarding their criminal activities. 
Studies have shown inconsistent results in the use of self-report questionnaires with adolescent African American males (Paschall et al., 2001). In a comparison of official records and self-reported arrests, Huizinga and Elliot (1986) found that African American males tended to under-report their arrests. In their study only $11 \%$ of the selfreported data agreed with official records for the African American males as compared to 57\% agreement among the White male participants. However when the measure was broadened to include a wider range of offenses the rates increased to $61 \%$ agreement for African American participants and $81 \%$ for White male participants. Farrington et al. (1996) found a higher rate of agreement between the self-report and official arrest records for the African American participants (65\%) as compared to the White male participants (53\%). However, in the current literature it is not clear if these discrepancies exist as a result of lying, memory lapses or problems associated with the instrument or its administration. In a recent study, Paschall and associates (2001) used audiocassetterecorded questionnaires and audio computer assisted self-interviewing to study the involvement of African American male adolescent's in the criminal justice system. This method reduced the likelihood of socially desirable responses and interviewer biases.

\section{Data Analysis}

All data were analyzed using SPSS for Windows (Green et al. 2000). The statistical methods used in the analyses were descriptive statistics, frequencies, factor analysis, t-tests, multiple regression and, hierarchical multiple regression. This study employed no control variables as t-tests revealed no significant differences in socioeconomic status, age and parental education between the delinquent and non-delinquent participants. 
Hypothesis One.

a) Among African American adolescent males, participants with low levels of academic achievement are more likely to self-report involvement in delinquent behavior than participants with high levels of academic achievement.

(b) Among African American adolescent males, participants with low levels of academic achievement are more likely to be arrested than participants with high levels of academic achievement.

The first research hypothesis was analyzed using multiple regression. Multiple regression was used to examine whether academic achievement is useful in predicting delinquent behavior. The independent variable was academic achievement and the dependent variables were delinquent behavior and arrest. Academic achievement was measured at the ordinal level while delinquent behavior and arrest were measured at the nominal level.

Analysis of the Data Relevant to the Second Research Hypothesis

\section{Hypothesis Two}

(a) Among African American adolescent males, those who are very religious are less likely to be involved in delinquent behavior than those who are not religious.

(b) Among African American adolescent males, those who are very religious are less likely to be arrested than those who are not religious.

The second research hypothesis were analyzed using multiple regression to test for an association between religiosity, delinquent behavior and arrest. The independent variable was religiosity, and the level of measurement was ordinal. The dependent 
variables were delinquent behavior and arrest, and they were at the nominal level of measurement.

\section{Analysis of the Data Relevant to the Third Research Hypothesis}

Hypothesis Three

a) Among African American males, participants with authoritative parents are less likely to be involved in delinquent behavior than participants with authoritarian parents.

b) Among African American males, participants with authoritarian parents are less likely to be involved in delinquent behavior than participants with permissive parents.

c) Among African American males, participants with authoritative parents are less likely to be involved in delinquent behavior than participants with permissive parents.

The third research hypotheses were also be tested using multiple regression to examine the relationship between parenting style and delinquent behavior. Parenting style was the independent variable and it was measured using an ordinal level of measurement. Delinquent behavior was the dependent variable and it was measured using a nominal level of measurement.

Analysis of the Data Relevant to the Fourth Research Hypothesis

\section{Hypothesis Four}

(a) Among African American males, those who report high perceptions of discrimination are more likely to be involved in delinquent behavior than those who report low perceptions of discrimination. 
(b) Among African American males, those who report high perceptions of discrimination are more likely to be arrested than those who report low perceptions of discrimination.

The fourth research hypothesis was also be tested using factor analysis and multiple regression to examine the relationship between discrimination, delinquent behavior and arrest. Discrimination was the independent variable and it was measured using an ordinal level of measurement. Delinquent behavior and arrest were dependent variables and were measured using a nominal level of measurement. 


\section{CHAPTER IV}

\section{Results}

Chapter Four presents the results of the study. A description of variable properties for each of the variables used in this study is presented, followed by a brief comparison of the participants to other African American males using data from the 1990 and 2000 census. The statistical analyses conducted in relation to the four hypotheses are presented, followed by a brief summary of the findings for each research hypothesis.

\section{Variable Properties}

\section{Academic Achievement}

Academic achievement was measured by participants' responses to "What is the highest grade you completed" (see Tables 2, and 3). Responses ranged from 8th grade (coded 8) to "other" (coded 13). The "other" category referred to participants who have completed the $12^{\text {th }}$ grade and continued their education. The mean for grade completed was 11.90 , the median and mode for grade completed was 12 . These data show that the majority of the sample $(n=162)$ were high school graduates. As academic achievement was moderately negatively skewed and kurtotic (see Table 3), the variable was transformed using reflect and square root transformation (Tabachnick \& Fidell, 1989), and the transformed variable was used in all subsequent analyses (see Table 3). 
$\underline{\text { Table } 3}$

Academic Achievement

\begin{tabular}{|c|c|c|}
\hline & $\begin{array}{c}\text { Academic Achievement } \\
\text { Variable }\end{array}$ & $\begin{array}{c}\text { Transformed Academic } \\
\text { Achievement Variable }\end{array}$ \\
\hline $\mathrm{N}$ & 242 & 242 \\
\hline Mean & 11.90 & 1.00 \\
\hline Median & 12.00 & 1.00 \\
\hline Mode & 12.00 & 0.46 \\
\hline Std. Deviation & 0.77 & -0.77 \\
\hline Skewness & -1.52 & 0.88 \\
\hline Kurtosis & 4.57 & .00 \\
\hline Minimum & 8.00 & 2.44 \\
\hline Maximum & 13.00 & .94 \\
\hline
\end{tabular}

\section{Religiosity}

Religiosity was measured using the following three variables: (1) religious perception, (2) spirituality, and (3) church attendance (see Table 4). The Likert scale for the religious perception variable is as follows: $1=$ not very religious, $2=$ not too religious, $3=$ moderately religious, $4=$ very religious. The mean, median and mode scores related to religious perception were $2.80,3.00,3.00$, respectively. These scores indicate that the majority of the sample considered themselves to be moderately religious. The Likert scale for the spirituality variable is as follows: $1=$ never, $2=$ rarely, $3=$ sometimes, $4=$ often, $5=$ always. The mean, median, and mode scores related to spirituality were $3.69,4.00$, and 4.00 , respectively, these scores indicate that 
the majority of respondents often relied on religious or spiritual beliefs to deal with daily problems. The Likert scale for the church attendance variable is as follows: $1=$ never, $2=$ once or twice a year, $3=$ once a month, $4=$ once a week, $5=$ more than once a week. The mean, median and mode scores related to church attendance were $3.00,3.00$, and 2.00. These scores indicate that the average respondent attended church approximately once a month.

$\underline{\text { Table } 4}$

$\underline{\text { Religiosity }}$

\begin{tabular}{|c|c|c|c|}
\hline & $\begin{array}{c}\text { Religious } \\
\text { perception }\end{array}$ & Spirituality & Church Attendance \\
\hline $\mathrm{N}$ & 242 & 242 & 242 \\
\hline Mean & 2.80 & 3.69 & 3.00 \\
\hline Median & 3.00 & 4.00 & 3.00 \\
\hline Mode & 3.00 & 4.00 & 3.00 \\
\hline Std. Deviation & 0.81 & 1.16 & 1.19 \\
\hline Skewness & -.44 & -.63 & .13 \\
\hline Kurtosis & -.12 & -.40 & -.96 \\
\hline Minimum & 1 & 1 & 1 \\
\hline Maximum & 4 & 5 & 5 \\
\hline
\end{tabular}

\section{Parenting Style}

Parenting style was determined by summing the total score on the parental authority measure. The maximum score on the measure of 60 points was viewed as an authoritarian style of parenting. A mid-range score of 30 points would be indicative of an authoritative style of parenting and a low-range score below 30 would indicate a permissive parenting style. Participant scores regarding parenting style were categorized by female or male parent (see Table 5). The mean, median, and mode scores for female parent were $35.48,35.00$, and 36.00 , respectively. These scores indicate that the majority of respondents rated their female parent as authoritative. 
The mean, median and mode scores for male parent were $36.77,36.00$ and 36.00 respectively. The scores indicate that the majority of respondents rated their male parent as authoritative.

\section{$\underline{\text { Table } 5}$}

\section{Parenting Style}

\begin{tabular}{|c|c|c|}
\hline & Female Parent & Male Parent \\
\hline $\mathrm{N}$ & 232 & 149 \\
\hline Missing & 10 & 93 \\
\hline Mean & 35.48 & 36.77 \\
\hline Median & 35.00 & 36.00 \\
\hline Mode & 36.00 & 36.00 \\
\hline Std. Deviation & 4.27 & 4.92 \\
\hline Skewness & .41 & .55 \\
\hline Kurtosis & .57 & 26 \\
\hline Minimum & 24 & 52 \\
\hline Maximum & 51 & .63 \\
\hline
\end{tabular}

\section{Delinquent Behavior}

The frequency distribution of the scores for the measure of delinquency indicated that approximately $22 \%$ of the sample $(n=52)$ were involved in delinquent behavior (see Table 6). The measure included eight items indicative of types of crimes committed, among which, participants were asked to respond "yes" or "no". The types of crimes committed by the fifty-two respondents ranged in seriousness from petty theft, and property damage to carrying a handgun (see Table 7). As the delinquency score was severely positively skewed and very kurtotic, the variable was 
transformed using an inverse transformation (Tabachnide \& Fidell, 1989), and the transformed variables was used in all subsequent analyses (see Table 6).

\section{$\underline{\text { Table } 6}$}

Delinquent Behavior

\begin{tabular}{|c|c|c|}
\hline & Delinquent Behavior & $\begin{array}{c}\text { Delinquent Behavior } \\
\text { Transformed }\end{array}$ \\
\hline $\mathrm{N}$ & 240 & 240 \\
\hline Missing & 2 & 2 \\
\hline \multicolumn{3}{|l|}{ Frequency } \\
\hline $0=$ no & 188 & 188 \\
\hline $1=$ yes & 52 & 52 \\
\hline Mean & 0.30 & 0.88 \\
\hline Median & 0.00 & 1.00 \\
\hline Mode & 0.00 & 1.00 \\
\hline Std. Deviation & 0.69 & 0.23 \\
\hline Skewness & 3.16 & -1.53 \\
\hline Kurtosis & 13.17 & 0.63 \\
\hline Minimum & 0.00 & 0.17 \\
\hline Maximum & 5.00 & 1.00 \\
\hline
\end{tabular}


Table 7

Descriptive Statistics for Delinquent Behavior

\begin{tabular}{|c|c|c|}
\hline & $\mathrm{N}$ & Percent \\
\hline $\begin{array}{c}\text { Strong-arm Robbery } \\
\text { Yes } \\
\text { No }\end{array}$ & $\begin{array}{c}6 \\
234\end{array}$ & $\begin{array}{c}2.50 \% \\
97.50 \%\end{array}$ \\
\hline $\begin{array}{c}\text { Breaking/Entering } \\
\text { Yes } \\
\text { No }\end{array}$ & $\begin{array}{c}2 \\
238\end{array}$ & $\begin{array}{c}.80 \% \\
99.20 \%\end{array}$ \\
\hline $\begin{array}{c}\text { Property Damage } \\
\text { Yes } \\
\text { No }\end{array}$ & $\begin{array}{c}9 \\
231\end{array}$ & $\begin{array}{c}3.70 \% \\
95.50 \%\end{array}$ \\
\hline $\begin{array}{l}\text { Auto Theft } \\
\text { Yes } \\
\text { No }\end{array}$ & $\begin{array}{c}7 \\
233\end{array}$ & $\begin{array}{c}2.90 \% \\
96.30 \%\end{array}$ \\
\hline $\begin{array}{c}\text { Stolen Item }>\$ 50 \\
\text { Yes } \\
\text { No }\end{array}$ & $\begin{array}{c}6 \\
234\end{array}$ & $\begin{array}{c}2.5 \% \\
96.70 \%\end{array}$ \\
\hline $\begin{array}{c}\text { Carried a Handgun } \\
\text { Yes } \\
\text { No }\end{array}$ & $\begin{array}{c}39 \\
201\end{array}$ & $\begin{array}{l}16.10 \% \\
83.10 \%\end{array}$ \\
\hline $\begin{array}{c}\text { Stolen item }>\$ 20 \text { from } \\
\text { family/friends } \\
\text { Yes } \\
\text { No }\end{array}$ & $\begin{array}{c}4 \\
236\end{array}$ & $\begin{array}{l}1.70 \% \\
97.5 \%\end{array}$ \\
\hline $\begin{array}{c}\text { Participated in gang fight } \\
\text { Yes } \\
\text { No }\end{array}$ & $\begin{array}{c}0 \\
240\end{array}$ & $\begin{array}{c}0.0 \% \\
100.0 \%\end{array}$ \\
\hline
\end{tabular}

Arrest

Of participants, $30.2 \%(n=73)$ had been arrested at least once, while $69.4 \%$ $(n=168)$ reported never being arrested (see Table 8$)$. The mean, median, and mode for the scores on the arrest measure were $0.30,0.0,0.0$, respectively. 
$\underline{\text { Table } 8}$

Arrest

\begin{tabular}{|c|c|}
\hline & Ever Arrested \\
\hline $\mathrm{N}$ & 241 \\
\hline Missing & 1 \\
\hline $\begin{array}{c}\text { Frequency } \\
0=\text { no } \\
1=\text { yes }\end{array}$ & $\begin{array}{c}168 \\
73\end{array}$ \\
\hline $\begin{array}{c}\text { Number of arrests for: } \\
\text { Assault } \\
\text { Robbery } \\
\text { Burglary } \\
\text { Car theft } \\
\text { DUI } \\
\text { Selling drugs } \\
\text { Other offense }\end{array}$ & $\begin{array}{c}21 \\
16 \\
7 \\
12 \\
1 \\
11 \\
25\end{array}$ \\
\hline Mean & .30 \\
\hline Median & .00 \\
\hline Mode & .00 \\
\hline Std. Deviation & .46 \\
\hline Skewness & .86 \\
\hline Kurtosis & -1.27 \\
\hline Minimum & 0 \\
\hline Maximum & 1 \\
\hline
\end{tabular}

\section{Discrimination}

Discrimination was divided into two factors, (1) perceived discrimination, and (2) experienced discrimination (see Table 9). The mean, median and mode scores for perceived discrimination were $2.42,2.43$, and 2.57 respectively. These scores suggest that the majority of the participants rarely felt discriminated against. The mean, 
median and mode scores for experienced discrimination were 1.68, 1.50, and 1.00, which suggest that the majority of the participants reported never experiencing discrimination.

\section{$\underline{\text { Table } 9}$}

Discrimination

\begin{tabular}{|c|c|c|}
\hline & Perception & Experience \\
\hline $\mathrm{N}$ & 242 & 1 \\
\hline Missing & 0 & 1.68 \\
\hline Mean & 2.42 & 1.50 \\
\hline Median & 2.43 & 1.00 \\
\hline Mode & 2.57 & .78 \\
\hline Std. Deviation & .76 & 1.44 \\
\hline Skewness & .35 & 2.21 \\
\hline Kurtosis & .32 & 1.00 \\
\hline Minimum & 1.00 & 5.00 \\
\hline Maximum & 4.86 & \\
\hline
\end{tabular}

Note: $1=$ never, $2=$ rarely, $3=$ sometimes, 4=often, 5=almost always

Comparison to National, State and County Sample (US Census)

\section{Year 1990 census data demographics}

The following data provides a basis for comparison of the sample used in the current study using 1990 and 2000 figures for national, state and county demographic variables. Data on which this current study is based, was gathered between 1990 (initial data collection) and 2000 (fourth data collection period).

According to data from the 1990 Census, there were 549.8 thousand African American males in the United States between the ages of 10 and 11 years old. $6.2 \%$ 
( $n=33.9$ thousand) resided in Florida including the $1.3 \%(n=7.2$ thousand) who resided in Dade County, which included the sample for this study. Of the 664.3 thousand persons (all races and both sexes), 3 years and older, living in the United States and enrolled in elementary or high school, $6.35 \%(n=421.9$ thousand $)$ resided in Florida, including the $1.5 \%$ ( $\mathrm{n}=98.3$ thousand) who resided in Dade County. This Dade County statistic included the study's sample of African American males.

There were 314.1 thousand African Americans (males and females) between the ages of 6-11 years old living in the United States for whom poverty status was determined. Approximately $40 \%$ of these children were living below the poverty level, including $2.6 \%(n=82.2$ thousand) who resided in Florida and $0.5 \%(n=17.4$ thousand) who were Dade County residents. The total population of African American children in Dade County between the ages of 6-11 years old was 44.8 thousand of which the above 17.4 thousand (39\%) were living below the poverty level.

Based on the aforementioned statistics, the African American males at wave one in the parent study (Vega \& Gil, 1998), were representative of African American males across the United States, Florida and Dade County as indicated by their age, school enrollment and socio-economic background. At wave one the mean age of the sample was 11.6 years, they were all enrolled in middle school and approximately $50 \%$ of these African American males were living at or near the poverty level (Vega \& Gil, 1998).

\section{Year 2000 census data demographics}

At the time of the fourth data collection period, the African American males in this study ranged in ages from 18-23 years, with a mean age of 20 years old. According to 2000 census data there were 1.8 million African American males in the 
United States between the ages of 18-24 years. Approximately $7 \%(n=127.4$ thousand) were Florida residents , including 1.3\% ( $\mathrm{n}=23.7$ thousand) residing in Dade County. Due to lack of specificity in the 2000 census data collection, educational achievement or attainment will compared using the data collected for African American males 25 years and older. While these males were a minimum of 2 years older than average age of the sample, the information gleaned does provide some basis of comparison to the sample, which is preferable than having nothing to compare. There were 8.98 million African American males 25 years and older in the United States, 590.4 thousand who resided in Florida and 114.3 thousand Dade County residents. Among African American males 25 and over in the United States, Florida and Dade County, an average of $10 \%$ had less than a $9^{\text {th }}$ grade education; approximately $23 \%$ had a $9^{\text {th }}$ to $12^{\text {th }}$ grade education but no diploma; and approximately $30 \%$ had a high school diploma. The sample in the current study would be expected to fall within these ranges as they were representative of African American males in the United States, Florida and Dade County at the beginning of the parent study (Vega and Gil, 1998).

\section{Hypotheses}

The results are presented for the hypotheses provided in Chapter II, with the measure of statistical significance set at the .05 confidence level.

\section{Hypothesis One}

Hypothesis one focused on the relationship between academic achievement and delinquent behavior. Hierarchical multiple regression analysis was used to examine the hypothesis that academic achievement will account for significant variance in delinquent behavior among African American adolescent males (see Table 10). Highest grade completed is used as the measure of academic achievement. 
Approximately $3 \%$ of the variance of delinquent behavior was accounted for by its linear relationship with academic achievement $\left(\mathrm{R}^{2} \Delta=.03, \mathrm{p}=.01\right)$. An additional analysis was conducted with arrest and academic achievement (see Table 11), based on the hypothesis that academic achievement will account for significant variance in arrest among African American adolescent males. Due to the transformation of the highest grade completed variable, the variable should now be interpreted in the reverse, as higher scores indicate less academic achievement. The positive beta in the regression analysis with arrest (see Table 11) should be interpreted as of lower academic achievement being related to lower likelihood of arrest. The findings revealed that highest grade completed accounted for approximately $10 \%$ of the variance in arrest $\left(\mathrm{R}^{2} \Delta=.10, \mathrm{p}=.000\right)$.

\section{$\underline{\text { Table } 10}$}

Delinquent behavior regressed on academic achievement.

\begin{tabular}{|l|l|l|l|}
\hline $\begin{array}{l}\text { Independent } \\
\text { variable }\end{array}$ & Block-wise $\beta$ & $\mathrm{R}^{2}$ total & $\mathrm{R}^{2}$ change \\
\hline $\begin{array}{l}\text { Highest grade } \\
\text { completed }\end{array}$ & $-.17^{*}$ & $.03^{*}$ & $.03^{*}$ \\
\hline
\end{tabular}
$* \mathrm{p}<.05$

\section{$\underline{\text { Table } 11}$}

Arrest regressed on academic achievement

\begin{tabular}{|l|l|l|l|}
\hline $\begin{array}{l}\text { Independent } \\
\text { variable }\end{array}$ & Block-wise $\beta$ & $\mathrm{R}^{2}$ total & $\mathrm{R}^{2}$ change \\
\hline $\begin{array}{l}\text { Highest grade } \\
\text { completed }\end{array}$ & $.323^{*}$ & $.10^{*}$ & $.10^{*}$ \\
\hline$* \mathrm{p}<.001$ & \multicolumn{2}{|l}{} \\
\hline
\end{tabular}

\section{Hypothesis Two}

Hierarchical multiple regression analysis was used to examine the hypothesis that religious perception, church/synagogue attendance, and spirituality independently will account for significant variance in delinquent behavior among African American 
adolescents. Religious perception was entered in the first block, church/synagogue attendance was entered into the second block and spirituality was entered into the third block of the regression analysis (see Table 12).

These variables had no significant effect on delinquent behavior. Tests for possible interactions among these variables were also conducted, all of which were nonsignificant. Additionally, after making these variables dichotomous, logistic regressions were conducted, however the results were also not significant.

\section{Table 12}

Delinquent behavior regressed on religious perception, church/synagogue attendance, and spirituality.

\begin{tabular}{|l|l|l|l|}
\hline $\begin{array}{l}\text { Independent } \\
\text { variable }\end{array}$ & Block-wise $\beta$ & $\mathrm{R}^{2}$ total & $\mathrm{R}^{2}$ change \\
\hline $\begin{array}{l}\text { Religious } \\
\text { perception }\end{array}$ & .10 & .01 & .01 \\
\hline $\begin{array}{l}\text { Church/Synagogue } \\
\text { attendance }\end{array}$ & .09 & .02 & .00 \\
\hline Spirituality & -.01 & .02 & .00 \\
\hline
\end{tabular}

Hierarchical multiple regression analysis was used to examine the hypothesis that religious perception, church/synagogue attendance and spirituality will account for significant variance in arrest. Religious perception was entered into the first block, church/synagogue was entered into the second block and spirituality was entered into the third block (see Table 13). Both religious perception and church/synagogue attendance accounted for unique and significant variance in arrest. Approximately $3 \%$ of the variance in arrest was accounted for by its relationship to religious perception (religious perception $\mathrm{R}^{2} \Delta=.03, \mathrm{p}=.005$ ), and approximately $4 \%$ of the variance in arrest was accounted for by its relationship with church attendance (church/synagogue attendance $\left.\mathrm{R}^{2} \Delta=.04, \mathrm{p}=.001\right)$ 
Inspection of the block-wise beta-weights associated with each of the subscales of religiosity revealed than religious perception and church/synagogue attendance was significantly related to arrest. African American adolescents who reported greater religious perception and higher church attendance were less likely to be arrested. Adolescents' perceptions of spirituality had no effect on arrests.

\section{Table 13}

Arrest regressed on religious perception, church/synagogue attendance, and spirituality.

\begin{tabular}{|l|l|l|l|}
\hline $\begin{array}{l}\text { Independent } \\
\text { variable }\end{array}$ & Block-wise $\beta$ & $\mathrm{R}^{2}$ total & $\mathrm{R}^{2}$ change \\
\hline $\begin{array}{l}\text { Religious } \\
\text { perception }\end{array}$ & $-.12^{*}$ & $.03^{*}$ & $.03^{*}$ \\
\hline $\begin{array}{l}\text { Church/Synagogue } \\
\text { attendance }\end{array}$ & $-.21^{*}$ & $.07^{*}$ & $.04^{*}$ \\
\hline Spirituality & .00 & .07 & .00 \\
\hline \multicolumn{2}{|l}{$* \mathrm{p}<.05$} & & \\
\hline
\end{tabular}

Hypothesis Three

Hierarchical multiple regression analysis was used to examine the hypothesis that parenting style independently will account for significant variance in delinquent behavior among African American adolescents. Authoritative parenting style was hypothesized to result in less delinquent behavior. Due to the construction of the measure, parenting style was presented as two variables namely father parenting style and mother parenting style. Mother parenting style was entered into the first block and father parenting style was entered into the second block of the regression analysis (see Table 14). Parenting style did not account for significant variance in delinquent behavior as indicated by $\mathrm{R}^{2}$ change values. Additional analyses were conducted to examine the effect of Baumrind's three styles of parenting (authoritarian, authoritative, permissive). The effects of the styles were also non-significant. 
Parenting style was also regressed on arrest and found to be non-significant as

indicated by $\mathrm{R}^{2}$ change values.

\section{Table 14}

Delinquent behavior regressed on parenting style

\begin{tabular}{|l|l|l|l|}
\hline $\begin{array}{l}\text { Independent } \\
\text { variable }\end{array}$ & Block-wise $\beta$ & $\mathrm{R}^{2}$ total & $\mathrm{R}^{2}$ change \\
\hline $\begin{array}{l}\text { female parenting } \\
\text { style }\end{array}$ & -.07 & .01 & .01 \\
\hline $\begin{array}{l}\text { male parenting } \\
\text { style }\end{array}$ & .00 & .01 & .00 \\
\hline
\end{tabular}

\section{Hypothesis Four}

Hierarchical multiple regression analysis was used to examine the hypothesis that discrimination will account for significant variance in delinquent behavior among African American adolescents. Perceived discrimination was entered into the first block, experienced discrimination was entered into the second block and the score from the interaction between perceived discrimination and experienced discrimination was entered into the third block of the regression analysis (see Table 15). Perceived discrimination and the interaction between perceived discrimination and experienced discrimination, respectively accounted for approximately $4 \%$ and $3 \%$ of the variance in delinquent behavior as indicated by the $\mathrm{R}^{2}$ change values. The values for perceived discrimination and experienced discrimination were centered by subtracting the mean scores and calculating the median splits for each group of the variables (Jaccard, Turrisi \& Wan, 1990; Cohen \& Cohen, 1983).

Inspection of the block-wise beta weights associated with each of the subscales of discrimination revealed that discrimination perception and interaction between perceived and experienced discrimination were significantly related to delinquent behavior. Adolescents who reported greater perceptions of discrimination 
were more likely to be involved in delinquent behavior and adolescents who reported higher exposure to discriminatory acts were less likely to be involved in delinquent behavior. However the interaction effect of the two indicators of delinquency showed that adolescents who reported both lower perceptions of discrimination and higher exposure to discriminatory acts were more likely to be involved in delinquent behavior.

\section{Table 15}

Delinquent behavior regressed on discrimination perception, discrimination act, and discrimination interaction.

\begin{tabular}{|l|l|l|l|}
\hline $\begin{array}{l}\text { Independent } \\
\text { variable }\end{array}$ & Block-wise $\beta$ & $\mathrm{R}^{2}$ total & $\mathrm{R}^{2}$ change \\
\hline DISC_PER & $-.20^{*}$ & $.04^{*}$ & $.04^{*}$ \\
\hline DISC_ACT & -.08 & .04 & .00 \\
\hline DISC_INT & $.20^{*}$ & $.07^{*}$ & $.03^{*}$ \\
\hline
\end{tabular}

$* \mathrm{p}<.05$

Hierarchical multiple regression analysis was used to examine the hypothesis that discrimination will account for significant variance in arrest. Discrimination act was entered into the first block, discrimination perception was entered into the second block and discrimination interaction was entered into the third block (see Table 16). The subscales did not account for unique and significant variance in arrest as indicated by $\mathrm{R}^{2}$ change values. Inspection of the block-wise beta-weights associated with each of the sub-scales of discrimination revealed that they were not significantly related to arrest. 
Table 16 - Arrest regressed on discrimination act, discrimination perception, and

discrimination interaction.

\begin{tabular}{|l|l|l|l|}
\hline $\begin{array}{l}\text { Independent } \\
\text { variable }\end{array}$ & Block-wise $\beta$ & $\mathrm{R}^{2}$ total & $\mathrm{R}^{2}$ change \\
\hline Discrimination act & .06 & .01 & .01 \\
\hline $\begin{array}{l}\text { Discrimination } \\
\text { perception }\end{array}$ & .04 & .01 & .00 \\
\hline $\begin{array}{l}\text { Discrimination } \\
\text { interaction }\end{array}$ & -.01 & .01 & .00 \\
\hline
\end{tabular}




\section{CHAPTER V}

Discussion

The present study was designed to explore putative predictors of delinquent behavior and arrest among African American males. In this chapter, the results of the current study are discussed in terms of the hypotheses. Next, limitations of the current study and implications for future research are presented. Finally, implications for social welfare policy and social work practice are examined and the summary and conclusion are presented.

Hypothesis One

Hypothesis one, that academic achievement will account for significant variance in delinquent behavior among African American males, was supported by the data. Approximately three percent (3\%) of the variance in delinquent behavior was associated with academic achievement. In their meta-analysis, Maguin and Loeber (1996) reported an effect size of -.149 for the association between academic achievement and delinquency. In the current study, the effect size based on the association among these two variables was -.17 , which closely approximates the findings of Maguin and Loeber. It should be noted that while the study's sample reported low delinquent behavior and demonstrated relatively high academic achievement, it is possible that in a sample of known delinquents academic achievement may account for a larger proportion of variance in delinquent behavior because the sample would exhibit an increased range of delinquency and hypothetically less academic success.

The design of the questionnaire also affected the variance between academic achievement and delinquent behavior. The items used to measure delinquent behavior asked about delinquency that occurred within the past month. Specifically the 
instructions on the delinquent behavior measure for eight of the items instructed participants, "I am going to read a list of behaviors that people sometimes do. Please tell me whether you have done each behavior IN THE LAST MONTH..." This limited the participants' responses to behavior only within the past month and effectively eliminated responses from participants about behavior that may have occurred further back in time. A greater proportion of the sample may have reported delinquency if queried about the past twelve months rather than just the past month. Despite the limitations regarding the measurement of delinquency, it is important to note that there was a statistically significant relationship between delinquent behavior and academic achievement.

A stronger relationship was found between academic achievement and arrest. Academic achievement accounted for approximately twelve percent (12\%) of the variance in arrest among African American males. Participants were asked if they had "ever been arrested or spent at least one night in jail or juvenile hall?" This question effectively captures any instances of arrest over the participant's lifetime, and thus does not suffer from the limitations due to the limited recall timeframe associated with the measure of delinquency.

Hypothesis Two

Hypothesis two examined the relationship between religiosity and delinquent behavior. As religiosity is a multidimensional concept, it was measured using the following three variables: religious perception, spirituality, and church attendance. The result of the hierarchical multiple regression indicated that the participant's religious perception accounted for approximately two percent $(2 \%)$ of the variance in delinquent behavior. Spirituality and church attendance were not significantly related to delinquent behavior in this sample. Religiosity has been widely accepted in the 
delinquency literature as a measure of attachment to conventional society and as such, may increase an adolescent's resilience to the development of delinquent behavior. Due to the lack of significant findings among two of the three dimensions of the religiosity, results of the current study were not entirely consistent with this formulation.

An additional analysis which examined the relationship between religiosity and arrest indicated that religious perception and church attendance were significantly related to arrest. Findings indicated that among the African American adolescent males in this study, religious perception and attending church were associated with significantly lower likelihood of arrest. An African American adolescent male who perceives himself as being very religious may be less likely to participate in delinquent behavior as this would possibly violate the tenets of his belief. Additionally, attending church on a regular basis may not only be indicative of the attachment to conventional society but it also effectively reduces the time spent in unsupervised activity. Lack of supervision during the weekend and after-school hours is one of the risk factors associated with delinquent behavior, and church involvement may mitigate against this risk factor.

\section{Hypothesis Three}

Hypothesis three examined the relationship between parenting style and delinquent behavior. Parenting styles by either paternal or maternal parent did not account for significant variance in delinquent behavior among African American adolescent males. The parenting measure had a reliability of .35 which is on the low end of the reliability scale (Pedhazur \& Schmelkin, 1991). The measure lacked specificity as it did not capture data related to monitoring and supervision of adolescents, parenting dimensions which consistently have been identified as key risk 
factors in the development and involvement in delinquent behavior (Jensen, 1997; Smith \& Stern, 1997; Williams et al. 1997).The current study lends support to previous findings that the measure may be inappropriate for use with an African American sample. Mason et al., (1996) stated that Baumrind's categories may mistakenly portray African American parents as very restrictive or authoritarian. Additionally, Baumrind (1991) also stressed caution in the use of the categories as she felt more definitive information was needed about adolescents from "families of color" before making assumptions as to their parenting styles (p.755). It is noteworthy however, that neither researcher conclusively rejected the use of the categories with African Americans, instead they suggested that use be approached with caution as to the potential unsuitability of the categories. In this regards the current study suggests that the measure in its current form, is not suitable for use with a sample of African American males.

In measuring parental styles, prior research has shown that it would be more appropriate to include items related to monitoring techniques than measuring parenting styles with regards to control of household rules and decision-making. Parental monitoring would be an appropriate indicator of the supervision dimension of parenting styles, as lack of parental supervision and monitoring is a potential risk factor in the development of delinquent behavior (Gray-Ray \& Ray, 1990; Jensen, 1997, Smith \& Stern, 1997, Williams et al., 1997). An appropriate measure may include items such as "How often do your parents ask you where you are going?" and "Do your parents know (a) the names of your friends (b) where your friends live or their telephone numbers?" Responses to the aforementioned items would provide information on parental monitoring, and responses can be triangulated by also asking the parents the same questions. 
There is also the possibility that the measure was appropriate for this population but failed to produce desired results based on the instability of parenting influences over time. Participants in the current study (wave 4) were asked to retrospectively report their experiences at earlier ages which may have also been affected by their ability to recall events with some degree of accuracy. Participants at age 20 may have given accurate accounts of their current level of parenting which would conceivably differ from parenting experienced at age 11 . Parenting may change over time and be influenced by other factors such as peer group involvement (Mason et al., 1996). Involvement with delinquent peers may result in an authoritarian parenting style focused on limiting peer group contact and strict enforcement of household rules.

The measure also had items that were difficult to interpret such as "My father gave me direction for my behavior and activities as I was growing up and he expected me to follow his direction, but he was always willing to listen to my concerns and to discuss that direction with me." Participants may have become confused with the item and responded inaccurately. Consequently, due to the aforementioned difficulties, the parenting style hypothesis should be re-examined in subsequent research with a more rigorously designed measure.

\section{Hypothesis Four}

Hypothesis four predicted that discrimination will be positively associated with delinquent behavior among African American adolescent males; this hypothesis was supported by the data. Based on a factor analysis, discrimination was divided into two factors, perceived discrimination and experienced discrimination. The findings indicated that perceived discrimination and the interaction between perceived and experienced discrimination were significantly related to delinquent behavior while 
experienced discrimination was not. Perceived discrimination accounted for $4 \%$ of the variance between discrimination and delinquent behavior while the interaction between perceived and experienced discrimination accounted for $3 \%$ of the variance. African American adolescent males who had high perceptions of discrimination were significantly more likely to be involved in delinquent behavior than adolescents who did not have a high perception of discrimination. These findings suggest that an adolescent's perception of discrimination was more of a risk factor for delinquency than his actual experience of discrimination. However, adolescents who reported both high perceived and high experienced discrimination were at the greatest risk for involvement in delinquent behavior (i.e., the interaction of perceived and experienced discrimination was significantly related to delinquency). Subsequent research should re-examine this relationship with samples of known delinquents to further clarify the strength of this relationship and the role of the two dimensions of discrimination and their interaction as related to the type of crime committed and other indicators of delinquency.

\section{Limitations}

While self-report measures are widely used as a data collection method in studies of juvenile offenders (Junger-Tas \& Marshall, 1999), there are advantages and disadvantages inherent in their use which will be discussed in this section. The following sub-sections outline the major limitations of the study as related to design, data collection procedure, and the sample.

\section{Design}

A basic limitation of this study is that it was correlational and as such did not utilize randomization or manipulation of variables. Non-experimental research involves the observation of variability in dependent variables and collection of information on an 
independent variable to which the variability may be attributed (Pedhazur \&

Schmelkin, 1991) as demonstrated by this study. A study focused on treatment efficacy using an experimental design would be an improvement over the current design as discussed in the following section on design.

The follow-up study from which the data for the current study was gleaned was a longitudinal study. Longitudinal studies are subject to major threats to internal validity such as instrumentation, testing, history, maturation, mortality. Instrumentation refers to changes in the measure that affect the way the variable of interest is measured. Internal validity may have been compromised in the parent study by cosmetic changes in the measures used (Pedhazur \& Schmelkin, 1991). For example changes made to wording on the measure in an effort to provide clarification may effectively change the way participants respond. Previous responses may not correspond to responses made after the changes have taken place. Researchers would then need to analyze these responses separately and acknowledge the changes in measures in their final analyses.

Testing refers to the source of error which occurs when participants are assessed repeatedly on the same variable. Participants' performance may be affected by "practice, memory of earlier responses, sensitization and /or conjectures regarding the purpose of the research and the expectations of the researcher "(Pedhazur \& Schmelkin, 1991, p.225). Participants may complete the measures based on recall or by rote due to memory of previous responses effectively resulting in inaccuracies in the data collection. History refers to events that may have taken place during the course of the study that may have affected its outcome (Pedhazur \& Schmelkin, 1991). In the longitudinal study from which the current study is derived, one obvious historical event that may have influenced responding is Hurricane Andrew in 1992. 
Researchers need to acknowledge significant events which may have occurred during the course for the study which may have impacted the data in order to fully understand the findings from their research.

Maturation refers to "changes that people being studied undergo with the passage of time, including growing older, gaining experience, becoming tired, hungry and the like" (Pedhazur \& Schmelkin, 1991, p. 225). In the parent study, participants' aged from an average age of 11 years at wave 1 to approximately 20 years at wave 4 . Participants' responses must then be analyzed within the context of their mental, emotional, physical and psychological maturity. Mortality refers to attrition or the drop-out rate among participants during the course of the study. Mortality may result due to unknown reasons as it may be difficult to contact participants to find out their motives. Researchers must acknowledge and compensate for the missing data due to dropouts in their final analyses.

While the current study focused on retrospective reports collected during an interview in late adolescence, it is also subject to these threats because participants had to rely on their individual recall of events and feelings from their earlier adolescent years. Reliance on recall could be viewed as the basis for threats such as history, maturation, and mortality. The time lapse between data collection periods may be affected by threats such as changes in personnel, and revisions to the measures that were used. Therefore, establishment of cause and effect among variables may be particularly thorny in studies like the present one. However, correlation and descriptive data regarding the relationships among the variables were provided.

While it would be unethical to do an experimental study examining the causes of delinquency by withholding treatment from one group, an experiment designed to 
determine effectiveness of three differing treatment modalities could strengthen the ability to make conclusions about possible cause and effect relationships. An example of this would be an experimental study which would include a sample known African American delinquents randomly assigned to receive either of two interventions. The study would include a wait-list control group who receives the usual treatment which is generally monitoring by a juvenile probation officer. This study would be an improvement over the current study as it would involve randomization and the administration of three treatment modalities, whose effectiveness could be compared while controlling for age, socio-economic status, delinquent involvement, geographical location and other relevant factors. While correlations as to the strength of associations with delinquent behavior or arrest and variables such as academic achievement, parental monitoring, religiosity and discriminations can still be accomplished with this design, additional analyses of relationships affecting amenability to treatment would also be feasible.

Generalizability of the current study's results is also limited, as the findings can only be generalized to African American adolescent males who have the same characteristics as the participants. African American youth in Miami may be different from African American youth in other parts of the United States based on varying ethnic origins. Miami is composed of people of diverse international backgrounds who may also have children who were born in the United States. There is a large Caribbean population in Miami which poses a problem when one tries to separate groups into African American or Caribbean without obtaining reliable identifiers such as survey information from the census or other related sources.

In the original study, participants were asked whether they were born in the United States and then instructed to select among several ethnic identities including 
African American. Data generated from the participants who identified themselves as African American were used in the current study. It is highly probable that some participants were youth from Caribbean heritage who were born in the United States. The ethnic and cultural background of their parents may distinguish them from other African American youth. As this study did not focus on distinctions among these groups, the resultant group's responses and experiences may be unique and as such should not be generalized to African American males in other areas without ensuring sufficient similarities.

\section{Data Collection Procedure}

A limitation in this study is the reliance on self-reported retrospective data without corroborating evidence from official sources. The data used in this study were solely based on participants' self-reports. Self-Reports are advantageous over official reports as not every incidence of delinquent behavior results in an arrest. Using only official reports can result in an erroneous account of actual delinquency and may underestimate the actual prevalence of delinquent behavior. Self-report questionnaires also contribute significant information such as age of onset, patterns of offending related to escalation and crimes in which the victim is also the offender such as prostitution and drug dealing (Junger-Tas \& Marshall, 1999). While self-reports are widely accepted in the study of delinquent behavior, there are conflicting arguments on both sides as to their reliability and validity (Farrington et al, 1996; Paschall et al. 2001). In an effort to increase reliability and validity, triangulation of data sources would therefore be preferable in future research with this population (Rubin \& Babbie, 1993). Triangulation would involve not only self-reported data but corroborating information from official sources and also parental, familial and school sources. 
The original study attempted to triangulate data sources by using parent and teacher reports. Participants were aware that their parents and teachers were also participants, therefore this may have influenced the validity and reliability of the adolescents' self-reports. Reliability of self-reports among African American adult males has been controversial as there are findings that African American males tend to under-report their arrests ( Huizinga \& Elliot, 1986) due to a bias toward socially desirable responses. However, among juvenile participants there is reduced likelihood of bias due to more social acceptance of juvenile non-conformity than adult non-conformity (Junger-Tas et al., 1999).

Retrospective reports may also affect the validity of the data due to reliance on the participant's memory of previous events as well as participants' need to conceal involvement in serious crimes. Participants' memory and accurate recall of nonserious delinquency (such as petty theft and property crimes) may be flawed as these events are more easily forgotten even when they occur and with greater frequency than more serious offenses (Junger-Tas et al., 1999). Under-reporting or denial of involvement in serious offenses has been more problematic among un-incarcerated adult samples rather than juvenile samples. These adults tend to project an inaccurate and pro-social image due to the consequences associated with admitting to antisocial/criminal behavior (Junger-Tas et al., 1999). Research with juvenile samples suggests that juveniles are less likely to under-report due to lower investment in conforming to societal norms (Junger-Tas et al., 1999).

In summary, the reliability and validity of data collected in future studies with this population can be increased by triangulation, using not only self-report and official records, but from several sources in the ecological environment such as parent, extended family members, community organizations and teacher reports. 
The use of existing data in the current study also limited the scope of the study, as secondary data analysis is restricted by the design of the study for which the data was originally collected. While existing data has the advantage of lower cost and time savings (Bickman \& Rog, 1998), it may also be problematic as it can curtail the structure of a study due to the measures used and the ways in which variables are conceptualized. For example, a better way to measure delinquency would be to ask participants about their lifetime involvement in delinquent behaviors rather than limiting them to behaviors exhibited in the prior month. Unfortunately, doing so was precluded because the data had already been collected.

\section{Sample}

A limitation of the study was the lack of a comparison group. A group of similar African American Adolescent males from another geographical location would have broadened the study's generalizability and offered additional basis for comparison among the variables. The use of clinical sample or an exclusively delinquent sample may have yielded more statistically significant results with the variables used in the study as compared to the current study's community sample. A study of this type with an exclusively delinquent population may provide more information as to the effect of the independent variables on delinquent careers of the participants. The restricted range of delinquency in the sample may have obscured the impact of variables such as academic achievement. While this study's sample showed a significant relationship between delinquency and academic achievement, data gathered from delinquent sample with a greater range of academic achievement may provide an opportunity to further explore the relationship between the variables. Information such as the age of onset, patterns in offending, escalation and severity 
could be compared to academic achievement to further understand the development of delinquency in this population.

Religiosity (specifically church attendance and spirituality) did not have a significant impact on delinquency in this sample as hypothesized. However a more delinquent sample or use of a larger sample may increase the likelihood of detecting a relation between the putative predictors and delinquency. Johnson et al. (2001) analyzed data from a major longitudinal study using a national probability sample of 1,725 persons aged $11-17$. In their study, religiosity was similarly operationalized as a multidimensional concept, race was controlled using two categories, White and nonWhite, and there were no controls for gender. Findings of Johnson et al. (2001) indicated that adolescent's religiosity had significant negative effect on delinquency. While their findings were not specific to African American males, they lend support to future research with this population regarding the effect of religiosity on delinquent behavior.

\section{Implications for Future Research.}

The current study was conducted using a multisystemic causal model based on the theory of social ecology. The theory presents a view of the individual in the context of multiple and interacting systems. While the current study examined individual level variables, there are additional factors that may impact delinquent behavior such as community, court, law enforcement, and peer groups. These additional factors (especially peer group involvement) may have strong influences on delinquent behavior. Peer group influence has been shown in numerous studies to be a major risk factor in the development of delinquent behavior and to also peak during adolescence. While this study did not include these factors due to the limitations inherent in the use of existing data, their influence is neither negated nor diminished. 
There are also many other theoretical bases associated with the study delinquency such as social disorganization theory (Shaw \& McKay, 1969), opportunity theory (Cloward \& Ohlin, 1960), and social control theory (Hirschi, 1969).Social disorganization theory posits that youth form disorganized communities characterized by high crime; drugs and poverty become attracted to delinquent values due to the lack of positive socialization. Opportunity theory posits that youth living in low socio-economic conditions tend to seek illegitimate means to attain middle class success goals through involvement in delinquency. Social control theory posits that youth's lack of attachment to conventional societal structures increases their likelihood for delinquency. While these theories evidence varied and conflicting explanations for delinquent behavior, when they are considered relative to the risk factors associated with delinquent behavior there is validity in aspects of each theory. Therefore, future research must focus on disentangling the influence of these theoretical models in clarifying the relationship among the risk factors associated with delinquent behavior.

Studies regarding delinquent behavior among African American males are essential as this group is most likely to be arrested for delinquent behavior and is over-represented among the delinquent population. Factors affecting risk and resiliency among this population are unclear as the majority of previous studies have been conducted using mainly White male adolescents. The effectiveness of future interventions should be based on the findings of research studies which are culturally sensitive to the needs of this population. In their discussion regarding multicultural issues in juvenile justice, Corley and Smitherman (1994) argued that intervention programs utilizing a culturally sensitive approach have been shown to be successful in treating delinquent behavior among African American males. Culturally sensitive 
intervention programs should not only demonstrate an understanding of the culture but should also establish links between the adolescent and persons or resources supportive of that bond (Corley \& Smitherman, 1994).

The findings of the current study also raised questions as to the effect of parenting styles on delinquency among African American males. A more clearly defined instrument that details parental monitoring and supervision techniques similar to the measures used in the 1985 study by Oregan Social Learning Center researchers, Patterson and Dishion, may be more appropriate with this population. Patterson and Dishion's parental questionnaire asks parents "How important do you think it is to know where your child is?" and "Where does he usually go after school?" The measure is triangulated using several sources such as, interviews with parent and child concerning a variety of defiant behaviors, the child report of parental supervision practices and the interviewer impression of parental supervision (Patterson and Dishion, 1985). Patterson and Dishion's measure was used with a majority White male population therefore in its current form it may not be appropriate for African American males. However it can be used as a starting point for the development of a more appropriate culturally sensitive measure. The development of this measure would involve extensive testing using pilot studies, focus groups and pre-tests to establish it appropriateness for use with African American males.

Discrimination was shown to be positively associated with delinquent behavior among African American adolescent males, specifically the perception of discrimination and additionally, the interactive effect of perceived and experienced discrimination. Future research could be enhanced by the inclusion of a known delinquent population and the use of controls such as age, number of arrests and type of crimes committed. Additionally comparative data from non-delinquent African 
American juveniles may yield more precise information as to the strength of the association between discrimination and delinquency. Use of controls and a comparison group may rule out any extraneous variables and clarify cause and effect relationships.

\section{Implications for Social Welfare Policy and Social Work Practice}

Juvenile delinquency is a serious social problem due to the increasing violence among juvenile offenders (Loeber \& Farrington 2001). Recent increases in school and community violence committed by juvenile offenders (Egan, 2000) not only affects society as whole, but also disrupts the lives of the juvenile offenders, their families and the victims. Smith and Stern (1997) viewed delinquency and its associated consequences (substance use, dropping out of school, gang activity) as a "failure to master normal life transitions into responsible and productive adulthood." African American adolescent males face many other obstacles in their journey to productive adulthood such as poverty, racism, joblessness, and violence (Wilson, 1994).

Delinquent behavior and arrest serve as additional obstacles, and it has been argued that these factors may interact to trap African American males in a state of perpetual adolescence (Elliot, 1994).

Policies designed to increase awareness of the link between delinquency and risk factors such as discrimination may assist efforts in reducing delinquency. Implementation of cultural sensitivity training for practitioners in the delinquency arena should be inclusive of the relationship between discrimination and delinquency among African American males. Increasing practitioner's understanding of this relationship may lead to changes in the servicing of this population.

Educating society on the impact of discrimination and placing harsher sanctions on discriminatory practices may eventually decrease the occurrence of said practices. 
Television advertisements can provide the medium in which this message is relayed to the general population. Social workers and other practitioners who work with this population can petition the courts, Congress and the Senate and advocate for stricter sanctions against discriminatory practices. Practitioners should also focus efforts on educating African American males and their families about the link between discrimination and delinquency and ways to combat this risk factor through the development of improved coping skills which may also help in reducing delinquency.

The Office of Juvenile Justice and Delinquency Prevention has mandated that states must address disproportionate minority confinement as a requirement to being awarded funding, due to the excessive numbers of minorities confined to residential juvenile facilities nationwide. The juvenile justice system in Florida has identified the facilities in which this is occurring and has begun to implement interventions such as reducing the use of residential facilities for youths whose needs can be met in non-residential community based programs (Flores, 2003). This is significant as the State of Florida also leads the nation in transfers of juveniles to the adult system, and the majority of juveniles transferred are Black males. Based on the findings of the current study, other approaches to addressing this disproportionality may include implementing policies and agendas focused on improving delinquency risk factors related to African American adolescent males specifically academic performance, coping skills pertaining to discrimination, and attachment to societal structures which promote religiosity.

The current study's findings also suggest that higher academic achievement reduces the risk of delinquent behavior and arrests. Increasing efforts focused on drop-out prevention and maintaining African American males in the school system may have significant impact on the arrest and confinement rates, the subsequent 
transfer of juveniles to the adult system may also be impacted by a reduction in delinquent behavior. Increased accountability for educating African American males should be one of the operational priorities for public schools however it should not negate the rights of educators to remove disruptive students from their school. Mainstream schools would need to work in a more collaborative manner with nontraditional or alternative schools to ensure that African American males with previous symptoms of learning disabilities or behavioral problems are mainstreamed in a timely manner. Efforts targeting drop-out prevention among this population would also involve prioritizing funding for educationally focused or supportive programs such as home based counseling, after-school activities, child-care, tutoring and parent education, which may decrease the incidence of involvement in delinquency.

The Office of Juvenile Justice and Delinquency Prevention's current research agenda focuses on young offenders between the ages of 7 and 12 years old as there has been a $33 \%$ increase among this population in the past decade (Flores, 2003). Youth who become involved in criminal behavior at earlier ages are more likely to persist in offending than those who begin in their teen years. The current study is incompliance with the current research agenda as participants were within this age range (i.e. they were approximately 11 years old) at the first wave of data collection. African American males, their families and other parties in their social environment and in the general population can benefit from information regarding the types of behavior or circumstances that would place these youth at significant risk for the development of delinquent behavior. Efforts such as increasing monitoring or supervision of youth, stressing educational attainment and increasing involvement in religious activities can be employed at earlier ages to decrease the likelihood of delinquency. The findings of this study may benefit African American males and their 
families currently involved in the juvenile justice system by providing information which may improve the effectiveness of current interventions. Interventions such as Multisystemic Therapy (Henggeler \& Borduin, 1990) could be improved by including components focused on the culturally and racially specific needs of African American youths and families. Components focused on educating youth as to the effects of their perception of discrimination and also assisting them in developing better coping mechanisms when faced with discriminatory practices may reduce the likelihood of delinquent behavior. Moreover, attention to the roles of religion and church in protecting at-risk African-American adolescent males appear warranted given the findings of previous and current research. While the findings of this study did not fully support previous research, the relationship between the variables may continue to be controversial among social scientists.

Due to the multiple and complex mechanisms in the youth's social environment that promote and sustain delinquent behavior additional research is needed to continually improve existing interventions. The Office of Juvenile Justice and Delinquency Prevention has given priority to research on designing interventions/treatments that would effectuate the youth's successful re-integration into society (Flores, 2003). At present, interventions such as Multidimensional Treatment Foster Care (Chamberlain \& Bell, 1998) have shown short-term success with serious and violent offenders in majority White male samples.

Multidimensional Treatment Foster Care (Chamberlain \& Bell, 1998) has been used with youth exhibiting more severe involvement in serious and violent offending than those youth typically involved in Multisystemic Therapy. Youth are removed from their homes and placed in a foster home setting due to the increased risk that they pose to society (Chamberlain \& Bell, 1998). This intervention not only involves 
the youth but also includes a parent-training component as part of the treatment protocol. While this intervention has shown promising results, the generalizability of the findings are currently limited due to the small sample size of other ethnic or racial groups such as African Americans (Chamberlain \& Bell, 1998).

The findings of the current study on African American males could improve the treatment protocol of this type of intervention through the incorporation of the risk factors associated with increased risk of delinquency. The treatment protocol may be improved by the following measures:

1. Ensuring an educational placement prior to re-integration and educating client and family as to the importance of maintaining this placement.

2. Developing a component to educate clients on coping with discrimination in a constructive manner.

3. Stressing some form of religious involvement.

While the need to develop more effective interventions for delinquent African American males remains an important research agenda, efforts focused on prevention must not be overlooked in the process as this would be a disservice to those youth who have not yet committed their first delinquent act.

\section{Summary and Conclusions}

The current study focused on the relationship of academic achievement, religiosity, parenting styles and discrimination to delinquent behavior and arrest among the African American males. A multisystemic causal model was used as the study's theoretical basis for establishing relationships among the chosen variables. This study was unique in that it focused on an exclusively African American male sample while previous research efforts have included majority White male samples. The findings of prior research have been used to develop interventions for all racial 
groups however one can speculate as their appropriateness across racial groups. The over-representation of African American males in the juvenile delinquent population and also in transfers to adult criminal courts provided additional rationale for this study. While there are many studies on the development of delinquent behavior, there are still gaps in the research as to African American males and other minority populations such as development, risk and protective factors. This study sought to address some of these gaps by beginning to identify the relationships between some of the pertinent risk factors.

The results of this study indicated that among African American adolescent males, delinquent behavior had a significant relationship with academic achievement, perceived discrimination and the interaction between perceived discrimination and experienced discrimination. Arrest was significantly related to academic achievement, religious perception, and church attendance. Neither dependent variable was significantly related to parenting styles.

The findings of this study indicate that experimental studies are needed to clarify cause and effect relationships among the variables associated with juvenile delinquent behavior in African American males. While there are many studies on delinquent behavior in the literature, there are still gaps in the research as to the risk factors specifically associated with African American males. The African American male continue to be among the minority populations over-represented in the criminal justice system and therefore are deserving of further study focused on addressing this problem. While there are other environmental and social variables which impact the over-representation of African American males in the criminal justice system such as law enforcement's responses and court processing/sanctions, this study was focused on individual level variables. More complex experimental studies of this population 
should also be approached from an ecological perspective similar to the current study, as this perspective is inclusive of other larger domains such as society and culture which also impacts the development of delinquent behavior. 


\section{List of References}

Bank, L., Hicks Marlowe, J., Reid, J.B., Patterson, G. R., \& Weinrott, M. R. (1991). A comparative evaluation of parent -training interventions for families of chronic delinquents. Journal of Abnormal Child Psychology, 19(1), 15-33.

Bartollas, C. (1993). Juvenile Delinquency. (3rd ed.). New York: Macmillian Publishing Company.

Baumrind, D. (1966). Effects of authoritative parental control on child behavior. Child Development, 37(4), 887-907.

Baumrind, D. (1972). An exploratory study of socialization effects on black children: Some black-white comparisons. Child Development, 43(1), 261-267.

Baumrind, D. (1978). Parental disciplinary patterns and social competence in children. Youth and Society, 9, 239-276.

Baumrind, D. (1991). Parenting styles and adolescent development. In J. Brooks-Gunn, R. Lerner, \& A.C. Petersen (Eds.), The Encyclopedia on Adolescence (pp. 746758). New York: Garland.

Benda, B. (1995). The effect of religion on adolescent delinquency revisited. Journal of Research in Crime and Delinquency, 32(4), 446-466.

Benda, B. (1997). An examination of a reciprocal relationship between religiosity and different forms of delinquency within a theoretical model. Journal of Research in Crime and Delinquency, 34(2), 163-186.

Bickman, L. \& Rog, D. (1998). Handbook of Applied Social Services Research Methods. Thousand Oaks, CA: Sage Publications.

Bishop, D., Frazier, C., Lanza-Kaduce, L., \& White, H.G. (1999). A study of juvenile transfers to criminal court in Florida. Washington: DC: Office of Juvenile Justice and Delinquency Prevention.

Borduin, C. M. (1994). Innovative models of treatment and service delivery in the Juvenile Justice System. Journal of Clinical Child Psychology, 23(Suppl.), 19-25.

Borduin, C. (1999). Multisystemic Treatment of Criminality and Violence in Adolescence. Journal of American Academy Adolescent Psychiatry, 38(3), 242249. 
Borduin, C. M., Mann, B. J., Cone, L. T., Henggeler, S. W., Fucci, B. R., Blaske, D. M. \& Williams, R. A. (1995). Multisystemic treatment of serious juvenile offenders: long term prevention of criminality and violence. Journal of Consulting and Clinical Psychology, 63, 569-578.

Brewer, D.D., Hawkins, J.D., Catalano, R.F., \& Neckerman, H.J. (1995).Preventing serious and violent, chronic juvenile offending: A review of evaluations of selected strategies in childhood, adolescence, and the community. In J.C. Howell, B. Krisberg, J.D. Hawkins, \& J.J. Wilson (Eds.), Sourcebook on serious, violent \& chronic juvenile offenders (pp. 61-142). Thousand Oaks, CA:Sage Publications.

Bronfenbrenner, U. (1970). Two Worlds of Childhood. New York: Sage.

Bronfenbrenner, U. (1979). The ecology of human development. Cambridge, Massachusetts: Harvard University Press.

Brunk, M., Henggeler, S.W., \& Whelan, J.P. (1987). A comparison of multisystemic therapy and parent training in the brief treatment of child abuse and neglect. Journal of Consulting and Clinical Psychology, 55, 311-318.

Capaldi, D.M. \& Patterson, G.R. (1996). Can violent offenders be distinguished from frequent offenders: Prediction from childhood to adolescence. Journal of Research in Crime and Delinquency, 33(2), 206-231.

Cernokovich, S. A., Giordano, P. C. (1992). School bonding, race, and delinquency. Criminology, 30 (2), 261-291.

Cernovich, S. A., Giordano, P. C. \& Rudolph, J. L. (2000). Race, crime and the American dream. Journal of Research in Crime and Delinquency, 37(2), 131-170.

Chamberlain, P. R, \& Bell, J. G. (1995). The effectiveness of family therapy in the treatment of adolescents with conduct disorders and delinquency. Journal of Marital and Family Therapy, 21(4), 441-459.

Chamberlain, P. R., \& Bell, J. (1998). Comparison of two community alternatives to incarceration for chronic juvenile offenders. Journal of Consulting and Clinical Psychology, 66(4), 624-633.

Chamberlain, P. (1998). Treatment Foster Care. Juvenile Justice Bulletin. Washington: DC: Office of Juvenile Justice and Delinquency Prevention.

Cloward, R. A., \& Ohlin, L.E. (1960). Delinquency and Opportunity: A theory of delinquent boys. Glencoe: IL: Free Press. 
Cochran, J., Wood, P., \& Arneklev, B. (1994). Is the religiosity-delinquency relationship spurious? A test of arousal and social control theories. Journal of Research in Crime and Delinquency, 31(1), 91-123.

Cohen, J., \& Cohen, P. (1983). Applied Multiple Regression/Correlation Analysis for the Behavioral Sciences ( $2^{\text {nd }}$ ed.). Hillsdale, NJ: Lawrence Erlbaum Associates.

Conley, D. J. (1994). Adding color to a black and white picture: Using qualitative data to explain racial disproportionality in the juvenile justice system. Journal of Research in Crime and Delinquency, 31(2), 135-148.

Corley, C.J. \& Smitherman, G. (1994). Juvenile justice: Multicultural issues. In J.E. Hendricks \& B. Byers (Eds.), Multicultural perspectives in criminal justice and criminology. (pp.259-290).Springfield, IL: Charles C. Thomas, DuRant, R. H., Cadenhead, C., Pendergrast, R. A., Slavens, G., \& Linder, C. W. (1994). Factors associated with the use of violence among urban black adolescents. American Journal of Public Health, 84, 612-617.

Egan, T. (2000). From adolescent angst to shooting up schools. In Struckhoff, D. R. (Ed.). Annual Editions: Juvenile Delinquency 00/01 (1 st ed.). Gilford, CT: Dushkin/McCraw-Hill.

Elliot, D. S., Huizinga, D., \& Menard, S. (1989). Multiple problem youth: Delinquency, Substance Use and Mental Health Problems. New York: Springer-Verlang.

Elliot, D. S. (1994). Serious violent offenders: Onset, developmental course, and termination _ The American society of Criminology 1993 Presidential Address. Criminology, 32(1), 1-21.

Fagan, J., \& Wilkinson, D. L. (1998). Guns, Youth Violence and Social Identity in Inner cities. In M. Tonry. M. H. Moore (Eds.), Youth Violence, 24,105-188. Chicago: IL: The University of Chicago Press.

Flores, R. (2003). 2001 Annual Report. Washington: DC: Office of Juvenile Justice and Delinquency Prevention.

Gray-Ray, P. \& Ray, M. (1990). Juvenile delinquency in the Black community. Youth \& Society, 2(1), 67-84.

Green, S. B., Salkind, N.J., \& Akey, T.M. (2000). Using SPSS for Windows: Analyzing and Understanding Data. Upper Saddle River: NJ: Prentice-Hall, Inc. 
Guerra, N. (1998). Serious and violent offenders: gaps in knowledge and research priorities. In R. Loeber, \& Farrington, D. P. (Eds.), Serious \& violent juvenile offenders: Risk factors and successful interventions (pp. 389-404). Thousand Oaks, CA: Sage.

Hawkins, D.F., Arthur, M.W., Catalano, R.F. (1995). Preventing substance abuse. In M. Tonry \& D.F. Farrington (Eds.) Building a safer society: Strategic approaches to crime prevention: Vol. 19. Crime and Justice: A review of research (pp. 343-427). Chicago: University of Chicago Press.

Hawkins, D. F., Laub, J. H., Lauritsen, J.L. (1998). Race, Ethnicity, and Serious Offending. In R. L. D. Farrington (Ed.), Serious and Violent Juvenile Offenders: Risk Factors and Successful Interventions (pp. 30-45). Thousand Oaks, CA: Sage.

Henggeler, S. W., Rodick, J. D., Borduin, C. M., Hanson, C. L., Watson, S. M. \& Urey, J. R. (1986). Multisystemic treatment of juvenile offenders: effects on adolescent behavior and family interaction. Developmental Psychology, 22(1), 132-141.

Henggeler, S. W., \& Borduin, C. M. (1990). Family therapy and beyond. Pacific Grove, CA: Brooks/Cole Publishing Company.

Henggeler, S. W., Burr-Harris, A. W., Borduin, C. M. \& McCallum, G. (1991). Use of the Family Adaptability and Cohesion Evaluation Scales in child clinical research. Journal of Abnormal Child Psychology, 19(1), 53-63.

Henggeler, S. W., Melton, G. B., \& Smith, L. A. (1992). Family preservation using multisystemic therapy: An effective alternative to incarcerating serious juvenile offenders. Journal of Consulting and Clinical Psychology, 60(6), 953-961.

Henggeler, S. W., Melton, G. B., Smith, L.A., Foster, S. L., Hanley, J. H., \& Hutchinson, C. M. (1993). Assessing violent offending in serious juvenile offenders. Journal of Abnormal Child Psychology, 21(3), 233-243.

Henggeler, S. W., Smith, B. H., \& Schoenwald, S. K. (1994). Key theoretical and methodological issues in conducting treatment research in the juvenile justice system. Journal of Clinical Child Psychology, 23(2), 143-150.

Henggeler, S. W., Schoenwald, S. K., Borduin, C.M., Rowland, M. D. \& Cunningham, P.B. (1998). Multisystemic Treatment of Antisocial Behavior in Children and Adolescents. New York: The Gilford Press.

Hindelang, M. J., Hirschi, T., \& Weis, J.G. (1979). Correlates of delinquency: The illusion of discrepancy between self-report and official measure. American Sociological Review, 44, 995-1014. 
Hirschi, T., Stark, R. (1969). Hellfire and Delinquency. Social Problems, 17, 202-213.

Hirschi, T. (1969). Causes of Delinquency. Berkley: University of California Press.

Howell, J. C., Krisberg, B., Hawkins, J. D., \& Wilson, J. J. (Eds.). (1995). A source book: Serious, violent and chronic offenders. Thousand Oaks, CA: Sage.

Howell, J. C., Krisberg, B., \& Jones, M. (1995). Trends in juvenile crime and youth violence. In J.C. Howell, Krisberg, B., Hawkins, J. D., \& Wilson, J. J. (Eds.), A sourcebook: Serious, violent \& chronic Juvenile Offenders (pp. 1-35). Thousand Oaks, CA: Sage.

Howell, J. C. (1997). Juvenile Justice \& Youth Violence. Thousand Oaks, CA: Sage.

Huizinga, D. \& Elliot, D. S. (1986). Assessing the reliability and validity of self report delinquency measures. Journal of Quantitative Criminology, 2(4), 293-327.

Jaccard, J., Turrisi, R., \& Wan, C.K. (1990). Interaction Effects in Multiple Regression. Newbury Park, CA: Sage.

Jang, S. J. (1999). Different definitions, different modeling decisions, and different interpretations: A rejoinder to Lauritsen. Criminology, 37(3), 695-702.

Jang, S.J., \& Smith, C.A. (1997). A test of reciprocal causal relationships among parental supervision, affective ties and delinquency. Journal of Research in Crime and Delinquency, 34(3), 307-336.

Jang, S. J., \& Krohn, M. D. (1995). Developmental patterns of sex differences in Delinquency among African American adolescents: A test of the sex-invariance hypothesis. Journal of Quantitative Criminology, 11(2), 195-222.

Jenson, J. M. (1997). Risk and protective factors for alcohol and other drug use in childhood and adolescence. In M. W. Fraser (Ed.), Risk and Resilience in Childhood: An Ecological Perspective (pp. 117-139). Washington: DC: NASW.

Johnson, B. R., Jang, S.J., Larson, D.B. \& De Li, S. (2001). Does Adolescent Religious Commitment Matter? A Reexamination of the Effects of Religiosity on Delinquency. Journal of Research in Crime and Delinquency, 38(1), 22-44.

Joseph, J. (1995a). Black Youths, Delinquency, and Juvenile Justice. West Port, CT: Praeger.

Joseph, J. (1995b). Juvenile delinquency among African Americans. Journal of Black Studies, 25(4), 475-491. 
Joseph, J. (1996). School factors and delinquency: A study of African American youths. Journal of Black Studies, 26(3), 340-355.

Junger-Tas, J., Marshall, I. H. (1999). The self-report methodology in crime research. In M. Tonry (Ed.), Crime and Justice: A Review of Research Vol. 25, (pp. 291-367). Chicago: Chicago Press.

Kazdin, A. E. (1997). A model for developing effective treatments: progression and interplay of theory, research and practice. Journal of Clinical Child Psychology, 26(2), 114-129.

Kazdin, A. E. (1997). Practitioner review: Psychosocial treatments for conduct disorder in children. Journal of Child Psychology and Psychiatry, 38(2), 161-178.

Kazdin, A. E., \& Weisz, J. R. (1998). Identifying and developing empirically supported child and adolescent treatments. Journal of Consulting and Clinical Psychology, 66(1), 19-36.

Lattimore, P., Linster, R. \& MacDonald, J. (1997). Risk of death among serious young offenders. Journal of Research in Crime and Delinquency, 34(2), 187-209. Loeber, R., \& Farrington, D. P. (Eds.). (1998). Serious \& violent juvenile offenders: Risk factors and successful interventions. Thousand Oaks, CA: Sage.

Loeber, R., Farrington, D. P. \& Waschbusch, D. A. (1998). Serious and violent juvenile offenders. In R. Loeber. D. P. Farrington (Eds.), Serious \& violent offenders: Risk factors and successful interventions (pp. 13-29). Thousand Oaks, CA: Sage.

Maguin, E., \& Loeber, R. (1996). Academic Performance and Delinquency. In M. Tonry (Ed.), Crime and Justice: A Review of Research Vol. 20, pp. 145-264). Chicago IL: Chicago Press.

Mason, C. A., Cauce, A.M., Gonzales, N., \& Hiraga, Y. (1996). Neither too sweet nor too sour: Problem peers, maternal control, and problem behavior in African American adolescents. Child Development, 67, 2115-2130.

McCubbin, H., Fleming, W., Thompson, A., Neitman, P., Elver, K., Savas, S. (1998). Resiliency and coping in "at risk"African American youth and their families. In H.I. McCubbin, E.A. Thompson, A. I. Thompson \& J.A. Futrell (Eds.), Resiliency in African-American Families (pp.287-328). Thousand Oaks, CA: Sage Publications.

Miller, W. B. (1958). Lower-class culture as a generation milieu of gang delinquency. Journal of Social Issues, 14, 9-10. 
Miller, J. G. (1996). Search and Destroy: African -American Males in the Criminal Justice System. Cambridge, UK: Cambridge University Press.

Moffitt, T. (1993). Adolescence-limited and life-course-persistent anti-social behavior: A developmental taxonomy. Psychological Review, 100(4), 674-701.

Natalino, K. W. (1981). Methodological problems in self-report studies of black adolescent delinquency. In G. F. Jensen (Ed.), Sociology of Delinquency (pp. 6377). Beverly Hills: CA: Sage.

Paschall, M. J. (1998). Racial differences in violent behavior among young adults: Moderating and confounding effects. Journal of Research in Crime and Delinquency, 35(2), 148-165.

Paschall, M. J., Ornstein, M.L., \& Flewelling, R. L. (2001). African American male adolescents' involvement in the criminal justice system: The criterion validity of self-report measures in a prospective study. Journal of Research in Crime and Delinquency, 38(2), 174-187.

Patterson, G.R., \& Stouthamer-Loeber, M. (1984). The correlates of family management practices and delinquency. Child Development, 1299-1307.

Pedhazur, E. J. Schmelkin, L.P. (1991). Measurement, Design, and Analysis : An integrated Approach. Hillsdale ,NJ: Lawrence Earlbaum Associates, Inc. Pope, C. E., and Feyerhern, W. (1990a). Minority status and juvenile justice processing. Criminal Justice Abstracts Part I, 22(2), 327-336.

Pope, C. E., and Feyerhern, W. (1990b). Minority status and juvenile justice processing. Criminal Justice Abstracts Part II, 22(3), 527-542.

Pope, C. E., \& Feyerhern, W. (1995). Minorities and the Juvenile Justice System : Research summary. Washington, DC: Department of Justice, Office of Juvenile Justice Delinquency Prevention.

Roth, A. \& Fonagy, P. (1996). What works and for whom? A critical review of psychotherapy research. New York: The Gilford Press.

Rubin, A. \& Babbie, E. (1993). Research Methods for Social Work. (2nd Ed.). Pacific Grove, CA: Brooks/Cole Publishing Company.

Sampson, R.H., \& Laub, J.R. (1988). Unraveling families and delinquency: A reanalysis of the Gluecks' data. Criminology,26(3), 355-380.

Shaw, C. R., \& McKay, H. D. (1969). Juvenile delinquency and urban areas (Rev. Ed.). Chicago: University of Chicago Press. 
Sickmund, M., Snyder, H. N., \& Poe-Yamagata, E. (1997). Juvenile offenders and victims: 1997 update on violence. Washington : DC: Office of Juvenile Justice and Delinquency Prevention.

Smith, C. A, \&. Stern, S. B. (1997). Delinquency and antisocial behavior : A review of family processes and intervention research. Social Service Review, 71(3), 382420.

Snyder, H. N., \& Sickmund, M. (1999). Juvenile Offenders and Victims : 1999 National Report. Washington, DC: Office of Juvenile Justice and Delinquency Prevention.

Stark, R., Kent, L., \& Doyle, D. (1982). Religion and delinquency: The ecology of a "lost" relationship. Journal of Research in Crime and Delinquency, 19, 4-24.

Steinberg, L., Elmen, J.D., \& Mounts, N.S. (1989). Authoritative parenting, psychosocial maturity, and academic success among adolescents. Child Development, 60, 1424-1436.

Steinberg, L., Lamborn, S.D., Dornbusch, S.M., \& Darling, N. (1992). Impact of parenting practices on adolescent achievement: Authoritative parenting, school involvement, and encouragement to succeed. Child Development, 63, 1266-1281.

Struckhoff, D. R. (Ed.). (2000). Annual Editions : Juvenile Delinquency 00/01 (1st ed.). Gilford, CT: Dushkin/McCraw-Hill.

Sutherland, E. H. (1947). Principles of Criminology. Philadelphia: PA: Lippincott.

Tabachnick, B.G. \& Fidell, L.S. (1989). Using multivariate statistics. $\left(2^{\text {nd }}\right.$ Ed). New York: Harper \& Row.

Tannenbaum, F. (1938). Crime and the Community. New York: Columbia University Press.

Thornberry, T. P., Huizinga, D., \& Loeber, R. (1995). The prevention of serious delinquency and violence : Implications from the program of research on the causes and correlates of delinquency. In J. C. Howell, Krisberg, B., Hawkins, J. D., \& Wilson, J. J. (Eds.), A sourcebook : Serious, violent and chronic juvenile offenders (pp. 1-35). Thousand Oaks, CA: Sage.

Tonry, M.,\& Moore, M.H. (Eds.). (1998). Youth Violence Vol. 24. Chicago: The University of Chicago Press.

Tracy, P. E., Wolfgang, M. E., \& Figlio, R. M. (1990). Delinquency Careers in Two Birth Cohorts. New York: Plenum Press. 
United States Census (1990).American Fact Finder. Retrieved 8/12/2003, from http://factfinder.census.gov/servlet/

United States Census (2000).American Fact Finder. Retrieved 8/28/2003, from http://factfinder.census.gov/servlet/

Vega, W. A., \& Gil, A.G. (1998). Drug use and ethnicity in early adolescence. New York: Plenum.

Wells, L.E., \& Rankin, J.H. (1988). Direct parental controls and delinquency. Criminology, 26 (2), 263-285.

Williams, J. H., Ayers, C. D. \& Arthur, M. W. (1997). Risk and protective factors in the development of delinquency and conduct disorder. In M. W. Fraser (Ed.), Risk and Resilience: An Ecological Perspective (pp. 140-170). Washington, DC: NASW.

Willias, J. W., Stiffman, A. R., \& O'Neal, J. L. (1998). Violence among urban African American youths: An analysis of environmental and behavioral risk factors. Social Work Research, 22(1), 3-13.

Williams, J. H., Ayers, C. D., Abbott, R.D., Hawkins, D., \& Catalano, R. F. (1999). Racial Differences in risk factors for delinquency and substance use among adolescents. Social Work Research, 23(4), 241-256.

Wilson, J. J., \& Howell, J.C. (1993). Comprehensive strategy for serious, violent and chronic juvenile offenders. Washington, DC: Office of Juvenile Justice and Delinquency Prevention.

Wilson, W. J. (1996). When Work Disappears: The World of the New Urban Poor. New York: Alfred A. Knopf.

Windle, M. (1991). Problem behavior in adolescence. In J. Brooks-Gunn, R. Lerner, \& A.C. Petersen (Eds.), The Encyclopedia on Adolescence (pp. 839-843). New York: Garland.

Wolfgang, M., Figlio, R. M., \& Sellin, T. (1972). Delinquency in a birth cohort. Chicago: University of Chicago Press. 


\section{APENDICES}




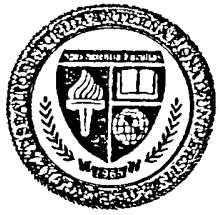 \\ Florida International University}

Office of the Director

\section{MEMORANDUM}

To: $\quad$ Lynette Atteloney

CC: $\quad$ Dr. Eric Wagner

File

From: Yvette Peterson, Coordinator Institutional Review Board

Date: $\quad$ October 2, 2001

Re: "Risk and Resilience Factors Associated with Serious and Violent Offending Among African American Males" Approval \# 09426001-00

Your study was deemed Exempt by the Institutional Review Board at Florida International University on September 26,2001. There are no additional requirements in regards to your study. However, if there are changes in the protocol after you commence your study that may increase the risks that the human subjects are exposed to, you are required to resubmit your proposal to a Representative of the IRB for review.

i

Please call the IRB office at 348-2494 with questions or concerns or visit the DSRT web-site at www.dst.fiu.edu. 


\title{
New PID
}

\section{Consent Form for Youth Interview}

\section{Project Title: Drug Use Trajectories: Ethnic/Racial Contrasts}

\author{
Investigators: R. Jay Turner, PhD, Dale Chitwood, PhD, Andres Gil, PhD, Eric \\ Wagner, PhD, Dorothy Taylor, PhD, Isabel Fernandez, PhD
}

We are asking you to participate in a research project. The researcher/interviewer will explain the present study to you. Please ask the researcher/interviewer any questions you have to help you understand this project. If you decide to participate in this project, please sign this form. You will be given a copy of this form to keep.

1. I understand that I am being invited to participate in a study that aims to find out how young adults feel about themselves, their family and friends and about social and, emotional problems they may have experienced in their lives. I will be asked some questions about illegal behavior, sexual behavior, the use of cigarettes, alcohol and drugs and other sensitive issues. I have been selected for this study because I took part in a similar study when I was in middle school or junior high school.

2. If I decide to participate, a researcher/interviewer will ask me questions about my social support, mood, drug use and background information. The interview will take about 2 hours to complete. All participants will be asked to complete a similar interview in approximately two years. In return for completing each interview, I will. be paid $\$ 25$.

3. My participation in this study will help you develop programs focused on young adult developmental problems. However, I understand that you cannot promise that I will personally receive any benefits from the study.

4. My participation is voluntary and I understand that I should not feel obliged to answer any questions that cause emotional discomfort. Names of counselors can be provided if I do feel emotionally upset as a result of this interview.

5. The information I give you will never be shared with my parents or anyone else. Code numbers, not names, will be written on the questionnaires, and the list which links code numbers to names will remain locked in the files of the director of the research project. My records will be kept confidential to the extent permitted by law. My records may also be reviewed for audit purposes by authorized Florida International University employees or other agents who will be bound by the same provisions of confidentiality. The Department of Health and Human Services (DHHS) may review these research records. 
6. As an additional protection, I understand that a Certificate of Confidentiality (DA97-74) from the Department of Health and Human Services has been obtained. This certificate affords the Principal Investigator the privilege to protect the privacy of research subjects by withholding the names and other identifying characteristics of those subjects from all persons not directly connected with the conduct of this research.

i

7. My decision whether or not to participate will not prejudice my present or future relations with Florida International University. If I decide to participate, I am free to withdraw my consent and to discontinue participation at any time.

8. I understand that if I have any questions, I should ask now. If I have any additional questions later, Dr. Turner, (305) 348-1060, will be happy to answer them. If I have questions about my rights as a research subject, I may contact Bernard Gerstman, Institutional Review Board Director, (305) 348-3115.

9. My signature acknowledges that I have read the information provided, have asked any questions I have about the project, and agree to participate in the study. I will be given a copy of this form.

Date 
Thank you very much for your willingness to participate in what we believe is a very important study. I want to remind you that your answers will be kept completely confidential. Your name will not appear anywhere in this computer and the list that connects your name with this material will be kept in a locked file maintained by the principal investigator. Not even our own research staff will ever be aware of whose answers they are processing.

\section{SECTION A - DEMOGRAPHIC INFORMATION}

\section{A1. INDICATE RESPONDENT'S GENDER 1 male 2 female}

A2. How old are you?

A3. Where were you born?
1. U.S
GO TO A5
2. Cuba
3. Colombia
4. Mexico
5. Dominican Republic
6. Nicaragua
7. Puerto Rico
8. Guatemala
9. El Salvador
10. Other
(specify)

A4. How many years have you been living in the United States?

A5. Turn to page 1 in your response booklet. With which of the groups shown do you most closely identify?
1. Non-Hispanic White
2. Hispanic White
3. Hispanic Black
4. African-American
5. Other

$$
\text { (specify) }
$$

A6. What is the highest grade you completed?

1. $6^{\text {th }}$ grade

2. $7^{\text {th }}$ grade

3. $8^{\text {th }}$ grade

4. $9^{\text {th }}$ grade

5. $10^{\text {th }}$ grade

6. $11^{\text {th }}$ grade

7. $12^{\text {tb }}$ grade

8. Other 


\section{INTERVIEWER CHECKPOINT}

IF COMPLETED GRADE 12 OR HIGHER

GO TO A10

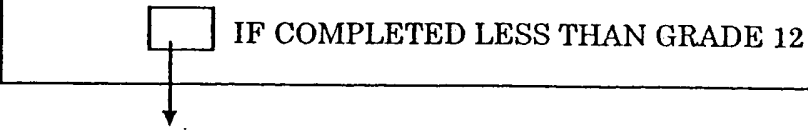

A7. How old were you when you stopped going to school during the day?

A8. Page 2 in your response booklet lists possible reasons for not graduating. Does one or more of these describe why you didn't graduate high school?

1. To go to work.

2. To help support the family.

3. Got bored, did not get anything out of it.

4. Saw no future in it.

5. Did not get along with other students.

6. Did not get along with teachers.

7. I was pregnant or became a father/mother.

8. Many of my friends had dropped out.

9. I did not feel safe at school.

10. Take care of ill/disabled family member.

11. Got in trouble with the law.

12. Had a drug or alcohol problem.

13. Was getting poor grades/failing.

14. Left the area.

15. Was expelled.

16. Other reason

\section{INTERVIEWER CHECKPOINT}

IF ANSWERED "WAS EXPELLED"

ALL OTHERS $\longrightarrow$ GO TO A10

A9. What was the major reason you were expelled?

1. Fighting in school

2. Selling drugs

3. Using drugs

4. Bringing a weapon to school

5. Excessive truancy (skipping school)

6. Other

A10. Do you plan to continue your education?
1. YES
5. NO
GO TO A14

A11. What are your educational plans? 
1. Get GED

2. Complete high school/get diploma

3. Get a 2-year (Associates) degree (junior/community college)

4. Get a 4-year degree (Bachelors)

5. Go to a business/trade/vocational school

6. Get a professional/graduate degree

7. Other

A12. Are you currently in school?

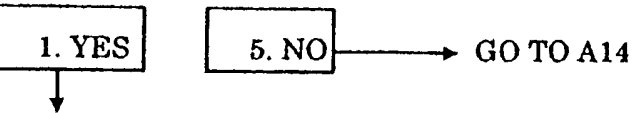

A13. What school do you attend?

[GET TYPE OF SCHOOL (E.G. JUNIOR OR 4-YEAR COLLEGE, MECHANIC OR BEAUTY SCHOOL, ETC.)]

A14. Have you ever worked for pay outside the home?

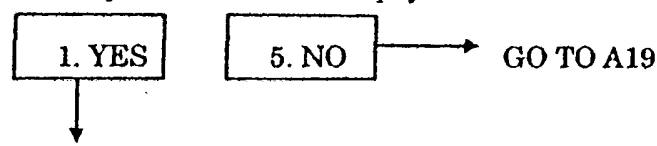

A15. What is the longest period of time you ever worked at a single job?

[GET YEARS AND MONTHS]

A16. Are you currently working for pay outside the home?

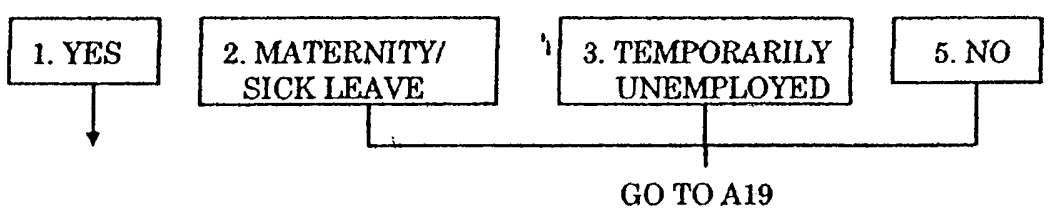

A17. What kind of work do you do?

A18. On the average, how many hours do you work per week?

A19. Do you belong to a church, temple, or synagogue?
1. Yes
2. No
3. Used to belong 
A20. Please tell me your religious denomination.
a) None
b) Baptist-southern
c) Baptist-national
d) Baptist-other
e) Catholic
f) Church of God
g) Church of Christ
h) Episcopal
i) Holiness
j) Jehovah's Witness
k) Jewish
1) Lutheran
m) Methodist-United
n) Methodist-AME
o) Methodist-other
p) Pentecostal
q) Presbyterian
r) Seventh Day-Adventist
s) Unitarian
t) United Church of Christ
u) Other Misc. sect groups
v) Mormon
w) Salvation Army
x) Christian Scientist
y) Other

(specify)

A21. How religious are you? Would you say you are very religious, moderately religious, not too religious or not at all religious?

\begin{tabular}{|c|c|}
$\begin{array}{c}\text { Very } \\
\text { religious } \\
1\end{array} \quad\left[\begin{array}{c}\text { Moderately } \\
\text { religious } \\
2\end{array}\right.$ \\
\hline
\end{tabular}

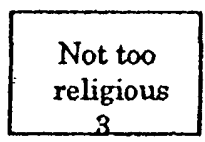

$$
\begin{gathered}
\text { Not at all } \\
\text { religious }
\end{gathered}
$$

A22. How often do you attend services at a church/synagogue?

1. Never

$$
\begin{gathered}
\text { 2. Once or twice } \\
\text { a year }
\end{gathered}
$$

4. Once a week

5. More than once a week

A23. How often do you turn to your religion or your spiritual beliefs to help you deal with your daily problems? Would you say always, often, sometimes, rarely or never? 
A24. Are you currently married, separated, divorced, widowed or have you never been married?
1. Married
2. Separated
3. Divorced
4. Widowed

5. Never

Been

Married

A24a. How many children do you have?

A25. Are you currently involved in a romantic relationship?

1. Yes 2. No $\longrightarrow$ GO TO NEXT SECTION

A26. (RB, P. 3) All in all, how satisfied are you with this relationship? Would you say you are... very satisfied, somewhat satisfied, not yery satisfied, or not at all satisfied?

\begin{tabular}{|c|}
\hline Very \\
Satisfied \\
1
\end{tabular}
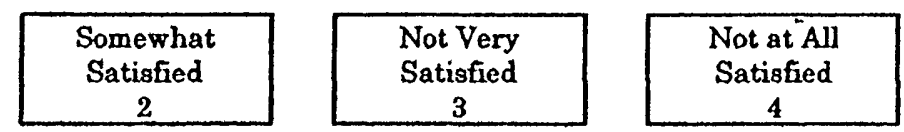

Turn to page 4 of your response booklet. For each of the statements I read, tell me the number of the answer that best describes you.

\begin{tabular}{|c|c|c|c|c|c|}
\hline & $\begin{array}{c}\text { Strongly } \\
\text { Agree } \\
1 \\
\end{array}$ & $\begin{array}{c}\text { Agree } \\
2 \\
\end{array}$ & $\begin{array}{c}\text { Neither } \\
\text { Agree Nor } \\
\text { Disagree } \\
3 \\
\end{array}$ & $\begin{array}{c}\text { Disagree } \\
4 \\
4 \\
\end{array}$ & $\begin{array}{c}\text { Strongly } \\
\text { Disagree } \\
\\
5 \\
\end{array}$ \\
\hline $\begin{array}{l}\text { A27. You feel very close to your } \\
\text { girlfriend/boy friend'/ partner. }\end{array}$ & 1 & 2 & (15 & 4 & 5 \\
\hline $\begin{array}{l}\text { A27a, Your girlfriend/ } \\
\text { boyfriend/ partner always takes } \\
\text { the time to talk over your } \\
\text { problems with you. }\end{array}$ & 1 & 2 & 3 & 4 & 5 \\
\hline $\begin{array}{l}\text { A27b. When you are with your } \\
\text { girlfriend/boyfriend/ partner } \\
\text { you feel completely able to } \\
\text { relax and be yourself. }\end{array}$ & 1 & 2 & 3 & 4 & 5 \\
\hline $\begin{array}{l}\text { A27c. No matter what happens, } \\
\text { you know that your } \\
\text { girlfriend/boyfriend/partner } \\
\text { will always be there for you. }\end{array}$ & 1 & 2 & 3 & 4 & 5 \\
\hline $\begin{array}{l}\text { A27d. You know that your } \\
\text { girlfriend/boyfriend/partner has } \\
\text { confidence in you. }\end{array}$ & 1 & 2 & 3 & 4 & 5 \\
\hline $\begin{array}{l}\text { A27e. Your girlfriend/boyfriend/ } \\
\text { partner often lets you know } \\
\text { that he/she thinks you are a } \\
\text { worthwhile person. }\end{array}$ & 1 & 2 & 3 & 4 & 5 \\
\hline
\end{tabular}




\section{SECTION BBBB - PARENTAL AUTHORITY}

For these next questions, please refer to page 51 in your response booklet and tell me how much you agree or disagree with each statement about your mother/female guardian.

BBBB1. As I was growing up, once family policy had been established, my mother discussed the reasoning behind the policy with the children in the family.

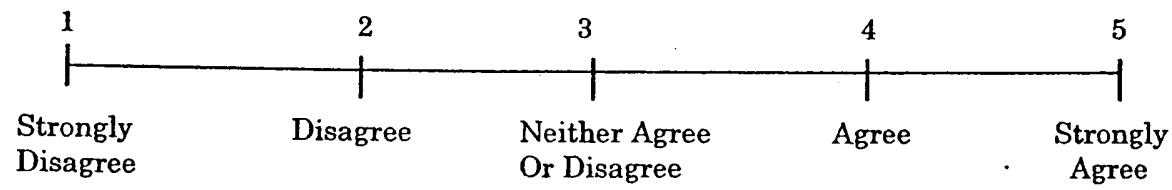

BBBB2. Whenever my mother told me to do something as I was growing up, she expected me to do it immediately without asking any questions.

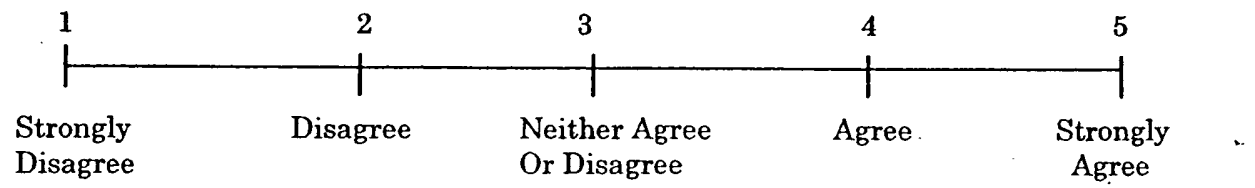

BBBB3. As I was growing up my mother did not feel that I needed to obey rules and regulations of behavior simply because someone in authority had established them.

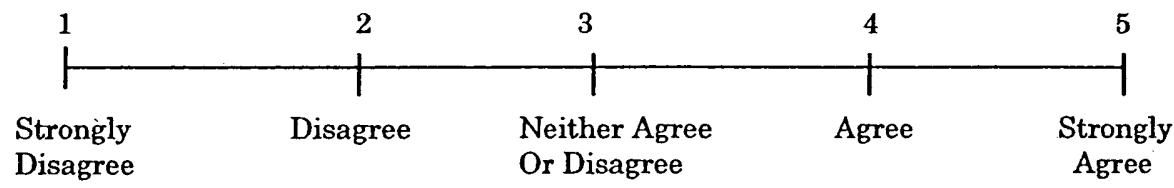

BBBB4. My mother has always encouraged verbal give-and-take whenever I have felt that family rules and restrictions were unreasonable.

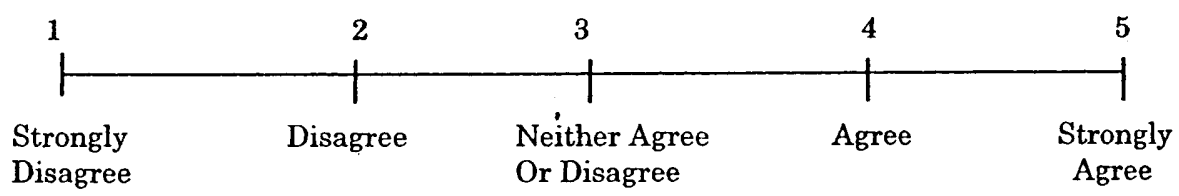

BBBB5. As I was growing up my mother did not allow me to question any decision she had to make.

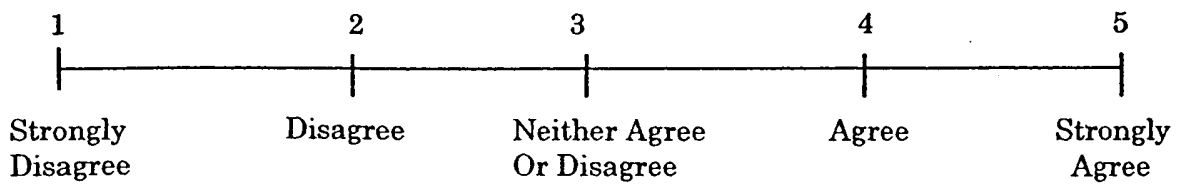


BBBB6. As I was growing up, my mother seldom gave me expectations and guidelines for my behavior.

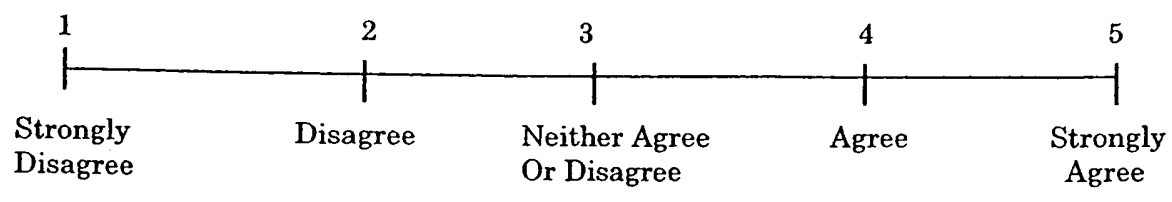

BBBB7. As I was growing up I knew what my mother expected of me in my family, but I also felt free to discuss those expectations with my mother when I felt that they were unreasonable.

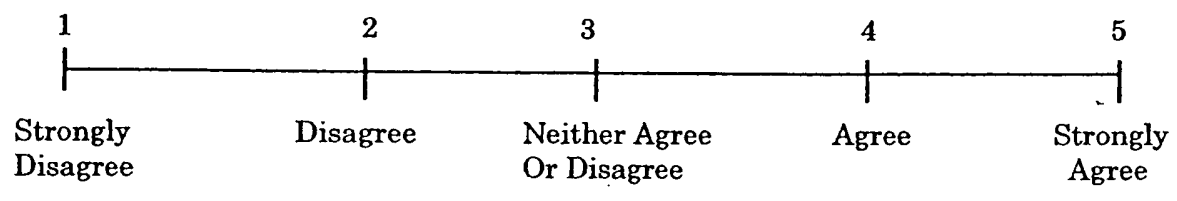

BBBB8. My mother felt that wise parents should teach their children early just who is boss in the family.

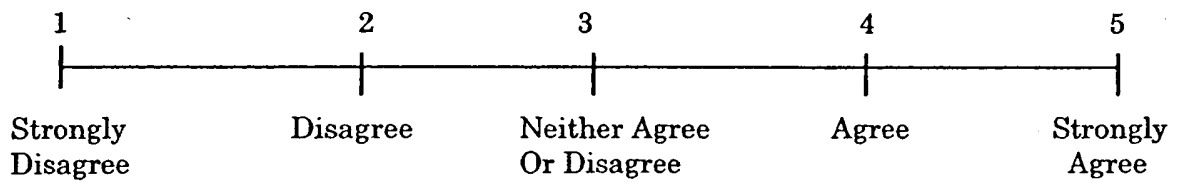

BBBB9. Most of the time as I was growing up my mother did what the children in the family wanted when making family decisions.

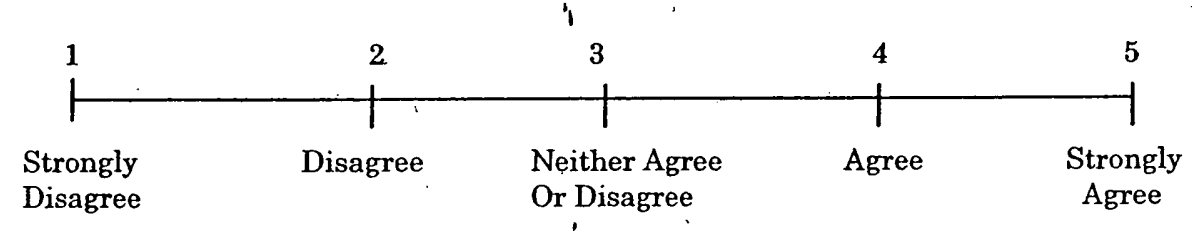

BBBB10. My mother gave me direction for my behavior and activities as I was growing up and she expected me to follow her direction, but she was always willing to listen to my concerns and to discuss that direction with me.

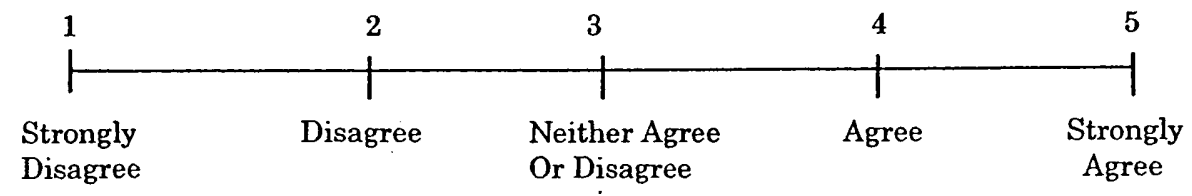


BBBB11. As I was growing up I knew what my mother expected of me in the family and she insisted that I conform to those expectations simply out of respect for her authority.

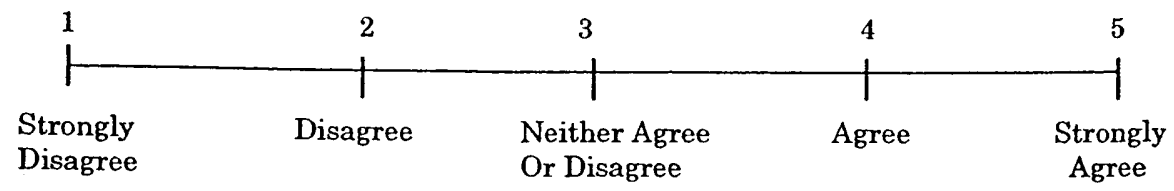

BBBB12. As I was growing up my mother allowed me to decide most things for myself without a lot of direction from her.

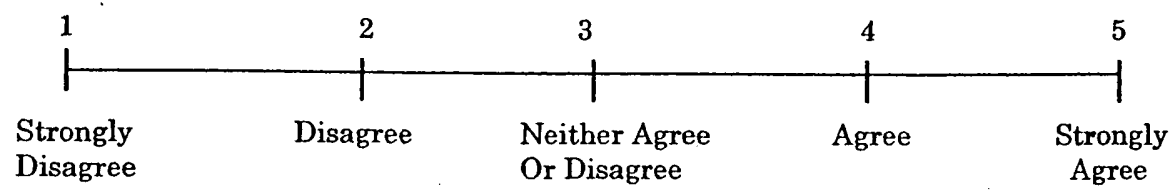

For these next questions, please refer to page 51 in your response booklet and tell me how much you agree or disagree with each statement about your father/male guardian.

BBBB13. As I was growing up, once family policy had been established, my father discussed the reasoning behind the policy with the children in the family.

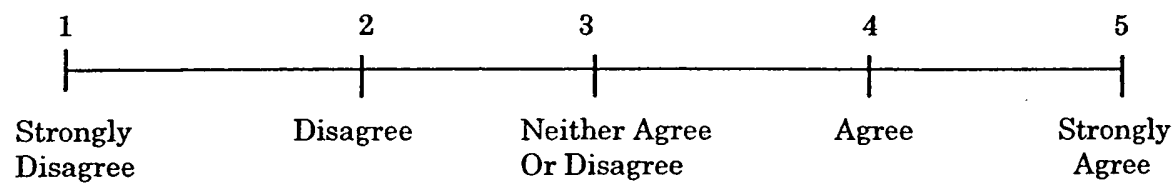

BBBB14. Whenever my father told me to do something as I was growing up, he expected me to do it immediately without asking any questions.

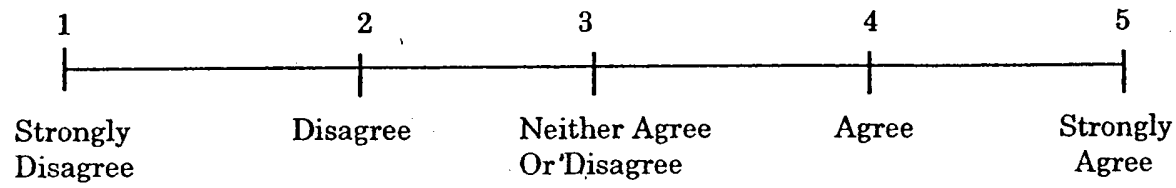

BBBB15. As I was growing up my father did not feel that I needed to obey rules and regulations of behavior simply because someone in authority had established them.

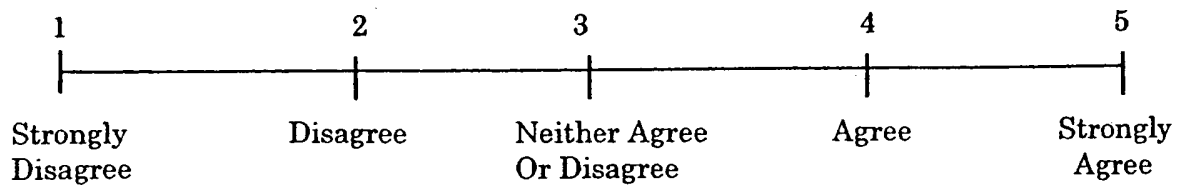


BBBB16. My father has always encouraged verbal give-and-take whenever I have felt that family rules and restrictions were unreasonable.

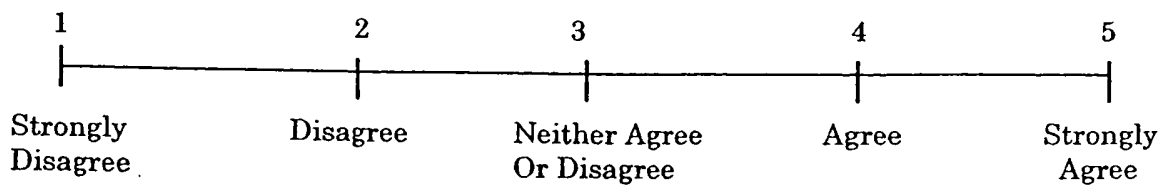

BBBB17. As I was growing up my father did not allow me to question any decision he had to make.

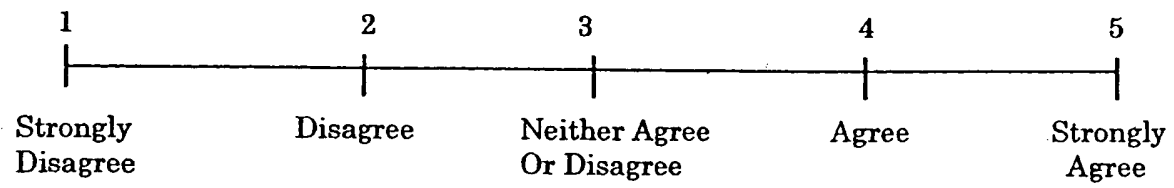

BBBB18. As I was growing up, my father seIdom gave me expectations and guidelines for my behavior.

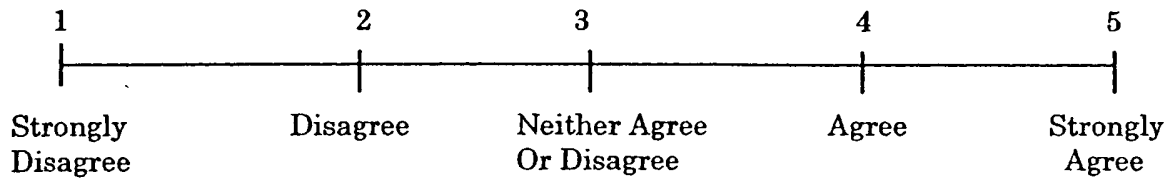

BBBB19. As I was growing up I knew what my father expected of me in my family, but I also felt free to discuss those expectations with my father when I felt that they were unreasonable.

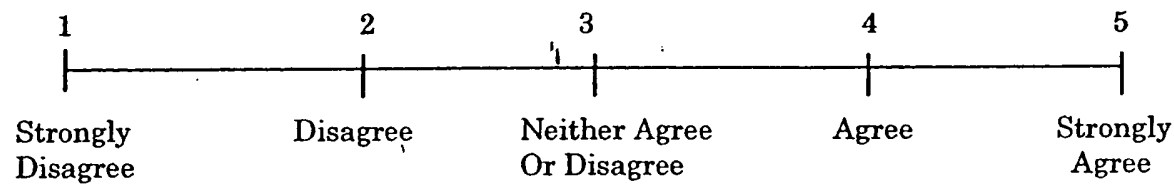

BBBB20. My father felt that wise parents should teach their children early just who is boss in the family.

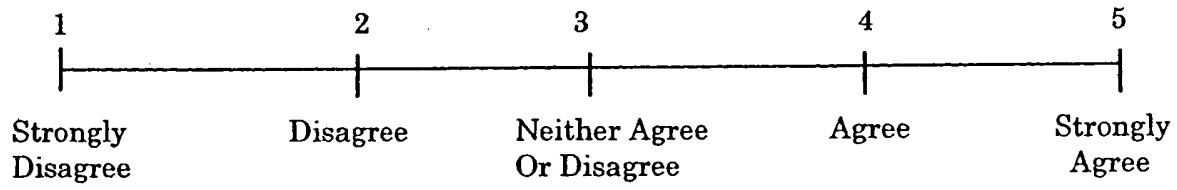


BBBB21. Most of the time as I was growing up my father did what the children in the family wanted when making family decisions.

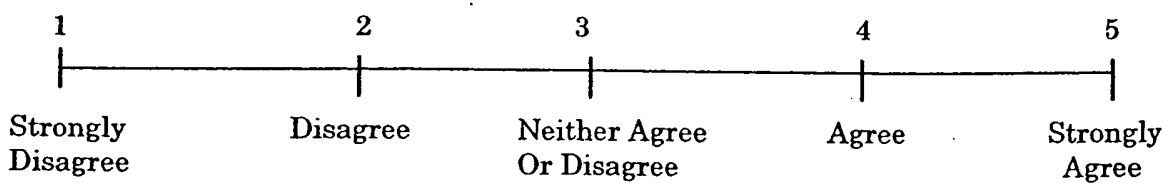

BBBB22. My father gave me direction for my behavior and activities as I was growing up and he expected me to follow his direction, but he was always willing to listen to my concerns and to discuss that direction with me.

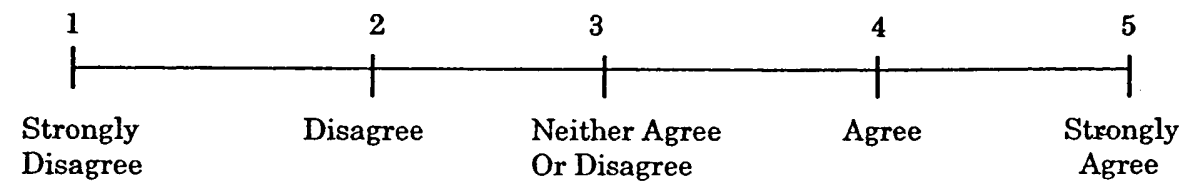

BBBB23. As I was growing up I knew what my father expected of me in the family and he insisted that I conform to those expectations simply out of respect for his authority.

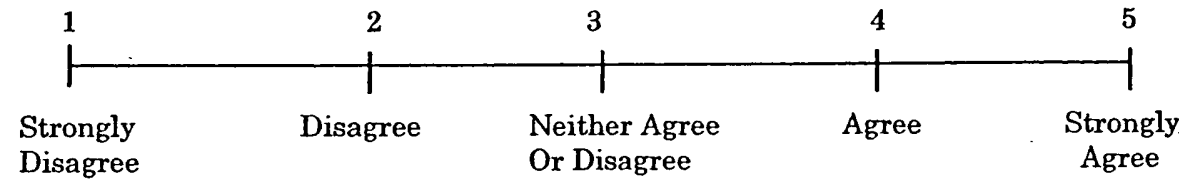

BBBB24. As I was growing up my father allowed me to decide most things for myself without a lot of direction from him.

\begin{tabular}{|c|c|c|c|c|}
\hline $\begin{array}{l}\text { Strongly . } \\
\text { Disagree }\end{array}$ & Disagree & $\begin{array}{l}\text { Neither Agree } \\
\text { Or Disagree }\end{array}$ & Agree & $\begin{array}{l}\text { Strongly } \\
\text { Agree }\end{array}$ \\
\hline
\end{tabular}




\section{SECTION J - DISCRIMINATION}

In this next section, we are interested in the treatment you have experienced from other people.

A

If Yes, when was

EVENT

Yes/No the last time?

J1. Have you ever been unfairly fired or denied a promotion?

1. $\mathrm{YES} \rightarrow 1$. In the last month

\begin{tabular}{l|l} 
1. YES & 2. In the last 6 months
\end{tabular}

3 . In the last year

4. Over a year ago

J2. For unfair reasons, do you

1. YES $\rightarrow$ 1. In the last month

think you have ever not been

2. In the last 6 months

hired for a job?

J3. Have you ever been unfairly treated by the police (e.g. stopped, searched, questioned, physically threatened or abused)?

J4. Have you ever been unfairly discouraged by a teacher or advisor from continuing your education?

J5. Have you ever been unfairly discouraged by a teacher or advisor from pursuing the job/career you want?

J6. For unfair reasons, has a landlord or a realtor ever refused to sell or rent you or your family a house or apartment?

J7. For unfair reasons, have neighbors ever made life difficult for you and your family?

5. NO

3. In the last year

4. Over a year ago

1. YES $\rightarrow$ 1. In the last month

5. NO

2. In the last 6 months

3 . In the last year

4. Over a year ago

1. YES $\rightarrow$ 1. In the last month

$\begin{array}{ll}\text { 5. NO } & \text { 2. In the last } 6 \text { months }\end{array}$

3 . In the last year

4. Over a year ago

1. YES $\rightarrow \quad$ 1. In the last month

5. NO 2. In the last 6 months

3 . In the last year

4. Over a year ago

\begin{tabular}{l|l} 
1. YES $\rightarrow$ & $\begin{array}{l}\text { 1. In the last month } \\
\text { 2. In the last } 6 \text { month }\end{array}$ \\
5. NO & 3. In the last year
\end{tabular}

3. In the last year

4. Over, a year ago

1. YES $\rightarrow$ 1. In the last month

5. NO 2. In the last 6 months

3 . In the last year

4. Over a year ago

\section{INTERVIEWER CHECKPOINT}

IF R ANSWERED YES FOR ANY OF J1 - J7

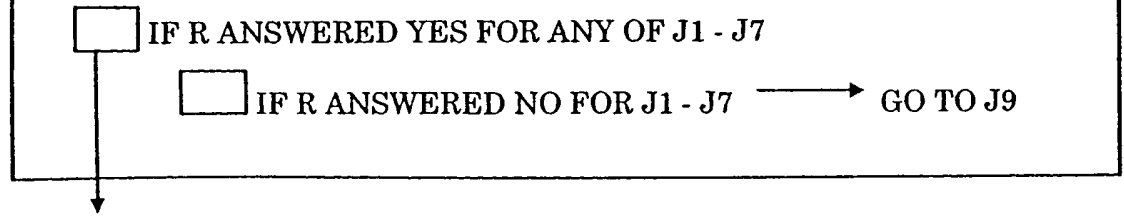


. J8. Page 32 in your response booklet lists reasons people are sometimes treated unfairly. What do you think was the main reason(s) for your experiences? Please tell me all the reasons you think apply to you.

01. Your Ethnicity

02. Your Gender

03. Your Race

04. Your Age

05. Your Religion

06. Your Personal Appearance

07. Your Sexual Orientation/Preference

08. Your Income Level/Social Class

09. The darkness or lightness of your skin

10. Your education level

11. Your Hair Style

12. Your Accent

13. Other (Specify):
J8a. (IF ONLY ONE REASON CITED IN LAST QUESTION, ENTER 14 AND DON'T READ.) Of these, which would you say was the most important reason?

01. Your Ethnicity

02. Your Gender

03. Your Race

04. Your Age

05. Your Religion

06. Your Personal Appearance

07. Your Sexual Orientation/Preference

08. Your Income Level/Social Class

09. The darkness or lightness of your skin

10. Your education level

11. Your Hair Style

12. Your Accent

13. Other (Specify):

14. (R GAVE ONLY ONE REASON IN LAST QUESTION.)

In your day-to-day life, how often have any of the following things happened to you? Refer to page 33 of your response booklet for options.

\begin{tabular}{|c|c|c|c|c|c|}
\hline EVENT & $\begin{array}{l}\text { ALMOST } \\
\text { ALWAYS } \\
\text { (1) }\end{array}$ & $\begin{array}{l}\text { OFTEN } \\
(2) \\
\end{array}$ & $\begin{array}{l}\text { SOMETIMES } \\
\text { (3) }\end{array}$ & $\begin{array}{c}\text { RARELY } \\
(4) \\
\end{array}$ & $\begin{array}{c}\text { NEVER } \\
(5) \\
\end{array}$ \\
\hline $\begin{array}{l}\text { J9. You are treated with } \\
\text { less courtesy than } \\
\text { other people. }\end{array}$ & 1 & 2 & 3 & 4 & 5 \\
\hline $\begin{array}{l}\text { J10. You are treated with } \\
\text { less respect than you } \\
\text { deserve. }\end{array}$ & 1 & $2^{\prime}$ & 3 & 4 & 5 \\
\hline $\begin{array}{l}\text { J11. You receive worse } \\
\text { service than other } \\
\text { people at restaurants } \\
\text { or stores. }\end{array}$ & 1 & 2 & 3 & 4 & 5 \\
\hline $\begin{array}{l}\text { J12. People act as if they } \\
\text { think you are not } \\
\text { smart. }\end{array}$ & 1 & 2 & 3 & 4 & 5 \\
\hline
\end{tabular}




\begin{tabular}{|c|c|c|c|c|c|}
\hline EVENT & $\begin{array}{c}\text { ALMOST } \\
\text { ALWAYS } \\
\text { (1) }\end{array}$ & $\begin{array}{l}\text { OFTEN } \\
(2)\end{array}$ & $\begin{array}{l}\text { SOMETIMES } \\
\text { (3) }\end{array}$ & $\begin{array}{c}\text { RARELY } \\
(4)\end{array}$ & $\begin{array}{c}\text { NEVER } \\
(5)\end{array}$ \\
\hline $\begin{array}{l}\text { J13. People act as if they } \\
\text { are afraid of you. }\end{array}$ & 1 & 2 & 3 & 4 & 5 \\
\hline $\begin{array}{l}\text { J14. People act as if they } \\
\text { think you are } \\
\text { dishonest. }\end{array}$ & 1 & 2 & 3 & 4 & 5 \\
\hline $\begin{array}{l}\text { J15. People act as if } \\
\text { they are better than } \\
\text { you are. }\end{array}$ & 1 & 2 & 3 & 4 & 5 \\
\hline $\begin{array}{l}\text { J16. You are called names } \\
\text { or insulted. }\end{array}$ & 1 & 2 & 3 & 4 & 5 \\
\hline $\begin{array}{l}\text { J17. You are threatened or } \\
\text { harassed. }\end{array}$ & 1 & 2 & 3 & 4 & 5 \\
\hline
\end{tabular}

\section{INTERVIEWER CHECKPOINT}

IF R ANSWERED 1 OR 2 IN J9 - J17

$$
\text { IF R DID NOT ANSWER } 1 \text { OR } 2 \text { IN J9 - J17 } \longrightarrow \text { GO TO NEXT SECTION }
$$

J18. Page 32 in your response booklet lists reasons people are sometimes treated unfairly. What do you think was the main reason(s) for your experiences? Please tell me all the reasons you think apply to you.

01. Your Ethnicity

02. Your Gender

03. Your Race

04. Your Age

05. Your Religion

06. Your Personal Appearance

07. Your Sexual Orientation/Preference

08. Your Income Level/Social Class

09. The darkness or lightness of your skin

10. Your education level

11. Your Hair Style

12. Your Accent

13. Other (Specify):
J18a. (IF ONLY ONE REASON CITED IN LAST QUESTION, ENTER 14 AND DON'T READ.) Of these, which would you say was the most important reason?

01. Your Ethnicity

02. Your Gender

03. Your Race

04. Your Age

05. Your Religion

06. Your Personal Appearance

07. Your Sexual Orientation/Preference

08. Your Income Level/Social Class

09 . The darkness or lightness of your skin

10. Your education level

11. Your Hair Style

12. Your Accent

13. Other (Specify):

14. (R GAVE ONLY ONE REASON IN LAST QUESTION.) 


\section{SECTION V - DELINQUENCY}

V1. Have you ever been a member of a street or other gang?

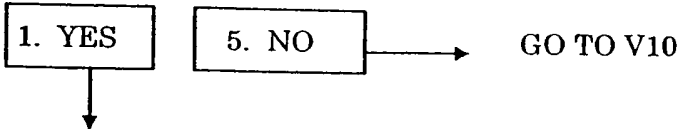

V1a. How old were you when you first joined?

V2. Are you currently a member of a street or other gang?
1. YES
5. NO

People differ a lot on how they describe their involvement with gangs. How strongly do you agree or disagree with each of the following statements about yourself?

\begin{tabular}{|l|c|c|c|c|}
\hline & $\begin{array}{l}\text { STRONGLY } \\
\text { AGREE } \\
1\end{array}$ & $\begin{array}{c}\text { AGREE } \\
2\end{array}$ & $\begin{array}{c}\text { DISAGREE } \\
\text { STRONGLY }\end{array}$ & $\begin{array}{c}\text { STSAGREE } \\
\text { DI }\end{array}$ \\
\hline $\begin{array}{l}\text { V3. In general, being a member of a } \\
\text { gang is/was very important to you. }\end{array}$ & 1 & 2 & 3 & 4 \\
\hline $\begin{array}{l}\text { V4. In general, you are/were happiest } \\
\text { when you are/were with the other } \\
\text { members of the gang. }\end{array}$ & 1 & 2 & 3 & 4 \\
\hline $\begin{array}{l}\text { V5. While a member, you spend/spent } \\
\text { most of your free time doing gang-related } \\
\text { activities. }\end{array}$ & 1 & 2 & 3 & 4 \\
\hline $\begin{array}{l}\text { V6. Your gang is/was like a family to } \\
\text { you. }\end{array}$ & 1 & 2 & 3 & 4 \\
\hline $\begin{array}{l}\text { V7. You feel/felt more appreciated by } \\
\text { other gang members than by your family. }\end{array}$ & & & 3 & \\
\hline
\end{tabular}

\section{CHECKPOINT: IF V2 IS CODED (1), GO TO V11 INTRODUCTION}

V8. Why did you leave the gang you joined?

1. Fear of arrest

2. Fear of injury/death

3. Family pressures

4. Outgrew it

5. Other (specify)

V8a. How old were you when you left your gang?

V8b. How long (IN MONTHS) were you a member of a gang?

V9. Were you in school when you joined?
1. YES
5. NO

\section{GO TO V11}

V10. Even though you were never in a gang, were you ever pressured to become a member of a gang?
1. YES
5. NO 
V10a. Have you worn gang colors on purpose?
1. YES
5. NO

V10b. Have you flashed gang signs?
1. YES
5. NO

V10c. Have you drunk alcohol or gotten high with gang members?
1. YES
5. NO

V10d. Have you hung out with gang members?
1. YES
5. NO

I'm going to read a list of behaviors that people sometimes do. Please tell me whether you have done each behavior IN THE LAST MONTH. Remember, your answers are completely confidential.

\begin{tabular}{|l|c|c|}
\hline & YES & NO \\
\hline $\begin{array}{l}\text { V11. used force to get money or expensive things } \\
\text { from another person }\end{array}$ & 1 & 5 \\
\hline $\begin{array}{l}\text { V12. broken into and entered a home, store or } \\
\text { building }\end{array}$ & 1 & 5 \\
\hline $\begin{array}{l}\text { V13. damaged or destroyed property on purpose that } \\
\text { didn't belong to you }\end{array}$ & 1 & 5 \\
\hline $\begin{array}{l}\text { V14. taken a car for a ride without the owner's } \\
\text { permission }\end{array}$ & 1 & 5 \\
\hline $\begin{array}{l}\text { V15. taken something worth more thà \$50 when } \\
\text { you weren't supposed to }\end{array}$ & 1 & 1 \\
\hline $\begin{array}{l}\text { V16. carried a hand gun when you went out } \\
\text { V17. taken more than } \$ 20 \text { from family or friends } \\
\text { without permission }\end{array}$ & 1 & 5 \\
\hline \begin{tabular}{l} 
V18. taken part in gang fights \\
\hline
\end{tabular}
\end{tabular}

\section{JUSTICE SYSTEM CONTACT}

V19. Have you ever been arrested or spent at least one night in jail or juvenile hall?
1. YES
5. NO
GO TO NEXT SECTION 
V20. How many times have you been arrested or spent at least one night in jail or juvenile hall?

1. ONCE

2. 2 TIMES

3. 3 TIMES

4. 4 TIMES

5. 5 TIMES OR MORE

IF ONCE, GO TO V21

IF MORE THAN ONCE, GO TO V22

V21. How old were you when this happened?

GO TO V24

V22. When was the last time this happened?

1. WITHIN THE LAST 6 MONTHS
2. WITHIN THE LAST YEAR
3. MORE THAN A YEAR AGO

V23. How old were you the first time you were arrested or detained?

V24. What type(s) of offense(s) were you arrested for? Look at page 45 of your response booklet. Just tell me the number(s) of the category(ies) that apply to you.

1. Assault

2. Mugging

3. Robbery

4. Break and enter (burglary)

5. Car theft

6. Car jacking

7. Driving while intoxicated

8. Selling drugs

9. Other (specify)

V25. Have you ever been convicted of a crime?

$$
\text { 1. YES }
$$$$
\text { 5. NO }
$$

V26. Have you ever been on probation or parole?

1. YES

5. NO 
VITA

LYNETTE ATTELONEY

FLORIDA INTERNATIONAL UNIVERSITY

Miami, Florida

Masters Degree in Social Work, 1995

YORK COLLEGE

Queens, New York

Bachelor of Science in Business Administration, 1987

EMPLOYMENT:

3/03 - Present

$11 / 01-1 / 03$

09/98- $2 / 01$

$02 / 01-10 / 03$

$04 / 96-08 / 98$

02/91- 04/96
NEW HORIZONS MENTAL HEALTH INC.

Miami, Florida

Therapist

CITRUS HEALTH NETWORK

Miami, Florida

Case Plan Facilitator for Family Safety Program

STATE OF FLORIDA: FLORIDA INTERNATIONAL UNIVERSITY

Miami, Florida

Graduate Teaching Assistant/ Graduate Research Assistant

STATE OF FLORIDA: FLORIDA INTERNATIONAL UNIVERSITY

Miami, Florida

Therapist: Alcohol Treatment Targeting Adolescents In Need (ATTAIN)

STATE OF FLORIDA DEPARTMENT OF JUVENILE JUSTICE District 10, Broward County, Florida

Juvenile Probation Officer Supervisor

STATE OF FLORIDA: DEPARTMENT OF JUVENILE JUSTICE

District 11, Dade County, Florida

Senior Juvenile Probation Officer: 02/93 - 04/96

Juvenile Probation Officer: 02/91 - 02/93 
TEACHING EXPERIENCE

M.S.W.

Integrative Field Seminar I

Integrative Field Seminar II

B.S.W.

Human Behavior and the Social Environment I

Introduction to Social Work

\section{CONFERENCE PRESENTATIONS}

Lynette Atteloney (July, 2000). An examination of the risk factors associated with juvenile delinquency among Black males classified as serious, violent juvenile offenders. Paper presented at the 2000 Scholarly Forum of the Florida International University Graduate Student Association Competitive Paper Presentation. 